\title{
Gender and Workplace Bullying in Lao Organisations
}

by

\section{Vanhsana Sayaseng}

\author{
A thesis \\ Submitted to the Victoria University of Wellington \\ In partial fulfilment of the requirements for the degree of \\ Master of Commerce
}

Victoria University of Wellington 


\begin{abstract}
Workplace bullying has gained more attention in many Western countries and in some Asian countries than in Laos. It is a serious workplace health and safety issue for both individuals and organisations. In order to understand workplace bullying experienced by individuals, it is important to put bullying in a gendered context. This will help people better understand the perceptions and coping tactics of individuals who have experienced workplace bullying. Where existing studies consider gender, they mainly focus on statistical differences in patterns of bullying experienced between women and men and only a few discuss the gendered processes of workplace bullying. This is an exploratory study addressing gender and workplace bullying in a distinctive non-Western context, taking specific cultural factors into account. This thesis studies the perceptions of ten Laotian women, including myself, of bullying in their current and previous workplaces. These include NGOs, private and public organisations. In this national context, the concept of workplace bullying is not well recognised and understood, and gendered and workplace bullying has not been studied at all. The topic is seen as an extremely sensitive one. Snowball sampling techniques were used to recruit participants. Selected key concepts of workplace bullying from Western-based studies were adapted in order to identify and explore bullying in the Laotian context. In addition, a qualitative epistemology, in which social constructionism and interpretivism were employed, was used to understand and interpret the forms of workplace bullying as experienced by the Laotian women in the study. Semi-structured interviews were developed to help identify experiences of bullying in relation to gender and culture. The analysis of gender and workplace bullying is based on gendered organisation theory and social dominance theory.
\end{abstract}

The findings indicate a number of risk factors that I have identified associated with workplace bullying in Laos. These include gender and culture factors such as marital status, power distance, ethnocentrism, Westerner privilege and religion. These risk factors give more context to the Negative Acts Questionnaire-Revised (NAQ-R) framework when understanding and interpreting the nature of workplace bullying. Importantly, gender and culture have a strong relationship and cannot be separated from each other when understanding workplace bullying. Various forms of workplace bullying appear to be different from that found in many 
Western studies and are based on the risk factors. Remedies are also different because of the lack of support systems available, and the fact that participants often have to cope with the bullying by themselves.

I hope that my findings can inform the Lao government to pay more attention in developing policies to address and prevent the phenomenon of workplace bullying in Lao organisations, and also can educate women's organisations about the nature of this problem so that they can find effective ways to better address and prevent the problems associate with workplace bullying. 


\section{Acknowledgements}

First of all, a massive thank you to my supervisor Associate Professor Deborah Jones. I have learnt a lot from you, and feel honored to have had the opportunity to be your supervisee. Thank you for helping me move through all the confusions, for bringing back my focus, and for your patience throughout my thesis journey. Without your invaluable advice and support, I would not have been able to successfully complete this thesis. Your time spent to supporting me is highly appreciated and will never be forgotten.

To Dr. Geoff Plimmer, thank you so much for listening to my problems in the beginning of my first trimester. Without your caring support in looking for the best possible way of solving my problem, I would not have been able to come this far.

My gratitude also goes to Esmé Franken, a $\mathrm{PhD}$ candidate, who has been advising and supporting me not only during my thesis writing, but from the beginning of my first trimester in VUW. Thank you for your guidance in constructing my thoughts and ideas.

I would also like to thank Student Learning Support for organising a number of useful programmes such as the Excel programme, public speaking, and critical thinking. These programmes have not only been useful in developing my specific skills during my time in New Zealand, but will also be useful in my home country.

My sincere thank also goes to the New Zealand Development Scholarship Programme for giving me the opportunity and financial support throughout my study in New Zealand. A special thank you to Ryan Stuart, my International Student Office Advisor (ISO), for listening to all of my problems, and helping me find solutions. Without your great support, I would have been unable to complete my thesis.

I would also like to thank Megan Key for helping me access the many rounds of printing credited in to my student ID. Thank you Thomas Martin for your help in accessing other resources for my thesis. 
To the participants of this thesis, thank you so much for sharing your experiences with me and for spending your time doing so. Without you, this thesis would not exist.

To my parents, especially my mother, thank you so much for taking good care of my little daughter or almost four months. I will never forget your support. My father, thank you for your encouraging words and thank you for being strong. I know you are waiting for me to come home and I will be home soon.

Most importantly, a huge thank you to my husband and my sister-in-law (Euy Tui) for taking great care of my beloved daughter, Arayanaleth Louangraj, who I left to pursue my study when she was seven months old. Ai Do, thank you so much for believing in me and allowing me to pursue my study in New Zealand. Thank you so much for being patient and so supportive in so many ways. Without you, I would have been unable to be in New Zealand. Words cannot express how grateful I am.

Naleth noi, mommy loves you so much and misses you in every second of my heartbeat. Words cannot explain how much I love and miss you, my dearest daughter.

Valinaleth Louangraj (nangnoi), my beautiful still born daughter (32 weeks gestation). You were with me during the application processes for New Zealand Scholarship Programme. I know you wanted mommy to pursue this study. I am doing this for you as well and finishing very soon. I miss you. 


\section{Table of Contents}

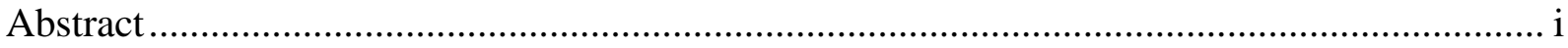

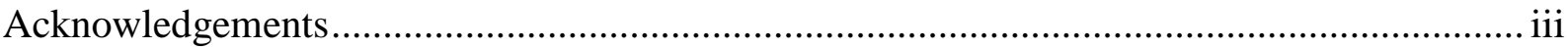

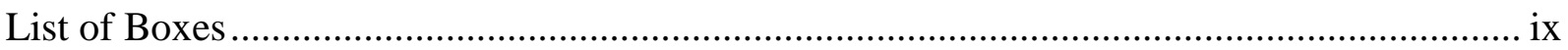

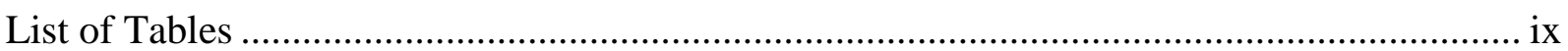

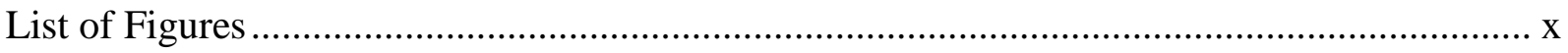

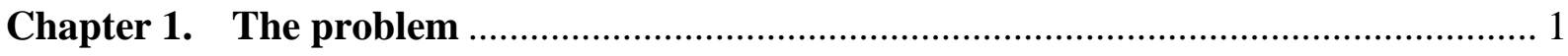

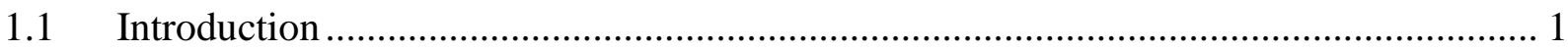

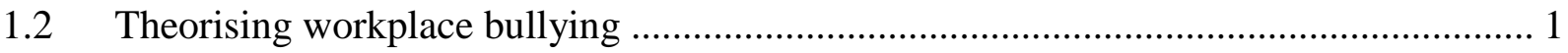

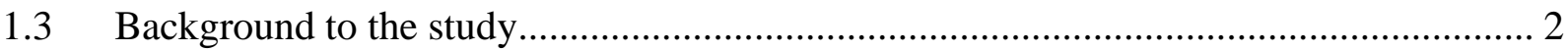

$1.4 \quad$ Lao PDR or Laos as the research context ........................................................... 3

1.4.1 Geographic and demographic factors .................................................. 3

1.4.2 Political context ............................................................................... 3

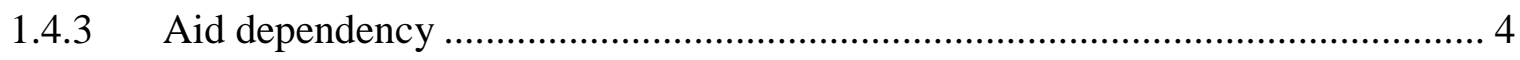

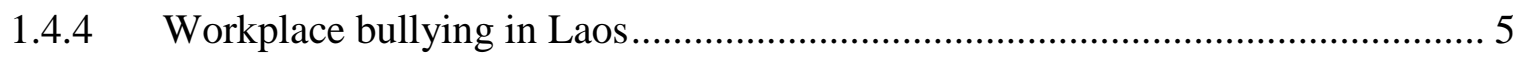

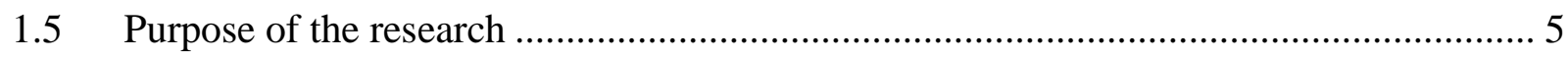

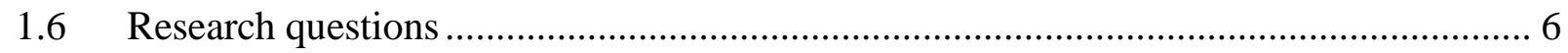

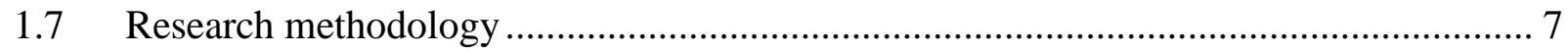

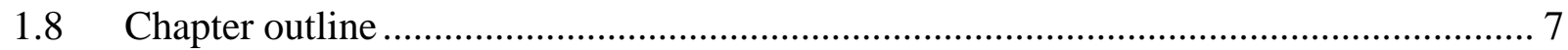

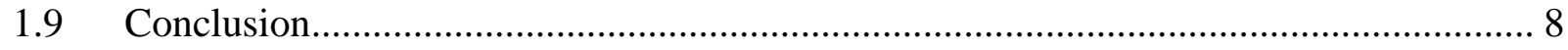

Chapter 2. Bullying, Gender and Culture ........................................................ 9

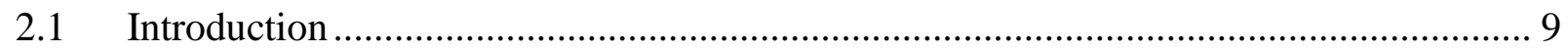

2.2 Concepts of workplace bullying ...................................................................... 10

2.2.1 Concepts and definition used in this thesis ............................................. 14

2.2.1.1 Definition of workplace bullying ................................................. 14 
2.2.1.2 Power distance

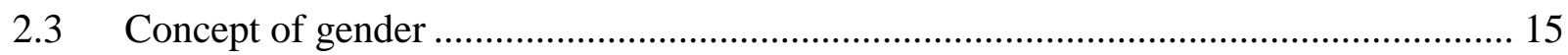

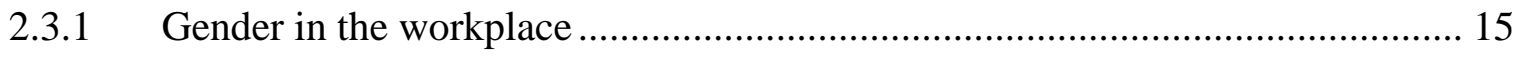

2.4 Cultural and gender in the Laotian context .................................................... 16

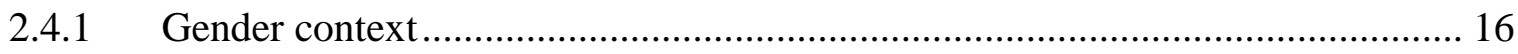

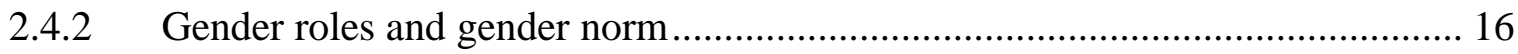

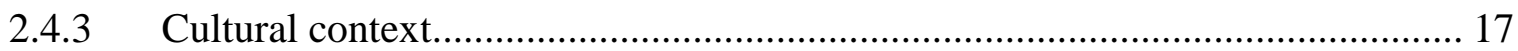

2.5 Workplace bullying in Western and Asian context............................................ 18

2.5.1 Workplace bullying in Western context ................................................ 18

2.5.2 Workplace bullying in Asian context .................................................... 20

2.5.2.1 Cultural impact on workplace bullying behaviour ............................... 20

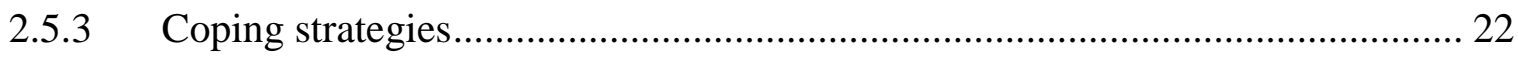

2.6 The link between gender and workplace bullying ................................................ 23

2.6.1 Gender and workplace bullying ......................................................... 24

2.6.2 Workplace bullying from a gender perspective ........................................ 25

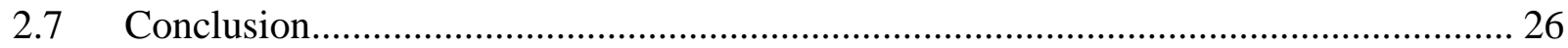

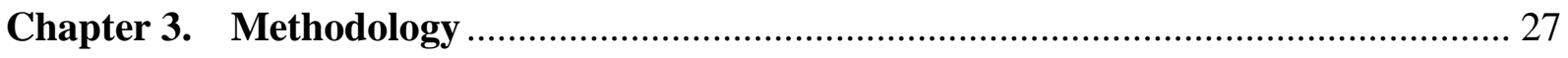

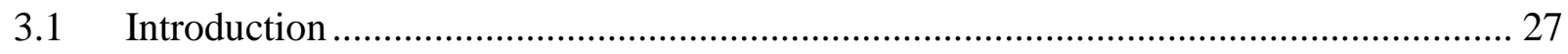

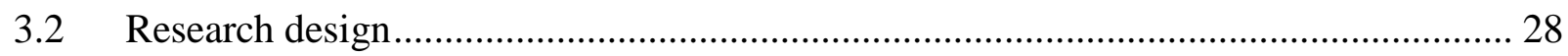

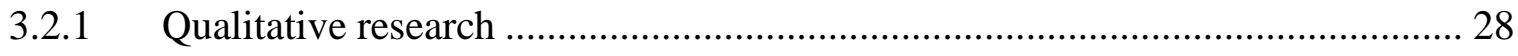

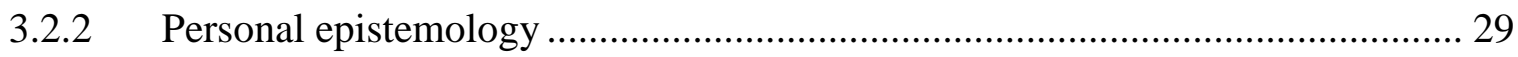

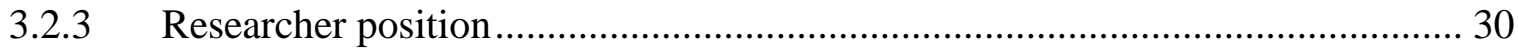

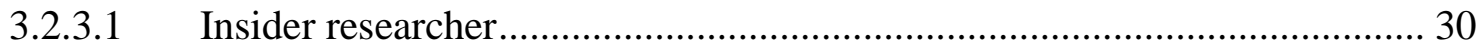

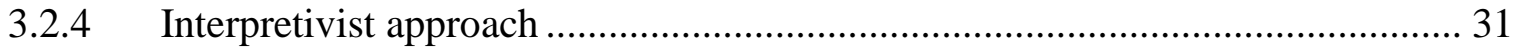

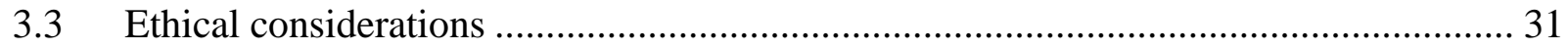

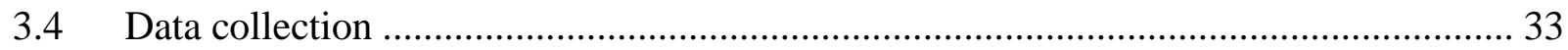




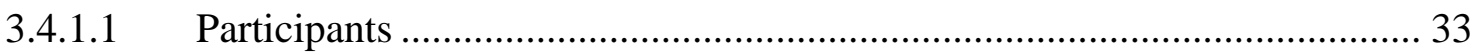

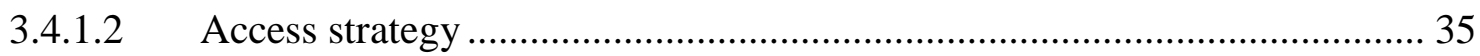

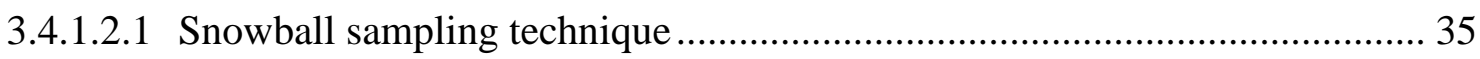

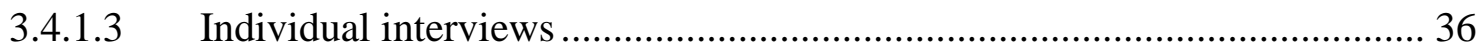

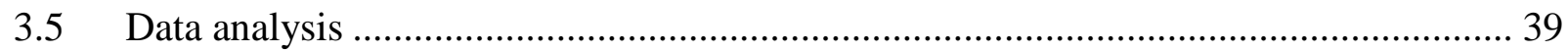

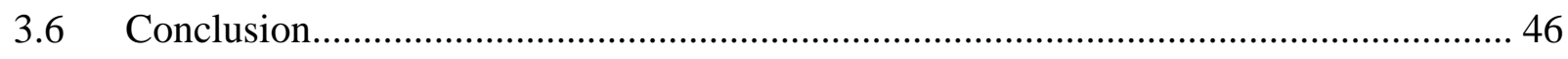

Chapter 4. Findings................................................................................................. 47

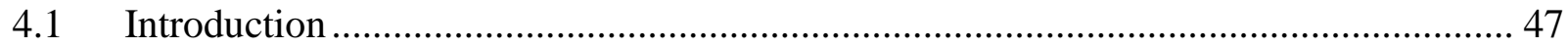

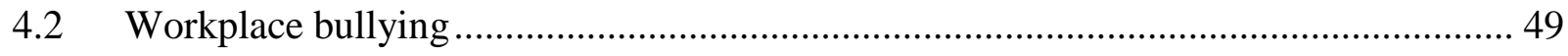

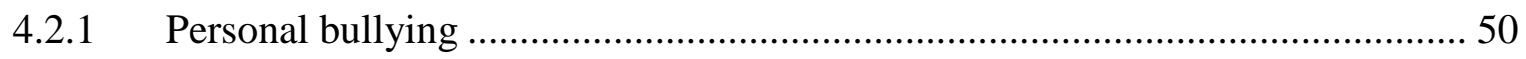

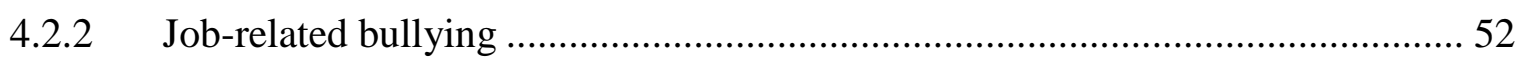

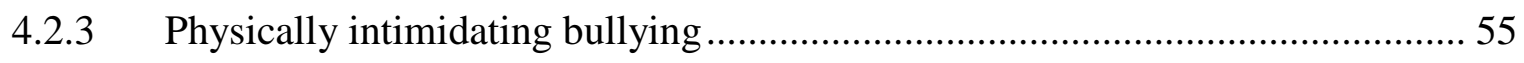

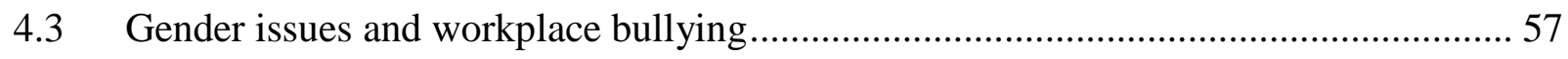

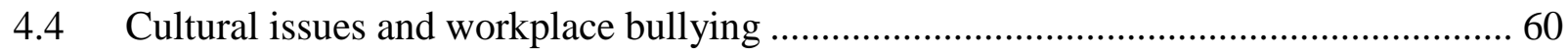

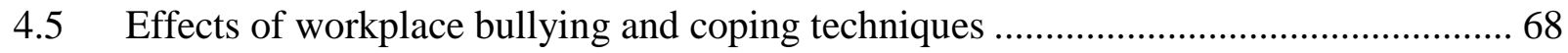

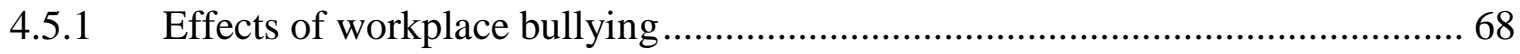

4.5.2 Workplace bullying and coping techniques ........................................... 68

4.5.2.1 Techniques used in coping with workplace bullying ............................ 68

4.5.2.2 Types of bullying and coping techniques ......................................... 69

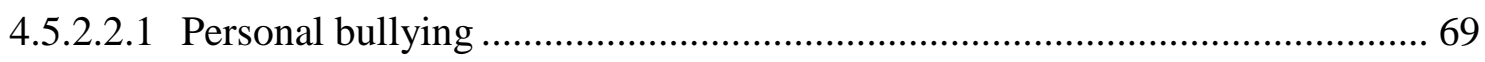

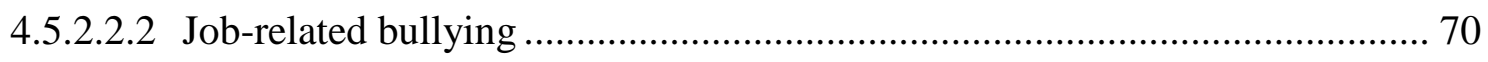

4.5.2.2.3 Age, working experience and coping techniques ................................ 72

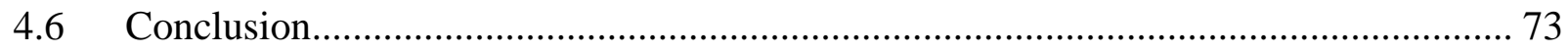

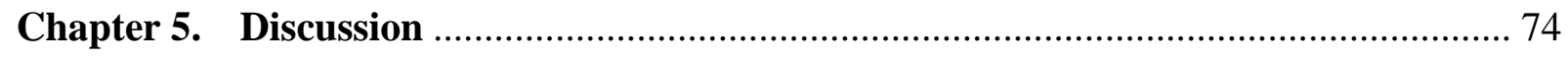

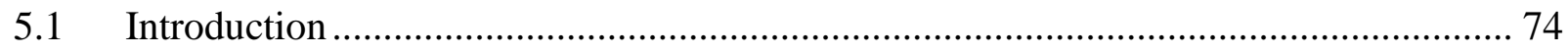

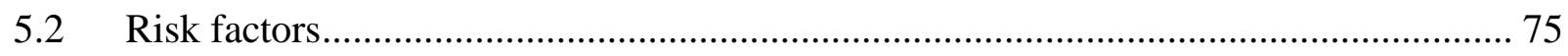


5.2.1 Gender and workplace bullying in Laotian context ..................................... 75

5.2.2 Culture and workplace bullying in Laotian context...................................... 76

5.2.2.1 Marital status and workplace bullying ........................................... 76

5.2.2.2 Power distance and workplace bullying ........................................... 77

5.2.2.3 Westerner privilege and workplace bullying ..................................... 78

5.2.2.4 Ethnocentrism and workplace bullying ......................................... 78

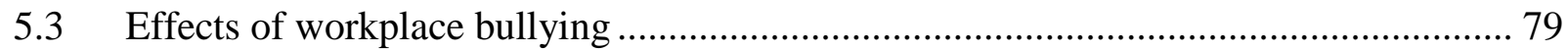

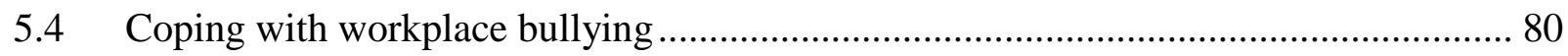

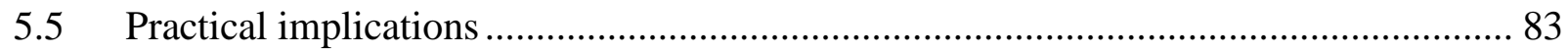

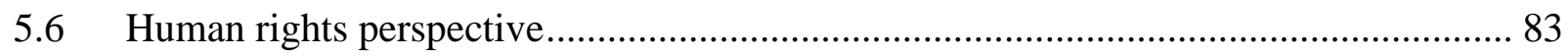

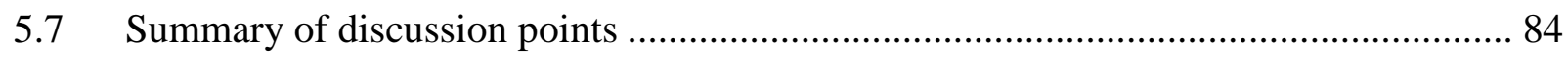

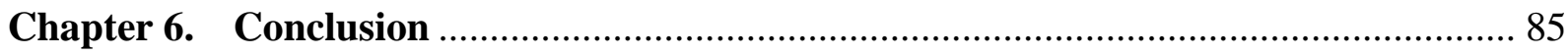

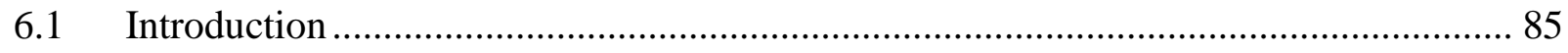

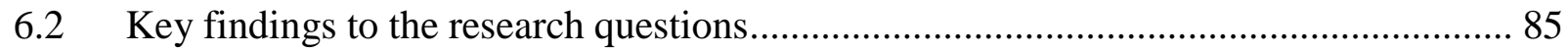

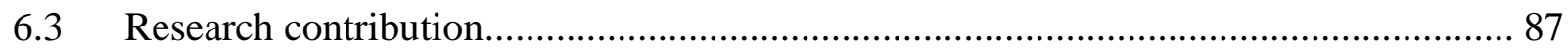

6.4 Relevance to other situations and future research exploration............................... 88

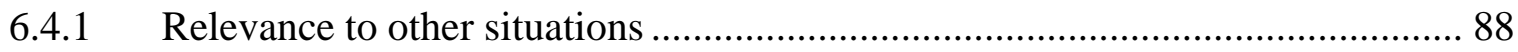

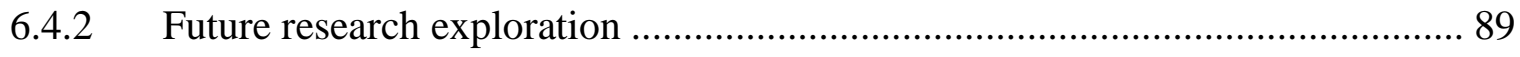

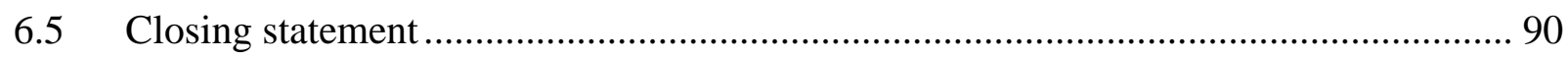

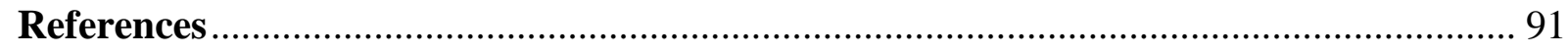

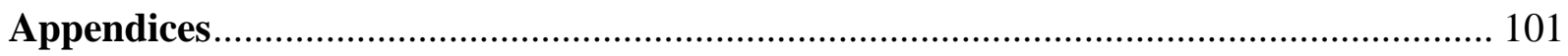

Appendix A: Participant information sheet (English version) ..................................... 101

Appendix B: Participant information sheet (Lao version) .......................................... 102

Appendix C: Research consent form (English version) ............................................ 103

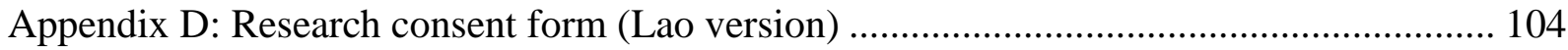




\section{List of Boxes}

Box 3. 1: Questions for keeping the bigger picture in mind

\section{List of Tables}

Table 2. 1: Classification of the forms of bullying

Table 3. 1: Participants' demographic information ........................................................... 34

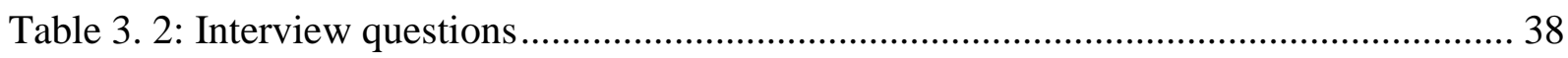

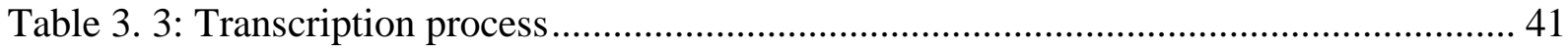

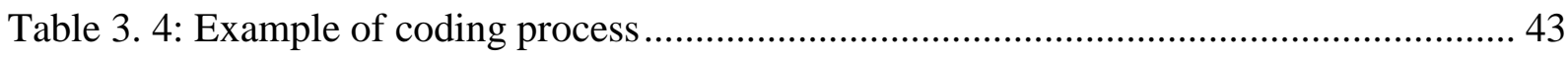

Table 3. 5: Theme development procedure (example: theme: gender issues) ....................... 44

Table 3. 6: Identified themes for data analysis ............................................................. 45

Table 4. 1 Risk factors for workplace bullying in the Lao context ...................................... 48

Table 4. 2: Personal bullying (the NAQ-R vs. the emergent findings) .................................. 51

Table 4. 3: Job-related bullying (the NAQ-R vs. the emergent findings) ............................. 53

Table 4. 4: Physically intimidating bullying (the NAQ-R vs. the emergent findings) ............ 55

Table 4. 5: Gender issues and workplace bullying ........................................................ 57

Table 4. 6: Cultural issues and workplace bullying that emerged in the data ....................... 61

Table 4. 7: Risk factors and forms of workplace bullying ............................................. 67 


\section{List of Figures}

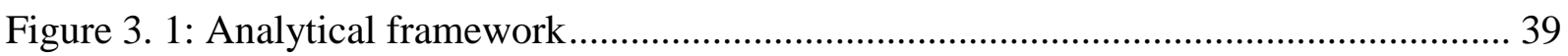

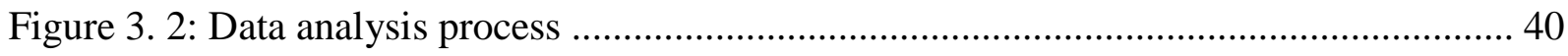




\section{Chapter 1. The problem}

\subsection{Introduction}

This thesis is an empirical and qualitative exploratory study of gender and workplace bullying, which involves ten Laotian women including myself, in the non-Western context of Laos. According to my knowledge, in Laos, the word bullying is not well recognised by many Lao people. The nature of bullying is also not well understood, despite its seriousness for individuals experiencing it. This may be a reason why there appear to be no studies about workplace bullying in Laos. Thus, this study is likely to be the first study of workplace bullying and its relationship with gender in Laos. I intended to do this study not only based on my participants' experiences, but also based on my own experiences, with the aim being to raise awareness that workplace bullying exists in the Lao context and that it can have serious consequences for individuals as well as organisations. I adapted some of the concepts from Western-based studies in order to recognise and interpret forms of workplace bullying experienced by Lao women. Therefore, it is hoped that this study will make a contribution to the existing literature on workplace bullying in general, as well as on gender and workplace bullying in particular, and in Laos specifically. It is also likely to contribute to understanding of the working lives and conditions of women in Laos. Moreover, my hope that this thesis will raise awareness about the issue of workplace bullying in Lao organisations so that the Lao government can pay more attention in developing policies to recognise and prevent the phenomenon of workplace bullying in Lao organisations including organisations aimed at empowering women.

\subsection{Theorising workplace bullying}

Workplace bullying is widely recognised in many Western countries particularly the United Kingdom, Australia, Norway, and New Zealand (Carter et al., 2013; Johnstone, 2017; Nielsen, Nielsen,Notelaers, \& Einarsen, 2015; Plimmer, Proctor-Thomson, Donnelly, \& Sim, 2017). Research has discovered that the consequences of workplace bullying not only directly impact on individuals, but also on organisations. A recent meta-analysis has shown that employees 
exposed to bullying behaviours usually suffer health-related problems such as anxiety, depression, or post-traumatic stress symptoms (Nielsen \& Einarsen, 2012). As for the organisation, the consequences of workplace bullying can disrupt employees' desire to perform their job to the best of their ability, and this can lead to a decrease in the productivity of the organisation (Hutadjulu, Saerang, \& Tielung, 2017).

Recognising the serious consequences of workplace bullying, I, as an international student who is studying in New Zealand, have noticed that a number of helpful workplace bullying studies in both private and public sectors have been conducted in New Zealand (Bentley et al., 2012; Catley et al., 2013; Plimmer et al., 2017). These studies share the fact that they have used a well-known survey format called the Revised Negative Acts Questionnaire (NAQ-R), which consists of 22 items to explore and to measure bullying in the workplace. These studies by scholars in New Zealand have helped to raise awareness of serious workplace bullying so that the appropriate laws and policies can be established. Recently there are also studies focusing on developing effective management and prevention of workplace bullying (Blackwood, 2015; Crimp, 2017), and WorkSafe New Zealand is a good example of regulation in response to workplace bullying. New Zealand is therefore an effective model for how bullying could be addressed in Laos where bullying definitely exists, but is not well recognised and understood. There are also no state-led policies to prevent the phenomenon of bullying in the country's organisations.

\subsection{Background to the study}

While workplace bullying has gained more attention in Western countries, we still do not understand much about how gender is related to the occurrence of workplace bullying and experiences of it. When gender does feature in workplace bullying research, it is often only used to signify the sex differences between women and men while ignoring the socially constructed nature of the concept of gender (Keashly, 2012). For example, studies on workplace bullying have focused only on statistical differences in bullying patterns such as whether women or men are the victims or the perpetrators of workplace bullying (e.g. Zapf, Escartin, Einarsen, Hoel, \& Vartia, 2011). There are some studies that discuss the gendered process of workplace bullying, which are the focus of this study (e.g. Lee, 2002; Salin \& Hoel, 2013; Simpson \& Cohen, 2004). In Asian countries, there is research on workplace bullying in 
general such as in China, Japan, Vietnam, and the Republic of Korea (see for example, Cheo, 2017; Naito, 2013; Nguyen, Teo, Grover, \& Nguyen, 2017; Park, 2013), but not at all in terms of the relationship of workplace bullying with gender as a social construct. (See Chapter 2 for wider review). In addition, these studies have tended to pay more attention to documenting the pervasiveness of workplace bullying, and have paid little attention to the subjective experiences of bullying (Parzefall \& Salin, 2010). Subjective experiences help us to understand the complex nature of individuals' perspectives and what has shaped them. Therefore, this study aims to recognise and interpret workplace bullying as experienced by myself and participants.

\subsection{Lao PDR or Laos as the research context}

In order to understand and interpret the complex nature of gender and workplace bullying in the Lao context, it is important to have an understanding of factors in the local context which, from my opinion, are likely to be relevant to workplace bullying and in turn may lead to explaining why or how workplace bullying is different in this context.

\subsubsection{Geographic and demographic factors}

The Lao People's Democratic Republic (LAO PDR), normally known as Laos, is a small and landlocked country located in South East Asia, bordered by Cambodia, the People's Republic of China, Myanmar, Thailand and Vietnam (Lao Statistics Bureau, 2017). About 59 percent of the approximately 6.5 million citizens live in rural areas, and about 50 percent of the population are females (Lao Statistics Bureau, 2017). Gender inequality remains poor as Laos is ranked 109 out of 189 countries on the gender inequality index (UNDP, 2018).

\subsubsection{Political context}

The Lao PDR was established, after the declaration of the country's independence in December 1975, by the Lao People's Revolutionary Party (LPRP), formed in 1930 and formally established in 1955. Since then, the country has been in the power of and ruled by the LPRP (Soukkaseum, 2017). In article 1 and 2 of the Lao constitution, it states that Laos, as a country, is “a People's Democratic State, all powers are of the people, by the people and for 
the interests of the multi-ethnic people of all strata in society with the workers, farmers and intellectuals as key components" (Soukkaseum, 2017, p. 51). It is quite interesting to observe that although the country strongly emphasises that democracy means the government of the people, by the people, and for the people, people are not free to express their opinions in regards to any critical problems which have affected their well-being as a consequence of government development projects. In general, the Lao government administration is centralised through a top-down structure from national to provincial, district, and village levels respectively (Saengouthay, 2015). This means that Laos is a bureaucratic and hierarchical as well as a high power distance country (Soukkaseum, 2017). I will argue in this study that this kind of governance can potentially be a risk factor for workplace bullying.

\subsubsection{Aid dependency}

Laos has relied heavily on foreign aid for more than half a century (Saengouthay, 2015). This heavy dependence started after the former Soviet Union collapsed (Laos' former international ally), and the government of Laos started to welcome the support of Western capitalist countries and international agencies (Takala \& Piattoeva, 2012). After this, international NGOs’ aid to Laos has continually increased (ADB, 2011).

According to Saengouthay (2015):

There are about 170 NGOs operating in Laos, of which 78 have a representative office in the country and their interventions range from humanitarian assistance to human resource development. Their tasks have been officially recognised by the Laos government and development partners, particularly for their capacity and effective approach in reaching poor and vulnerable people in the remote areas. (p. 53)

Recently, NGOs have slightly shifted their role from humanitarian and development interventions to policy advocacy as they have started to influence government policy, particularly through the different Sector Working Groups and Round Table Meeting Process (Saengouthay, 2015).

I presented the above views on aid dependency because some of my participants used to work and are working with NGOs during the time I conducted my research study. This view 
allowed me to understand the perceptions of these women of bullying in this context. This is discussed in my findings chapter.

\subsubsection{Workplace bullying in Laos}

In Laos, according to my knowledge, there are no studies about workplace bullying or its relationship with gender, either as a socially constructed idea or as the biological difference between women and men. The only relevant research is related to sexual harassment in the workplace, and was conducted by ADWLE-Association for Development of Women and Legal Education, (2017). It found that women were the majority of victims experiencing sexual harassment in the workplace, and that most of the cases were in the form of physical harassment. As sexual harassment can be seen as a specific form of bullying (Einarsen, 2000) this research, therefore, builds on the work of ADWLE (2017). Other forms of workplace bullying are likely to exist in the Lao context and gender is likely to play a key role in the nature and experiences of workplace bullying in Laos. According to ADWLE (2017), the women victims felt unsafe and were afraid whenever they went to their workplace. These consequences should be raised widely in Lao society. Therefore, it is important to look at workplace bullying from a gendered perspective.

\subsection{Purpose of the research}

As mentioned above, neither the word bullying nor its related concepts are well known in the Lao organisational context. By recognising the important consequences of workplace bullying, I have a strong personal interest in conducting this study because I have experienced a number of negative workplace behaviours and also witnessed bullying, and this affected me a lot in terms of my mental health. As a result of being bullied and witnessing bullying, I was very worried about my job security and also suffered insomnia and anxiety. Therefore, it is appropriate that I too share my experiences with my participants in my research to further the understanding that workplace bullying needs to be identified and prevented. 
The main purpose of this study is to explore workplace bullying based on ten Laotian women (including myself) in their current and previous workplaces by drawing on the women's own perceptions of bullying. I adapted some concepts from the survey questions in the NAQ-R (Einarsen, Hoel and Notelaers (2009) as it gave me ideas about how to ask questions while I was conducting the interviews. Concepts from the NAQ-R were appropriate in exploring women's perceptions of workplace bullying in this study as it categorises bullying as jobrelated bullying, personal bullying, and physically intimidating bullying and as consisting of 22 specific negative behaviours in the workplace. The findings of this study may differ from those in Western studies because cultural differences and context are highly likely to influence how individuals perceive or interpret and respond to workplace bullying (Samnani, 2013).My findings are not only guided by the knowledge gained from the literature, but are also derived from new ideas that emerged in my data.

\subsection{Research questions}

In order to explore workplace bullying from a gendered perspective, a clear understanding of the pattern of workplace bullying is essential. Thus, this research addresses the main question:

How do Laotian women employees experience bullying in their workplace?

The emotional effects of workplace bullying on individuals and their perceptions of workplace bullying affected by both the Laotian context and their position in the workplace as well as the coping techniques have not yet been documented in previous research. Therefore, four subquestions need to be addressed in order to understand the opinions of the women I interview.

\section{Sub-questions}
a). How do they perceive bullying?
b). How do they cope with it?
c). How is their perception of bullying affected by the Laotian context?
d). How is their perception of bullying affected by their position in their workplace?




\subsection{Research methodology}

This research is related to the concepts of workplace bullying drawn from Western research, and thus some of these concepts were used to guide the exploration of workplace bullying in Laos. Also, since the study deals with women's perceptions and their personal experiences, this research employed qualitative epistemology by adopting social constructionism and interpretivism as the main approaches to identify, understand and interpret workplace bullying experienced and perceived by them. Access to participants and data collection were accomplished, respectively, through the snowball sampling technique semi-structured interviews. The process of data analysis was done with reference to the analytical framework the five stages of data analysis suggested by O'Leary (2017). In these five stages, the process of developing themes was done based on the category development procedures suggested by Constas (1992). In regards to gender and workplace bullying incorporating a cultural perspective, the analysis was based on gendered organisation theory (Acker, 1990, 2006) and social dominance theory (Sidanius \& Pratto, 1999). The details are discussed in Chapter 3, Methodology.

\subsection{Chapter outline}

In Chapter 2, I introduce the concepts of workplace bullying, gender and culture with a focus on the key concepts and definitions from the literature which are used in this research. I also describe how these concepts are related to workplace bullying, and discuss the techniques used by individuals to cope with workplace bullying. In Chapter 3, I discuss the methodology used in this study. I focus on research epistemology, and include my personal epistemology and interpretive approach. I then present the process of data collection and data analysis. In

Chapter 4, I present the findings of this study. In Chapter 5, I discuss the findings with reference to the research questions and literature. Finally, Chapter 6 is the conclusion in which I discuss contributions and suggestions for the future research. 


\subsection{Conclusion}

As presented above, this is a small exploratory study which aims to provide the first research on gender and workplace bullying in the Laotian context. As such, it provides a useful comparison to Western studies. The research is limited in scope and thus may well not capture all kinds of workplace bullying in Laos, but it is expected to generate rich understandings by drawing on ten women's own perceptions of workplace bullying in their context. It is hoped that it will raise awareness that workplace bullying in the Lao context does exist, but can be addressed. 


\section{Chapter 2. Bullying, Gender and Culture}

\subsection{Introduction}

In this chapter, I provide an overview of concepts related to bullying, and introduce how bullying behaviours are associated with gender and culture. Even though culture is not the main focus of this study, it seems important in regards to bullying behaviours that are particularly strong and perceived as acceptable in various Asian countries.

There are five sections in this chapter. Firstly, I review research on concepts of workplace bullying and present the definition that I use in this research. Secondly, I discuss the concepts of gender, gender in the workplace, gender roles/gender norms, as well as a brief introduction on cultural context in Laos and how these are perceived in Laotian context. These concepts will help me to better understand and interpret bullying behaviours that may be identified and discussed by the Laotian women in this study. Thirdly, I review studies on workplace bullying in the Western context as well as in the Asian context to find out the impact of workplace bullying on both individuals and organisations. These studies will act as a guide to better understand how negative bullying behaviours affect Laotian women and Laotian organisations. In addition, I also present how culture is associated with bullying behaviours. Fourthly, I review the concepts of coping strategies in regards to workplace bullying. This will help me to be able to interpret how Laotian women cope with bullying behaviours. Fifthly, I discuss the connection of gender and workplace bullying which will be divided into two subsections, including gender and workplace bullying and workplace bullying from a gendered perspective. These reviews will help me understand how workplace bullying can be interpreted by using a gender-lens. Finally, this chapter is concluded. 


\subsection{Concepts of workplace bullying}

Workplace bullying has been widely recognised and researched in several Western countries such as New Zealand, Australia, the United Kingdom, and Norway. To date, there is no single agreement on defining the concept of workplace bullying (Crimp, 2017). Therefore, it must be defined through integrating a number of different concepts from different researchers in many Western countries (Chirila \& Constantin, 2013).

In English-speaking countries such as Australia, the United Kingdom, and New Zealand, the term "workplace bullying" is always used whereas, the terms "mobbing" is commonly used in German-speaking countries as well as in France (Saunders, Huynh, \& Goodman-Delahunty, 2007). In the United States, the term "aggression" and "emotional abuse" are used, while "harassment" is the term preferred by researchers in Finland (Saunders et al, 2007). These concepts make me aware that researchers in Western countries have used a wide range of terms to describe forms of negative workplace behaviours. In particular though, the term "workplace bullying" is the most preferable because it is the core focus in this study as discussed below.

The different concepts presented above imply that the definitions of workplace bullying vary depending on researchers and that among them, there exists no agreement in regards to what should be essential criteria for workplace bullying (Saunders et al., 2007). According to Rayner and Keashly (2005), there are five elements that are most frequently used to define workplace bullying:

(1) Individuals experience of negative behaviour; (2) negative behaviours experienced persistently; (3) individuals experience some effects, either psychological or physical; (4) targets label themselves as bullied; (5) targets perceive themselves with less power and have difficulty defending themselves. (p. 273).

These elements of workplace bullying are the main focus of this research. However, while the idea of negative behaviours experienced persistently is regarded as important (Rayner et al., 2005), it not essential in this study because I believe that any single negative behaviour 
experienced by individuals can potentially cause negative emotional effects on individuals, and thus can be considered as bullying.

The five components of workplace bullying suggested by Rayner et al., (2005) have been widely used by some researchers in exploring workplace bullying. However they have been considered along with forms of direct and indirect negative workplace behaviour, and the consequences of these behaviours experienced by individuals (Saunders et al., 2007). In regards to the idea of power imbalance (the inequalities of power between the bully and bullied), and labelling oneself as bullied, Rayner et al., (2005) perceive these as important, but not essential in defining forms of workplace bullying. In this study, even though these two aspects are considered less essential by Rayner et al., (2005), I do not agree because it is important to note that the idea of power imbalance can be a risk factor for workplace bullying. This can occur in organisations where a culture of a high power distance (Hofstede, 1980), (the inequality of power in hierarchical structure between boss and subordinate), is being practiced. Therefore, in this study, the idea of power distance is regarded as essential in recognising, understanding and interpreting workplace bullying experienced by Laotian women in their context. I discuss this more detail in Chapter 4 and 5.

Einarsen, Hoel and Notelaers (2009) developed a survey to measure bullying in the workplace called the Revised Negative Acts Questionnaires (NAQ-R). It focuses on bullying behaviours and consists of 22 items. The forms of bullying have been classified under three categories: job-related bullying, personal bullying, and physically intimidating bullying. However, according to Salin (as cited in Bentley et al., 2012), there are gaps in this survey. The NAQ-R does not explore all bullying behaviours and individuals don't have opportunity to express their opinion toward the behaviours (Bentley et al., 2012). They explain the latter as follows:

For example, some behaviours such as being given an unmanageable workload, or being ordered to do work below level of competency can be experienced regularly without being perceived as bullying while others which are experienced only occasionally can produce long-lasting effects. (p. 358) 
In this respect, I do agree with the criticism by Salin (as cited in Bentley et al., 2012). However, in this research, I am drawing some concepts from the NAQ-R because it has been the most widely used to examine the prevalence of workplace bullying in studies and countries by many researchers (Einarsen, Notelaers \& Nielsen, 2011). Therefore, it can be a useful guideline to interpret and to categorise bullying behaviours into different forms, particularly, in the Laotian context where bullying will be studied for the first time. Table 1 below shows examples of negative behaviours related to what bullying consists of for each classification. 


\begin{tabular}{|c|c|}
\hline Job-related bullying & $\begin{array}{l}\text { - Someone withholding information which affects your } \\
\text { - Berformance } \\
\text { - Having your opinions ignored } \\
\text { - Being given tasks with unreasonable deadlines } \\
\text { - Excessive monitoring of your work } \\
\text { - Pressure of not to claim something to which by right you are } \\
\text { - } \text { entitled (e.g. sick leave, holiday entitlement, travel expenses) } \\
\text { - Being exposed to an unmanageable workload }\end{array}$ \\
\hline Personal bullying & $\begin{array}{l}\text { - Being humiliated or ridiculed in connection with your work } \\
\text { - Having key areas of responsibility removed or replaced with } \\
\text { - Gossiping or spreading and rumours about you } \\
\text { - Being ignored or excluded } \\
\text { - Having insulting or offensive remarks made for you, your } \\
\text { - } \text { attitude or your private life } \\
\text { - Repeated reminders of your errors or mistakes } \\
\text { - Being ignored or facing a hostile reaction when you approach } \\
\text { - Persistent criticism of your errors or mistakes } \\
\text { - Practical jokes carried out by people you don't get along with } \\
\text { - Having allegations made against you } \\
\text { - Being the subject of excessive teasing and sarcasm }\end{array}$ \\
\hline Physically intimidating bullying & $\begin{array}{l}\text { - Being shouted at or being the target of spontaneous anger } \\
\text { - Intimidating behaviours such as finger-pointing, invasion of } \\
\text { personal space, shoving, blocking your way } \\
\text { - Threats of violence or physical abuse or actual abuse }\end{array}$ \\
\hline
\end{tabular}

Source: Adapted from Einarsen et al., (2009)

\section{Table 2. 1: Classification of the forms of bullying}




\subsubsection{Concepts and definition used in this thesis}

In this study, I define workplace bullying based on some of the concepts that I have mentioned above. In addition to the NAQ-R, the idea of power imbalance is also used to identify, understand and interpret workplace bullying in the Lao context.

\subsubsection{Definition of workplace bullying}

As mentioned previously, in my view, workplace bullying does not have to occur frequently and over a certain period of time. It can occur even in a single instance of negative behaviour. In this study, the main definitional elements of workplace bullying are based on four out of five components that are suggested by Rayner et al., (2005) including: negative behaviour experienced by individuals, negative emotional effects on individuals, targets perceiving themselves as being bullied and, targets perceiving themselves with less power and having difficulty defending themselves. Based on these four components, workplace bullying can be defined in my own understanding as a negative and unwanted behaviour, regardless of frequency and duration, experienced by individuals and, based on outcomes reported by participants, with associated negative emotional symptoms such as stress and anxiety, sadness and low self-confidence. This definition will be one of the main guidelines to identify and to interpret behaviours that are perceived as bullying by Laotian women in Laotian organisations.

\subsubsection{Power distance}

To understand a factor that can cause workplace bullying, I also apply the concept of power distance, which refers to "the degree to which a society accepts the fact that the inequality of individuals' abilities and inequality of power in institutions and organisations are inevitable" (Hofstede, 1980, p. 96). In this case, I substitute society for organisations and employees. According to Hofstede (1980), organisations in Western countries such as Sweden, Finland, and Norway are characterised by a low power distance, and pay more attention to the wellbeing of the individual worker and place a high negative value towards any sign of power abuse. Therefore, it can be assumed that the idea of power distance in Western countries might not be a main cause of bullying. 
In contrast, in Asian countries, where the culture consists of a high power distance, such as in Vietnam, workplace bullying can occur due to this culture (Nguyen et al., 2017). According to Nguyen et al, (2017), in the Vietnamese public sector with a high power distance, employees who accept authority and power from individuals in a higher position are more likely to experience bullying and it can lead to negative outcomes affecting employees and organisations. Laos, according to my knowledge, is a country where its culture is similar to Vietnam, therefore, I argue that power distance is part of its national culture and is a risk factor that causes workplace bullying. This is the context where certain kinds of power distance are displayed. I discuss this more detail in my findings chapter.

\subsection{Concept of gender}

As this study is focusing on workplace bullying from a gender perspective, it is important to understand how gender is understood because, as mentioned in Chapter 1, there are researchers who refer to gender as the biological differences between women and men without recognising the socially constructed nature of it (Keashly, 2012). In this study, gender refers to the social constructions surrounding males and females, meaning in my context that the roles and norms that are attached to Laotian men and women are created by Lao society or Lao culture. According to the World Health Organization (WHO) (2018), gender refers to the socially constructed roles, behaviours, activities, and attributes that a given society determines what is considered, expected, allowed and valued in a woman and man, and boy and girl in a specific context and it can be changed (WHO, 2018). The recognition of gender as a social construct is therefore the main focus of this study to identify, understand and interpret workplace bullying in Laotian context.

\subsubsection{Gender in the workplace}

There are a number of studies on gender in the workplace, for example, studies of gender discrimination in the workplace by Bobbitt-Zeher (2011), gender differences in aggression and counterproductive work behavior by Spector (2012), and workplace bullying and gender by Keashly (2012). As my study focuses on gender and workplace bullying in Lao organisations, I intend to introduce a broader discussion on specific aspects of gender in the 
workplace that are relevant to women in Laos, and I will use the concept of gendered organisations by Acker (1990), as outlined in section 2.6.2, to identify the issues of gender in the Lao workplace.

\subsection{Cultural and gender in the Laotian context}

In order to understand the nature of workplace bullying in the Lao context, it is crucial to understand how gender is constructed and related to the cultural beliefs of many Lao people. Also, it is important to note that there is little published research on women in the workplace in Laos. Therefore, I have drawn on a general government and NGO report as the evidence to back up information that I have mentioned, as outlined below.

\subsubsection{Gender context}

As mentioned in Chapter 1, in the discussion on the gender inequality index, the Lao PDR is ranked 109 out of 189 countries (UNDP, 2018). This shows how poor gender inequality is in Laos. However, currently, the Lao PDR is highly committed to the promotion of equality between men and women and mentioned it in the National Growth and Poverty Eradication Strategy (Gender Resource Information and Development Center-GRID, 2005). Even though equality between men and women is being promoted, it is not guaranteed that men and women will have the same opportunity in their workplaces, and also it is not guaranteed that gender differences will be acknowledged clearly in their organisations.

\subsubsection{Gender roles and gender norm}

Before discussing what gender roles and gender norms look like in Lao society, it is important to understand the general meaning of these two terms. The term gender role refers to the norms of behaviour and attitudes that a culture or society gives to people based on their sex (Griffin, 2017). For example, people may believe that women are better suited for domestic roles such as cleaning, cooking and taking care of children, while men's work is as a bread winner. Over time, these gender roles can become gender norms, which refers to the behaviour that women and men are expected to conform to in a particular group, community 
or culture (Sjoholm, 2017). This can lead to gender stereotypes. These refer to the oversimplified ideas, attitudes and behaviours that are attached to women and men in a particular group or culture (Dolan, 2014). Stereotypes become more difficult to change. For instance, the assumption that women are better suited for domestic roles is an example of a prevalent and long-standing gender stereotype that applies in various countries including Laos and is held by both males and females (Criterion venture, 2012).

In Lao society, many people still stick to traditional ideas that women and men should behave in ways that fall into specific categories determined by their gender. In supporting this, a report on gender power analysis conducted by CARE Int'l in 2018 revealed that non-paid household tasks such as cooking and caring are roles that tend to be assigned to women whereas men tend to be responsible for heavy work such as hunting or taking care of big animals. If they cannot do well in those tasks, they will be criticised by society as well as feeling shamed and valueless (CARE Int'l, 2018). Some Laotians may believe that because traditional gender roles have been practiced for so long, they should not be changed. These thoughts can be harmful because they motivate people to criticise those who do not fit the traditional gender roles. As a result, many Lao people may feel bad if they are not able to behave in accordance with traditional gender roles. These gender roles are types of socialcultural practices and therefore they become the gender norms that individuals are expected to follow. These points will help guide me on how to interpret workplace bullying from my own perspective as well as the participants' perspective.

\subsubsection{Cultural context}

The Lao PDR is considered to be one of the most ethnically diverse countries in the world, with an official 49 ethnicities that fall under four broad language families, the Lao-Tai/LaoLoom, the Mon Khmer, the Hmong-Mien and the Chine-Tibet (GRID, 2005, p. 18). Among these four, Lao-Tai/Lao-Loom is considered to be the dominant ethnic group and has traditionally lived in lowland areas, whereas the Mon-Khmer, the Hmong-Mien have lived in midland areas, and the Chine-Tibet have lived in highland areas (GRID, 2005, p. 19). It is believed that ethnic and cultural differences will impact gender roles because different ethnic groups have different cultures, traditions, and norms. Therefore, men and women will be 
ascribed different behaviours or activities based on their ethnic group. These points will not be the main focus of this study. However, this research will consider these points when interpreting how workplace bullying is perceived by Laotian women in their context.

In addition to the diversity of ethnic groups, marriage is considered as a main value of Lao society. Lao women are expected to marry and remain married regardless of the circumstances (GRID, 2005, p. 20). This implies that Lao women are expected to be a wife and a mother, and this relates to gender roles. Therefore, it can be argued that this tradition can cause negative emotional effects on Laotian women because they will be criticised by people in society if they do not marry or do not remain married. This view is important as it can be a guide to understanding and interpreting how workplace bullying is experienced by Laotian women in this study.

\subsection{Workplace bullying in Western and Asian context}

In this section, I review studies on workplace bullying in both Western and Asian contexts to find out how workplace bullying affects individuals and organisations. This is important as it helps me understand how the impact of workplace bullying affects the Laotian women in this study.

\subsubsection{Workplace bullying in Western context}

As mentioned in Section 2.2, workplace bullying research has been conducted in a number of Western countries, and since the introduction of the concept in 1990s, a number of scholars have paid attention to workplace bullying and its serious negative effects on both employees' health and well-being, as well as that of organisations (Giorgi, Leon-Perez, \& Arenas, 2015).

Recently, several authors have provided evidence indicating that workplace bullying tends to cause harm to employees' health. For example a recent meta-analysis has shown that employees exposed to bullying behaviours usually suffer health-related problems such as anxiety, depression, or post-traumatic stress symptoms (Nielsen \& Einarsen, 2012). These symptoms can in turn lead to other health-related issues. For example, depression and anxiety may contribute to diabetes risk (Nouwen et al., 2010) because individuals have different 
stress-related coping strategies, such as comfort eating behaviour with an increased preference for high density foods (Bazhan \& Zelena, 2013), which may result in weight gain (Kouvonen et al., 2011), a critical risk factor for diabetes (Tuomilehto et al., 2001). A recent study and meta-analysis has found a higher risk of type 2 diabetes among employees who have experienced bullying in the workplace (Xu et al., 2018). There is also evidence indicating that individuals who have been exposed to bullying have a higher risk of cardiovascular disease and depression compared to non-bullied people (Kivimaki et al., 2003). Additionally, the consequences of workplace bullying can have a negative impact on individuals' personal relationships at home (Lewis \& Orford, 2005).

Apart from the harm to the employees, recent evidence shows that bullying can damage an organisation's culture and reputation, and can result in high absenteeism, increased work errors, lower performance, less commitment and job satisfaction, decreased performance, and high turnover (Bartlett \& Bartlett, 2011; Catley et al., 2013)

Recognising the seriousness of the impact of workplace bullying, New Zealand has developed a tool to address and prevent workplace bullying named WorkSafe New Zealand's Preventing and Responding to Workplace Bullying Guidelines (2014). In Australia, there are national antibullying laws and state or territory health and safety bodies that can help people with bullying and harassment in the workplace. There is also the Safe Work Australia's Guide for Preventing and Responding to Workplace Bullying (2016). These two guidelines provide a similar content such as a definition of workplace bullying, tools to identify bullying, outlines the responsibilities of organisations, and preventions and management of bullying (WorkSafe NZ, 2014; Safe Work Australia, 2016). This helps distribute information to raise awareness of how serious workplace bullying is.

Western research into consequences of workplace bullying provides useful insights and guidelines for this study to find out how bullying behaviours at work affect Laotian women. Also, by identifying these consequences, it helps minimise the biases in regards to my findings, since, the interpretations are always entwined with a researcher's biases, prejudices, and worldviews - both recognised and unrecognised, conscious and subconscious., A good way for me to reduce these biases is to list as many of my assumptions and preconceived 
notions or information as possible (O'Leary, 2017). Further, it helps me to understand the opinions of Laotian women related to how to solve issues of workplace bullying.

\subsubsection{Workplace bullying in Asian context}

Although there is growing attention being paid to the issue of bullying affecting employees in many Western countries, there are only a few studies that explore the significance of workplace bullying in Asian countries. In South Korea, workplace bullying can be serious and life threatening for both the victims and the perpetrators. There was an incident that occurred in 2012, where a man who was bullied killed colleagues and the superiors who bullied him (Park, 2013). In Japan, workplace bullying occurs in many industries, but the highest cases were in the medical and welfare industry, manufacturing industry, and the wholesale and retail industry. As a result of bullying, most of the victims faced mental health problems for instance stress and anxieties (Naito, 2013).

In China, studies have found that increases in workplace bullying is related to decreases in reported levels of employee commitment. For example, McCormack, Casimir, Djurkovic and Yang (2006) studied the relationship between workplace bullying and affective commitment

for a sample of 142 Chinese teachers. Their findings indicate that teachers who experienced workplace bullying indicated lower levels of affective commitment toward their organisation (McCormack et al., 2006). Similar findings are found in research conducted by Aryee, Chen, Sun \& Debrah, (2007) which revealed that Chinese employees who experienced workplace bullying reported less commitment toward their organisation (Aryee et al.,2007).

The above studies indicate the similarity of the consequences of workplace bullying in both Asian and Western countries, and this research will take these findings as a guide to explore how bullying behaviours affect Laotian women.

\subsubsection{Cultural impact on workplace bullying behaviour}

Archer (1999) pointed that in some occupations and organisations certain negative acts are expected as part of the culture and therefore not considered bullying. For example, in Laos, 
there is not only a high power distance culture, but a particular bureaucratic management style, where there are a great number of rules and regulations and a high degree of formality in the way that work has to be done, and where decisions are made through the hierarchical structure of the organisations (Hofstede, 1980). This can represent a high level of managerial prerogative, meaning that a boss has rights to control/manage subordinates including the right to direct the work of subordinate (Nguyen et al., 2017). In this cultural context, bullying behaviours in a workplace are more likely to be acceptable.

A number of authors have proposed that bullying behaviours can be tolerated or even accepted in some cultures. For example, cultures with high performance orientation find bullying behaviours to be more acceptable because they value accomplishments, a sense of urgency, and direct and explicit communication. Therefore, bullying behaviour such as shouting at subordinates may be tolerated if this behaviour is believed to lead to better performance (Power et al., 2010). Furthermore, these authors also reveal that Confucian cultures find workrelated bullying and physically intimidating bullying to be more acceptable than the Anglo and Latin American cultures (Power et al., 2010). Authors such as Giorgi et al., (2015) argue that in Italian organisations bullying is very common, and therefore Italian employees may be less likely to be dissatisfied with their jobs as a result of experiencing negative behaviours at work. One could potentially conclude that the workplace bullying phenomenon in Italian organisations seems to be more culturally tolerated or even accepted (Giorgi et al., 2015).

In Singapore, a study found that Singaporean employees are less likely to respond strongly to bullying behaviours, and are more accepting of these behaviours (Loh, Restubog, \& Zagenczyk, 2010). This finding can be further explained in that Singapore is considered to be a high power distance culture, and, in this culture, differences between superiors and subordinates are clearly noticeable (Hofstede, 1997). Furthermore, employees always show respect to their superiors by addressing them as "Sir" or "Madam" or "Mister" or "Miss", and more importantly they are less likely to question the demands from their superiors (Hofstede, 1997). As a result, employees from this culture are more likely to have respect for authority and preference for harmony in the workplace, and this makes them less sensitive to occurrences of bullying (Loh et al., 2010). 
In Vietnam, a study by Nguyen et al., (2017) reported that of 274 officers working in six branches of a public sector agency in Ho Chi Minh city, approximately 53 per cent of them reported having been a target of bullying in their workplace, with the highest bullying behaviour being "devaluing of an individual's work and efforts" (p. 1426). Specifically, the findings of this study highlight the fact that Vietnam is a country with a high power distance culture and bureaucratic management practice (Nguyen et al., 2017). In such a culture, individuals tend to misinterpret and accept bullying behaviours because these behaviours are perceived as standard behaviours (Loh et al., 2010; Teagarden, 2005). They are also likely to accept tasks that fall outside their job descriptions, superiors' abuse of power and unfair treatment (Loh et al., 2010; Stone-Romero, Stone, \& Salas, 2003).

Laos is similarly considered to be a country with a high power distance culture, as well as having hierarchical and bureaucratic management practices (Soukkaseum, 2017). Therefore, the above studies are useful sources for this study to help understand how cultural context can influence workplace bullying in Laotian organisations

\subsubsection{Coping strategies}

There is no single technique or style when it comes to coping strategies for workplace bullying. In this study, coping refers to the techniques that the bullied person uses when they are faced with bullying situations. A number of coping strategies have been suggested by various researchers, for instance, problem-oriented or active coping strategies and emotionoriented or passive coping strategies (Dehue, Bolman, Vollink, \& Pouwelse, 2012). Problemoriented/active strategies are used when individuals believe that the stressful situation can be changed and the source of the problem can be overcome. An example is to ask someone to help solve the problem. Emotion-oriented/passive strategies are used when individuals think nothing can be done to change the problem to reduce the emotional distress associated with a stressful situation. Examples include avoidance or staying away from the problem, quitting the job, absenteeism, wishful thinking by casting a positive thought towards the problem (Dehue et al., 2012), or communicating about the problem with friends or one's spouse (McCarty, Zhao \& Garland, 2007). 
Those coping techniques will be used depending on the justification of the bullied person. I believe that in a country where a high level of power distance exists like Laos, the bullied persons are likely to respect the power and authority distribution and accept unfair treatment (Nguyen et al., 2017). It seems reasonable to predict that bullied persons in this study will potentially use emotion-focused/passive strategies rather than problem-focused/active strategies due to the fact that it is hard to radically deconstruct the hierarchical cultural system in the Lao context.

A study by Dehue et al., (2012) found emotion-oriented/passive strategies such as compensation and denial were used more frequently among people who had been bullied. They suggest that individuals who experience bullying and who use these strategies to cope with problems at work do not seem to benefit from these strategies. In fact, among these employees, bullying tended to be associated with more health complaints, more depressive symptoms, poorer well-being, and greater absenteeism. This is because the bullying behaviour remains unsolved, and this leads to the more serious psychological problems (Dehue et al., 2012). As mentioned previously, being bullied at work is associated with mental health

problems such as depression and anxiety as well as with a lack of job satisfaction and low performance.

The coping strategies and their consequences presented above provide me with a focus in my analysis of how Laotian women cope with workplace bullying and their stress-related problems.

\subsection{The link between gender and workplace bullying}

In this section, I discuss the connection between gender and workplace bullying which will be divided into two sub-sections, including gender and workplace bullying, and workplace bullying from a gendered perspective. These views help me understand how workplace bullying can be interpreted through a gender lens. 


\subsubsection{Gender and workplace bullying}

Although workplace bullying has recently received more attention in many Western countries and in some Asian countries due to the many negative consequences associated with it, we still do not know much about how gender is related to the experience and occurrence of workplace bullying. A number of scholars have criticised studies of workplace bullying with failing to provide a better analysis of gender (Hutchinson \& Eveline, 2010). However it is recognised as important. Simpson and Cohen (2004), for example, emphasise that in order to understand bullying behaviours experienced by individuals, it is necessary to put bullying in a gendered context. In my opinion, seeing bullying as gender specific will help readers better understand the perceptions of bullying and the coping strategies used in response to bullying behaviours.

Several studies have shown that women report more bullying and are more at risk for bullying (Hutchinson \& Eveline, 2010; Notelaers, Vermunt, Baillien, Einarsen, \& De Witte, 2011). Other studies have focused on statistical differences in bullying rates (e.g. Agervold, 2007; Matthiesen \& Einarsen, 2007), and bullying patterns (e.g. Salin, 2001; Simpson \& Cohen, 2004). Importantly, many researchers have used the term gender simply to signify biological differences while ignoring the socially constructed aspect of gender (Keashly et al., 2012). The problem here is that by focusing only on the biological sex of the perpetrators and the bullied (McGinley, 2008), bullying is perceived as gender-neutral rather than gender-specific behaviour (Salin \& Hoel, 2013). In addition, an author such as Field (1996) argues that bullying is not the gender issue because the perpetrators can be both males and females. Consistent with this argument is that presented by Simpson and Cohen (2004), where they claim bullies (either men or women) are those who sit in a higher hierarchical position than the bullied. This leads them to the conclusion that bullying, that cuts across gender, is concerned with "the role played by the possession of institutional power within which bullying takes place" (Simpson \& Cohen, 2004, p. 181).

In Asian countries, particularly in Laos, there is no research on workplace bullying generally, and not at all in terms of its relationship with gender. There needs to be more qualitative studies into the experiences of gender and bullying to enrich understanding of individuals' perceptions, and experiences in regards to gendered workplace bullying. 


\subsubsection{Workplace bullying from a gender perspective}

Workplace bullying from a gendered perspective can be understood by examining the theory of gendered organisation by Acker (1990). The theory states that all types of organisations play a crucial role in reproducing mainstream management theories mostly dominated by men. One of the ideas that helps in understanding the occurrence of bullying is gender segregation of work within workplaces (Acker, 1990). Gender segregation of work relates to work or an occupation itself being dominated by a particular gender. There can be both horizontal and vertical segregation. Horizontal segregation represents the belief that women are more competent than men in service, nurturing and social interaction, while vertical segregation represents the belief that men are more status worthy than women and therefore are more appropriate for positions of authority and dominance (Charles, 2003). This idea can explain the prevalence of workplace bullying based on gender in male-dominated organisations which implies that women are oppressed by the male-created and dominated structure of control (Acker, 1990).

In addition, workplace bullying based on a gendered perspective can be also understood by examining the theory of inequality regimes in organisations by Acker (2006). Acker states that "all organisations have inequality regimes, and it is defined as loosely interrelated practices,

processes, actions, and meanings that result in class, gender and racial inequality within particular organisations" (Acker, 2006, p. 443). Based on my own experience in Laos, there are particularly high levels of inequality and high power distance and these are related to the concept of gender and social dominance theory, as outlined below. For example, one of my friends who works in the public sector complained that in her workplace most of the women employees are not able to get promotion compared to men although they have better skills and performance. The concept of gendered organisation helps me to understand how and through what processes gender is treated in the Laotian organisations.

One of the theories, in addition to Acker (1990), that can provide further insight into the understanding of bullying based of gender difference is social dominance theory (Salin \& Hoel, 2013). This theory states that "all societies consist of power hierarchies, where one, or possibly more social groups dominate other groups" (Salin \& Hoel, 2013, p. 239). This theory will help me to better understand the cultural context of bullying in Laos because the national 
culture of Laos appears to have power hierarchies and may thus be expected to have a high frequency of mistreatment at work. In addition, in regards to dominant group, Lao-Tai/LaoLoom is considered to be the dominant ethnic group in Laos. Therefore, I argue, from social dominance theory, that many forms of bullying can occur in less power and vulnerable groups especially women, whose gender is socially constructed, and who are supposed to follow gender roles or norms.

\subsection{Conclusion}

In this chapter, I have discussed the concept of workplace bullying and given the definition that I will use in this study. I have discussed relevant bodies of gender and workplace bullying literature, including the concept of gender, gender in the workplace, and gender roles and norms. In addition, I have discussed how cultural context can be a risk factor for workplace bullying. Furthermore, I have reviewed the ideas of coping strategies and the consequences of the use of less positive ones on those being bullied. Most importantly, I have discussed the relation between gender and workplace bullying and how bullying can be interpreted by using a gender lens, particularly by making reference to gendered organisation theory. The review of concepts related to gender, bullying and culture provide an important foundation for interpreting the workplace bullying experienced by Laotian women in their context. 


\section{Chapter 3. Methodology}

\subsection{Introduction}

As mentioned in the previous chapter, there is no existing research on bullying in Laos. Thus, this is an exploratory study that attempts to explore workplace bullying based on women's perceptions and reported experiences. According to Stebbins (2001), exploratory research is "research conducted where a group, process, activity, or situation has received little or no empirical evidence to date, has been largely examined using hypotheses rather than openmindedness, and has existed for a long time, but would benefit from being explored anew" (Stebbins, 2001, p.8). By applying this concept in this study, I strongly acknowledge that in Laos, little attention has been paid to the phenomenon of workplace bullying, and that there is no empirical research concerning it or dealing with the seriousness of the consequences of workplace bullying. Therefore, I aim to explore bullying behaviours in Lao organisations by adapting the concepts of workplace bullying from Western research in order to understand and interpret the nature of, and the causes and effects of the bullying as perceived or experienced by Lao women. In addition, I will be looking for new insights that are unique to both the participants and the Lao context.

My research questions presented below are designed to explore workplace bullying from a gendered perspective, how it is perceived by Laotian women, and affected by their context. Following the research questions, I present my research design which discusses the importance of qualitative research, my personal epistemology, the interpretative approach I am taking, and my position as an insider researcher. Next, I talk about the ethical considerations and then continue with the process of my data collection. I then present how data was analysed. Finally, I conclude with the summary of this chapter. 
Main research question:

How do Laotian women employees experience bullying in their workplace?

Sub-questions

a). How do they perceive bullying?

b). How do they cope with it?

c). How is their perception of bullying affected by the Laotian context?

d). How is their perception of bullying affected by their position in their workplace?

\subsection{Research design}

To explore women's perceptions towards and experiences of workplace bullying, qualitative research appears to be the best suited methodological approach to acquire that type of data.

\subsubsection{Qualitative research}

The main tradition of qualitative research calls on both inductive logic (reasons based on flexibility and open-mindedness) and deductive logic (reasons based on confirming hypothesis/prediction), appreciates subjectivities, accepts multiple perspectives and realities, and has the goal of gaining an intimate understanding of people, places, cultures through rich engagement in the contextual uniqueness of the phenomenon being studied (O'Leary, 2017). Applying this to the context of workplace bullying, I aim to gain a deeper understanding of the reasons for, opinions about, and perceptions towards to the problem of bullying as perceived and experienced by Lao women in the Lao context.

There is debate about the credibility of the qualitative findings compared to those of quantitative research. Some researchers would say that without a large sample, the findings cannot be claimed to be statistically significant, and therefore cannot be generalised (O'Leary, 2017). However, I do not rely on this line of argument as I am not aiming to come up with an objective conclusion. Therefore, I confirm my stance to adopt a qualitative approach because I am seeking to explore, obtain, understand, and interpret the women's perceptions and feelings 
toward workplace bullying in the contextual uniqueness of Laos. Therefore, qualitative research is appropriate as it seeks to answer the question of how experience is created and given meaning (Bryman \& Bell, 2015). As a result, the experiences and perceptions are deemed to be credible and important in this research, because they provide more understanding of phenomena. A social constructionist epistemology is therefore, used in this study, and will be described below.

In regards to the transferability of research results, it is important to note that the findings of this study are specifically related to the Lao context. As asserted by Guba and Lincoln (as cited in Bryman \& Bell, 2015), “[W]hether or not findings hold in some other context, or even in the same context at some other time, is an empirical issue" (p. 402). Therefore, to make my findings as transferable as possible, I have produced "what Geertz (1973) calls a thick description" (as cited in Bryman \& Bell, 2015, p. 402), that is, rich accounts of the details of my experiences during data collection. For example, I have closely described how I accessed the participants, the place of interviews, and the difficulties that I encountered during my data collection. This information allows readers to make the transferability adjustment necessary to generalise the findings (Bryman \& Bell, 2015). In addition, I also provide detailed explanations and illustrate the process of my data analysis so that readers can make their own judgments about the credibility of the findings (Constas, 1992).

\subsubsection{Personal epistemology}

Epistemology is the study that seeks to explore the meaning of knowledge and how individuals come to know and use their belief and justification to analyse knowledge that they hold or have obtained (Godwin \& Kember, 2018). There are many approaches under the concept of epistemology, including historical, empiricist, rationalist or constructionist, and each of these interprets or perceives knowledge in different ways (Hofer, 2001).

In this research, I describe myself as a social constructionist, who is aware that all knowledge is derived from differing perspectives of societies and humanity. That is, the meaning of everything is constructed (produced or reproduced) through the interpretation of each individuals' experiences and perceptions (Burr, 2015). This in turn means that some of the meanings of the present study's findings are also created and interpreted based on my beliefs

and justification of the information that I obtained from the participants. Therefore, by 
positioning myself as a social constructionist, I have been able to confirm the credibility of my findings as I have been able to create and interpret new understandings related to the meaning and reasoning of workplace bullying behaviours based on the perception of women as well as my own perceptions and interpretations of the interviews and the literature. It is also important to note that in this study, knowledge and understanding is based on the perceptions of ten Laotian women on workplace bullying. Therefore, obtaining real objectivity or generalisability should not be expected from this study.

\subsubsection{Researcher position}

\subsubsection{Insider researcher}

Researchers can be positioned as outsiders or insiders, and this affects the participants' interaction toward the researcher (e.g. being trusted or not by the participants), and as a result it can result in different research processes and outcomes. For example, the process of getting participation or requesting appointments may be easier and faster, and biases in the research outcomes might occur (Kindon, Pain, \& Kesby, 2007; Sultana, 2007). In this research, I was categorised as an insider researcher because I am a Lao native woman, who has experienced bullying, and am undertaking research in my home country. These are my strengths as an insider researcher. It helped me to gain more trust and to communicate well by using my own language. I was able to explain the research and address concerns my participants might have, and I was able to get a response back from them quite fast in regards to the interviews (although some participants were unable to participate and some interview appointments took longer than expected).

However, there are some challenges in being an insider researcher. For example, as an insider researcher, I was aware that there was the risk of bias based on my personal experiences, knowledge, assumptions and this to some degree may have influenced the way I framed my discussion with interviewees which in turn influenced the way I analysed and interpreted workplace bullying. This may lead to a findings with biases in regards to my interpretation of how workplace bullying is experienced and perceived by my participants. Throughout my research project, I acknowledged that it was difficult to be completely unbiased. Therefore, following the advice of O'Leary (2017), I listed as many of my assumptions and preconceived ideas as possible about things that I expected to find. For example, the types of workplace 
bullying in NAQ-R, gender specific roles, cultural issues such as high power distance. This helped mediate my bias as well as explore potential risk factors for workplace bullying. It was important for me to always reflect on this suggestion and be aware of my position all the time in order to draw the most accurate and reasonable interpretations and conclusions for my research findings (Sultana, 2007). This meant that it was not practically possible to conduct this study in an objective way, but this was not the focus of this research.

\subsubsection{Interpretivist approach}

Along with my personal epistemology of social constructionism, interpretivism is an approach that I also used for both data collection and data analysis. This approach focuses on how people perceive their experiences and its stance is to give voice to people's experience in their own right (Bryman \& Bell, 2015). This is important as I aimed to obtain the perceptions of women on what bullying meant to them in their context. In order to obtain these perceptions, I used semi-structured interviews as a technique to collect my data. It was important as the interviews were done based on questions that were developed to obtain the women's personal perspectives in regards to the issues associated with the occurrence of bullying.

\subsection{Ethical considerations}

I am aware that conducting research on workplace bullying is sensitive and may cause the risk of emotional distress as well as a fear of public or employer exposure (Fahie, 2014). In regards to emotional distress, I carefully observed the reactions of my participants especially their voice and face, and was sensitive in my approach to questioning them. During the interview, I observed that one of my participants appeared to be quite angry as she talked about her experiences of being bullied. Her face and her voice became so emotional and I started to ask if she was alright to continue sharing her experiences. At that time, I was told that she was willing to continue the interview. In order to protect my participants' confidentiality and not to create a fear of public/employer exposure, I was aware that their identities must not be disclosed without their consent. Therefore, I did not mention the name of the participants as well as the name of their workplace. As I will discuss in section 3.4.1.2, access strategy, I used the snowball sampling strategy, and I did not mention who was interviewed to other participants. By doing this, among the interviewees, nobody knew who was interviewed. 
I informed each of my participants about the research purpose and their rights to withdraw from this research project at any time before data collection was completed on 31 January 2018. All related documents, both Lao and English versions, namely the information sheet and consent form were given to the participants on the day of interview as all of them preferred to see it at this day. In addition, verbal explanation on a mobile phone was also made before the appointment date was confirmed. As this thesis will be published, the participants' names have been replaced by the English capital letter and their organisation has not been not disclosed.

As already mentioned, this study uses the snowball sampling technique and assumes that victims of bullying are known to others, particularly to those who share their experience. Therefore, there is a risk that this methodology may fail to capture most forms of bullying and may fail to protect the confidentiality that a victim has placed in their friends. In order to protect the privacy of each Laotian woman who was recruited through snowball sampling, I gave an information handout to the first participant, and then she gave that to someone that she thought might be interested and qualified. This voids potential recruits being named to me without their consent and helps ensure that initial information about this research in accurate. As a result, there were two interested participants who potentially contacted me. In sum, to protect the privacy of individuals, I did not confirm to the first person whether or not participants who they contacted were interviewed by me.

Before undertaking my fieldwork, I received ethical approval from Human Ethics Committee (HEC) of Victoria University of Wellington (VUW). I read, understood and considered the ethical requirements in VUW Human Ethics Committee Guidelines throughout my application process. Ethical questions were raised by the HEC, and I (under the constructive advice from my supervisor) responded to those questions. 


\subsection{Data collection}

\subsubsection{Participants}

There was a change in participants. My plan was to interview ten Lao native women who consider themselves as people experiencing or having experienced workplace bullying. However, while I was conducting the interviews, the experiences that participants shared were very moving for me personally, and this made me think of my own experiences of being bullied in the workplace. At that time, I was thinking of including myself in this study. However, I was not quite sure if it was possible to change participants, until I came back to New Zealand, after my data collection. I met my supervisor and I shared some of my transcripts with her. She was interested in my data, and we discussed matters of workplace bullying. She asked me if I had ever experienced this. As I had experienced workplace bullying a lot, she advised me to consider if I could include my experiences. I decided to include myself in this study.

This thesis then is an appropriate starting platform for me to shed light on the complexity of workplace bullying as I personally believe it has been existed and affected the everyday lives of many Lao people, in particular, and readers, in general.

In total, there were still ten participants who participated in this study including myself. The other nine of them were living in Vientiane Capital. They are privileged and well educated, compared with other women and some other men in Laos. Some used to work and are working with NGOs and private organisations. Two participants are working in the public sector. Some are doing managerial work and some are working in the area of women's empowerment. They are at different levels in organisations and receive different pay. Five of them are married and have children while five of them are single. This information was important as it allowed me to understand the women's perceptions of workplace bullying in their context. Table 3.1 presents relevant demographic information related to the ten participants. 


\begin{tabular}{|c|c|c|c|c|c|c|c|c|c|}
\hline \multirow[t]{2}{*}{ Participants } & \multicolumn{3}{|c|}{ Marital status } & \multicolumn{2}{|c|}{ Qualification } & \multirow[t]{2}{*}{ Occupation } & \multicolumn{2}{|c|}{ Workplace } & \multirow[t]{2}{*}{ Place of living } \\
\hline & Married & Single & Children & Master & Bachelor & & Previous & Current & \\
\hline A & $\sqrt{ }$ & & 2 & $\sqrt{ }$ & & National gender advisor & NGO & NGO & $\begin{array}{l}\text { Vientiane } \\
\text { Capital }\end{array}$ \\
\hline B & $\sqrt{ }$ & & 1 & & & $\begin{array}{l}\text { Senior administrator and } \\
\text { procurement assistant }\end{array}$ & Private & Private & $\begin{array}{l}\text { Vientiane } \\
\text { Capital }\end{array}$ \\
\hline $\mathrm{C}$ & & $\sqrt{ }$ & & & $\sqrt{ }$ & Accountant & & & $\begin{array}{l}\text { Vientiane } \\
\text { Capital }\end{array}$ \\
\hline $\mathrm{D}$ & & $\sqrt{ }$ & & $\sqrt{ }$ & & Project technical advisor & & NGO & $\begin{array}{l}\text { Vientiane } \\
\text { Capital }\end{array}$ \\
\hline $\mathrm{E}$ & $\sqrt{ }$ & & 2 & $\sqrt{ }$ & & Lecturer & & Public & $\begin{array}{l}\text { Vientiane } \\
\text { Capital }\end{array}$ \\
\hline $\mathrm{F}$ & & $\sqrt{ }$ & & $\sqrt{ }$ & & Deputy director general & & Public & $\begin{array}{l}\text { Vientiane } \\
\text { Capital }\end{array}$ \\
\hline $\mathrm{G}$ & $\sqrt{ }$ & & 1 & & & $\begin{array}{l}\text { Head of finance and budget } \\
\text { division }\end{array}$ & & Public & $\begin{array}{l}\text { Vientiane } \\
\text { Capital }\end{array}$ \\
\hline $\mathrm{H}$ & & $\sqrt{ }$ & & $\sqrt{ }$ & & Project advisor & $\mathrm{NGO}$ & $\mathrm{NGO}$ & $\begin{array}{l}\text { Vientiane } \\
\text { Capital }\end{array}$ \\
\hline I & & $\sqrt{ }$ & & $\sqrt{ }$ & & Administrator & Private & Private & $\begin{array}{l}\text { Vientiane } \\
\text { Capital }\end{array}$ \\
\hline $\mathrm{J}$ & $\sqrt{ }$ & & 1 & $\sqrt{ }$ & & Student & $\begin{array}{l}\text { Private } \\
\text { NGO }\end{array}$ & $\mathrm{NGO}$ & New Zealand \\
\hline
\end{tabular}

Table 3. 1: Participants' demographic information 


\subsubsection{Access strategy}

\subsection{Snowball sampling technique}

Snowball sampling is a technique for finding subjects that involves building a sample through referrals. Once an initial participant is identified, I as a researcher can ask my participant to introduce others who meet the research criteria, and then each of these participants is asked for a further recommendation (O'Leary, 2017). This technique is often used by various researchers when working with populations who are not easily identified or are hard-to-reach (Shaghaghi, Bhopal, \& Sheikh, 2011) Applying this technique allowed me to build a sample through referrals, which meant that once the first interviewee was identified, I asked her to introduce others who have had the same or similar experiences to me. Identifying self-described experiences of bullying through others may well not fully capture every kind of bullying. This is a risk of snowball sampling, which is however invaluable and widely used in accessing hidden and hard-to-reach populations (Shaghaghi et al., 2011).

In order to find the first respondent, I used my networks. Some of my friends who work with NGOs, private organisations, and government organisations were contacted. I carefully consulted with them and asked them to introduce me to those women who had faced bullying and were willing to share their experiences. I was introduced to those women through my networks, and I was asked to wait until I got informed to see those women. I was then given the phone number of those women. I contacted them through their phone number and scheduled the interview date and time. Initially, those women were willing to participate in this research. However, later on, three participants refused to be part of this study, and this may due to the sensitivity of the topic. At the date of interview, two of them were not present. I then contacted them by phone and I was told that they were quite busy. They asked me to wait until they got back, and both of them got back to me, but instead of participating, they introduced me to other women and gave me their phone numbers. Another participant was present at the interview, but she changed her mind about being recorded. She apologised because she did not feel comfortable. At this stage, I did not try to convince her. We just had conversations and then she said she would introduce me to two of her friends who might be interested to participate. After two days, I got a call from her and was informed that her friends were willing to be contacted. 


\subsubsection{Individual interviews}

Semi-structured interviews are widely used by many researchers in qualitative research. They follow broad predetermined themes or areas of research discussion outlined in an interview guide (Creswell, 2014; O'Leary, 2017). This method was found to be an appropriate one for this study as this is an exploratory research on workplace bullying drawing from women's own perspectives. Thus it was important that participants had the opportunity to share their experiences with me, the researcher. By using a semi-structured interview, I was able to interact and exchange information with participants in a flexible way. Further, by responding to open-ended questions, on one hand, participants could freely express their thoughts, opinions and experiences in regards to bullying behaviours. On the other hand, I could also adjust my interview questions by asking additional questions to find out further opinions and clarify my understanding as well as participants' perceptions of certain points in regards to issues of workplace bulling behaviour.

In total, I interviewed nine women. To make sure that the participants were interviewed in a convenient and comfortable location, they were asked where they would prefer to be interviewed. Most of them preferred to be interviewed on a Sunday in a coffee shop especially in the late afternoon about $4 \mathrm{pm}$, while only two preferred in the morning at $10 \mathrm{am}$. There was one participant who preferred to share her experiences in her office. Each interview ended after about one and half hours which exceeded the initial plan of 45 minutes. Most of the interviews consumed more time because participants were eager to talk and share their experiences which sometimes were not related to the topic. I carefully listened to them and tried to bring them back to the original discussion.

Interview questions were prepared and developed in English. However, I also translated them into Lao so that my participants could understand the questions if they asked to read them beforehand. Few participants asked to see the interview questions together with the information sheet (which was also in Lao and English) prior to the interviews. The interviews were recorded when consented by participants. Although participants agreed to participate in my research project by allowing me to record the interviews, they were quite careful in providing and sharing their opinions and experiences and one of them refused to have her 
voice recorded. This may have been because she was worried about her job security, or she might not have trusted me enough, and this is absolutely understandable. Experiencing this, I felt that I was less of an insider than I had thought I was at the beginning of my research.

Concepts of workplace bullying, gendered organisation theory and social dominance theory are the concepts that I used to collect data and to interpret the interviews. The questions that I asked based on those concepts to collect the data were, for example, "Have you ever experienced any kind of personal bullying?" This question aimed to find about personal bullying. In order to find out how gender is treated in organisations, the question was: "What is the status of women in the organisation?" "Do they get paid the same?" Finally, I asked a question related to social dominance theory to find out how power and the hierarchy of the organisation works, what the dominant groups in the organisation were, and what the structure of the organisation was like. A final question I asked was: "In your opinion, is it too bureaucratic or too hierarchical?" Table 3.2 is the detail of interview questions that I asked participants.

As I included myself in this study, I used interview questions as a guide to inform my experiences of workplace bullying. I transcribed my thoughts directly in English. After I finished describing my own experiences, I re-read it many times to make sure that the experiences that I wanted to share were in there. 


\begin{tabular}{|c|c|c|}
\hline $\mathbf{Q}$ & Details & Aim of the question \\
\hline 1 & Please tell me something about your current job. What is it like? & $\begin{array}{l}\text { General question to find out how the current job of } \\
\text { participants look like }\end{array}$ \\
\hline 2 & What is your experience of bullying in the workplace? & $\begin{array}{l}\text { General question to find out the experience of } \\
\text { workplace bullying faced by participants }\end{array}$ \\
\hline 3 & $\begin{array}{l}\text { Have you ever experienced any kind of personal bullying? For example } \\
\text { Prompt questions are relevant } \\
\text { - } \quad \text { Being humiliated or ridiculed in connection with your work } \\
\text { - } \quad \text { Having key areas of responsibility removed or replaced with more } \\
\text { trivial or unpleasant tasks } \\
\text { - } \quad \text { Gossiping or spreading rumours about you } \\
\text { - } \\
\text { Being ignored or excluded } \\
\text { - }\end{array}$ & $\begin{array}{l}\text { To find out a person related bullying. } \\
\text { If any of these questions will be answered "yes", } \\
\text { then I will then as appropriate again ask as in } \\
\text { question about the experience of bullying. (The } \\
\text { same will apply for the other questions below). } \\
\text { I will then ask further questions to find out how } \\
\text { the participant handled that kind of bullying. }\end{array}$ \\
\hline 4 & $\begin{array}{l}\text { Have you ever experienced any kind of Physical intimidating related } \\
\text { bullying? For example: } \\
\text { - } \quad \text { Being shouted at or being the target of spontaneous anger } \\
\text { - Intimidating behaviours such as finger-pointing, invasion of personal } \\
\text { space, shoving, blocking your way } \\
\text { Threats of violence or physical abuse or actual abuse }\end{array}$ & $\begin{array}{l}\text { To find out physically intimidating bullying. } \\
\text { If any kind of these questions will be answered } \\
\text { "yes", then I will ask further questions to find out } \\
\text { how participant handled that kind of bullying. }\end{array}$ \\
\hline 5 & $\begin{array}{l}\text { Have you experienced any kind of job related bullying at work? For } \\
\text { example: } \\
\text { - } \quad \text { Someone withholding information which affects your performance } \\
\text { - } \quad \text { Being ordered to do work below your level of competence } \\
\text { - } \quad \text { Having your opinions ignored } \\
\text { - } \quad \text { Being given tasks with unreasonable deadlines } \\
\text { - }\end{array}$ & $\begin{array}{l}\text { To find out work related bullying. } \\
\text { If any kind of these questions will be answered } \\
\text { "yes", then I will ask further questions to find out } \\
\text { how participant handled that kind of bullying. }\end{array}$ \\
\hline 6 & $\begin{array}{l}\text { Gender in organisation } \\
\text { - What is the status of women in the organisation? } \\
\text { - Do they get paid the same as men? } \\
\text { - } \quad \text { What it looks like to be a subordinate female employee in that } \\
\text { organisation? } \\
\text { Do they tend to be in certain occupations? }\end{array}$ & $\begin{array}{l}\text { These questions aim to find out how gender is } \\
\text { treated in the organisation. }\end{array}$ \\
\hline 7 & $\begin{array}{l}\text { Social dominance theory } \\
\text { - What is the structure of the organisation? In your opinion, is it too } \\
\text { bureaucratic or too hierarchical? } \\
\text { What does the working culture look like in that organisation? For } \\
\text { example, is it a conservative organisation or Is it ok to share a new } \\
\text { idea? } \\
\text { Are personal relationships with senior positions important to getting } \\
\text { a promotion? }\end{array}$ & $\begin{array}{l}\text { These questions aim to find out how power and } \\
\text { the hierarchy of the organisation works and what } \\
\text { the dominant groups in the organisation are. }\end{array}$ \\
\hline 8 & $\begin{array}{l}\text { Is there anything else about your organisation or your experience of bullying } \\
\text { that you would like to add? }\end{array}$ & $\begin{array}{l}\text { To find out another thought about the experience } \\
\text { of bullying faced by participants }\end{array}$ \\
\hline
\end{tabular}

\section{Table 3. 2: Interview questions}




\subsection{Data analysis}

There is no universal format for qualitative data analysis, and researchers have to keep in mind that the aim of qualitative data analysis is to produce new understandings by exploring and interpreting complex data from sources such as interviews, group discussions, and observations (O'Leary, 2017). Researchers may decide to explore the data inductively (without pre-determined themes or theory in mind by allowing them to emerge from the data) or deductively (having some ideas or theories in mind and searching data for potential confirmation of these) (O'Leary, 2017). Figure 3.1 illustrates my decisions in the form of an analytical framework.

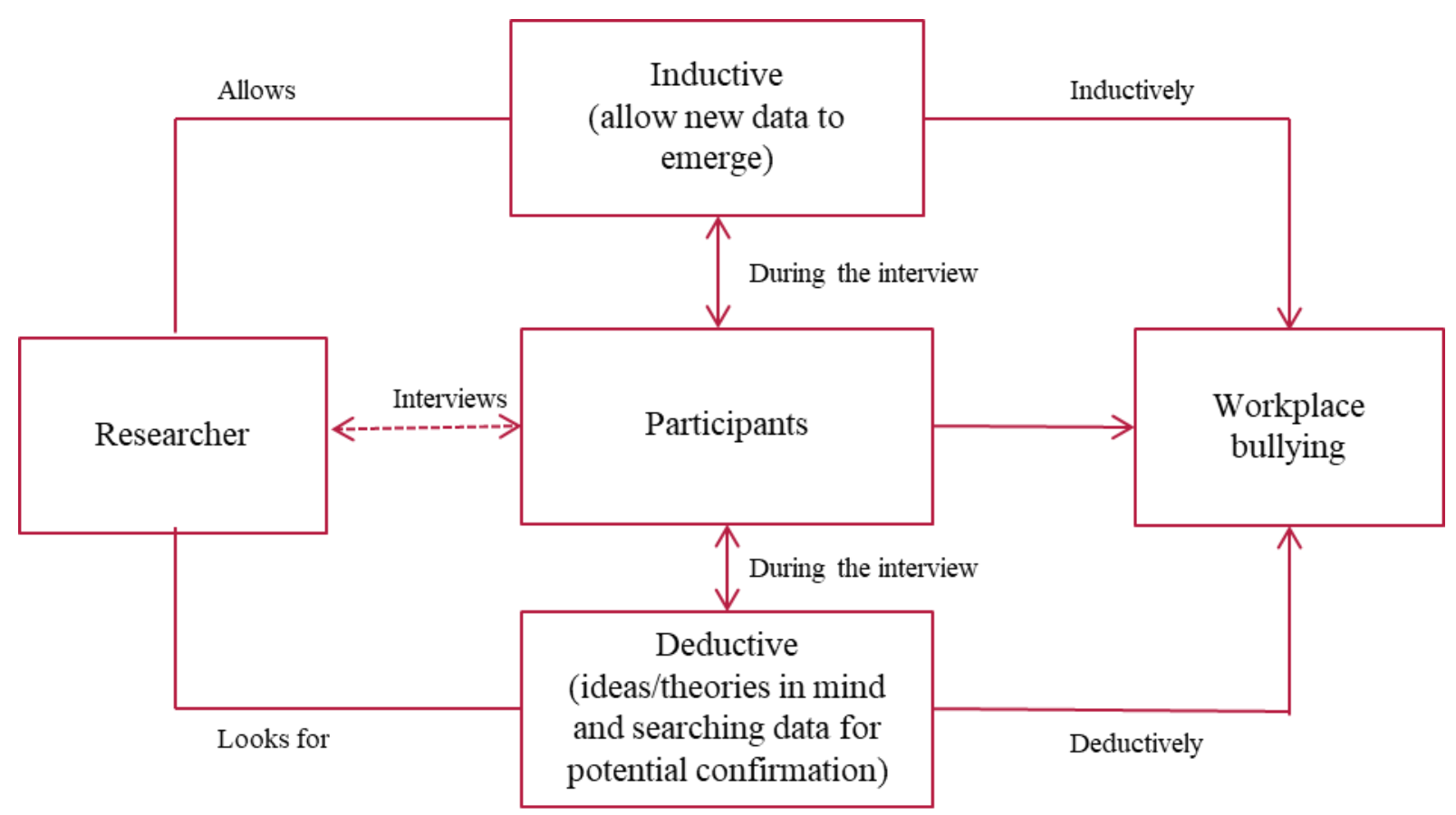

Figure 3. 1: Analytical framework 
Guided by concepts of workplace bullying, gendered organisation theory and social dominance theory, I used both inductive and deductive reasoning to explore and represent new understandings of workplace bullying in Laos. I both allowed the new themes to emerge and looked for the themes that I already had in mind. Following the advice of O'Leary (2017), I prepared and analysed the collected data in five steps as shown in Figure 3.2 below.

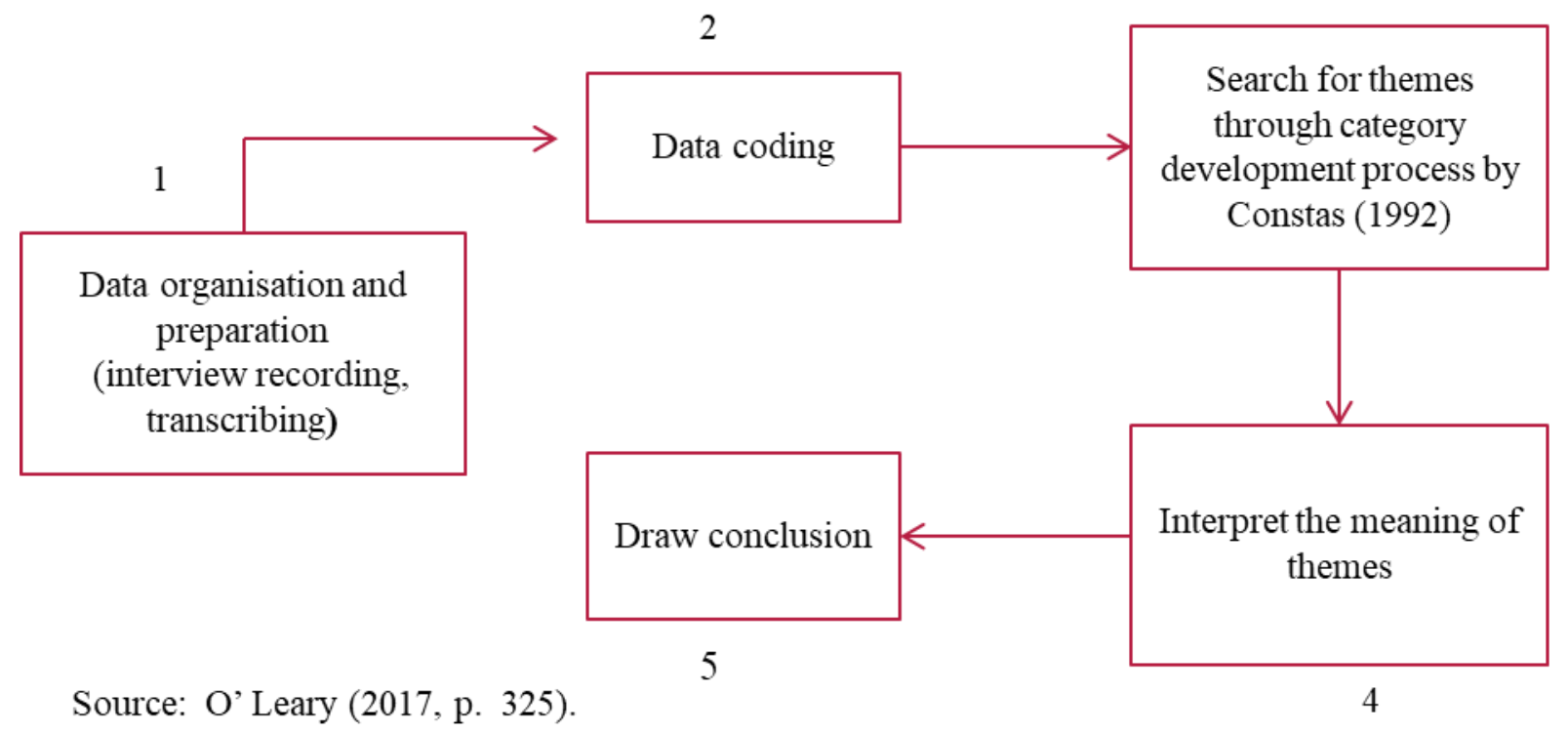

Figure 3. 2: Data analysis process

After completing the interviews, which was done in the Lao language, I began with organising and preparing the data. I transcribed the voice recordings in Lao and then translated them into English. While I was transcribing I recalled my thoughts at each interview and applied them toward each participants. This helped me to better understand and analyse each participant's context of understanding and their experiences of bullying behaviours in their workplace. Table 3.3 demonstrates how I did this. 
Code: A

\section{Date: 1 March 2018}

Role: National gender advisor

Marital status: Married with 2 children

Qualifications: Master degree

Previous organisation: NGO

Current Organisation: NGO

My intuition about this person: She is so confident and has got good understanding about gender. She is a critical thinker. She can reasonably analyse an issue and form her judgment, for example, she has got question in her mind

in regards to her position and her line manager's position. She questions that "my line manage was international advisor. I am national advisor and as an advisor it is the same position why $I$ have to be under her". This is quite impressive to me because many Lao people cannot be critical that much especially when they are working or dealing with government.

Word text

Comments

Q: Could you please tell me about your current Job?

A: I am now working with [organisation] as a national gender advisor. The nature of my work is about raising awareness of what gender is about. Lao people especially the government officers miss understand the concept of gender. Gender is translated as the role of male and female and I think this is completely not correct

Table 3. 3: Transcription process

However, it was not easy for me to always come up with relevant ideas in regards to workplace bullying experienced by my interviewees because I was confused sometimes when they brought up ideas which were not related to the research concerned. For example, one participant talked about age discrimination while she was applying for a job. From workplace bullying view, this can be a kind of bullying. However, in this case, I did not classify it as bullying because she was not yet working in that organisation.

While I was transcribing in Lao, I looked not only for the categories that were both based on my research questions and theory, but also developed emergent categories based on new concepts from the data. After each transcription, I carefully compared the transcribed documents by re-listening to the voice recording in order to make sure that I captured all the important ideas of workplace bullying that were perceived and experienced by the interviewees. 
After this, the most relevant workplace bullying behaviours were marked as direct quotes, while the new ideas that emerged during the interview were also coded. As I was working with only ten data sets, it was efficient enough for me to manually code (I highlighted the transcription in a word document and inserted my comments) and categorise the data and this helped me to not miss out on insights that related to my study (O'Leary, 2017). Table 3.4 demonstrates the processes of my data coding. As participants' names were not to be disclosed, I replaced their name with a capital letter.

As expressed earlier, in order to prevent myself from getting lost in the detail and losing focus, I followed the advice of O'Leary (2017) and always asked myself the questions below. These helped me to maintain the bigger picture of this study in focus. Box 3.1 lists the questions I referred to.

Questions related to my own expectations

- What do I expect to find? And what don't I expect to find and how can I look for it?

- Can my findings be interpreted in alternative way? What are the implications? For example, Rights or voiceless.

Questions related to my research questions, aims and objectives

- How should I treat my data in order to best address my research questions?

- How do my findings related to my research questions, aims, and objectives?

Questions related to theory

- Are my findings confirming my theories? How? Why? Why not? For example, gender role. This confirms the nature of the concept of gender in Laos which applies to Lao women.

- Does my theory inform/help to explain my findings? In what ways? For example, high power distance culture helps explain workplace bullying in the context of my participants.

- Can my unexpected findings link with alternative theories?

Questions related to methods

- Have my methods of data collection and/or analysis coloured my results? If so, in what ways?

- How might my methodological shortcomings be affecting my findings?

Source: O’Leary (2017, p. 300).

Box 3. 1: Questions for keeping the bigger picture in mind 


\begin{tabular}{|c|c|c|}
\hline Participant & Word text & $\begin{array}{c}\text { Codes } \\
\text { (Level } 1 \text { category) }\end{array}$ \\
\hline A & $\begin{array}{l}\text { Q: Could you please share with me about your experience of bullying? } \\
\text { A: My first workplace bullying was happened in one of NGOs that I used to work for..... They asked me to } \\
\text { do all the house work. I was asked to cook, clean the house, wash the toilet and wash the clothes for all the } \\
\text { male staffs in that staff's house. I was there for } 3 \text { years and my salary was not increase because I did not do } \\
\text { whatever I was asked regarding the house work. I think this was not fair. Why I have to serve the males?. At } \\
\text { that time I thought that..Ok.. I am a new graduate so I have to be patient in order to earn my living. However } \\
\text { at the third year, I decided to resign because I thought I was oppressed by the male colleagues in that house. }\end{array}$ & $\begin{array}{l}\text { Gender roles } \\
\begin{array}{l}\text { Effect: salary is not } \\
\text { increase }\end{array} \\
\} \text { The bully: colleague }\end{array}$ \\
\hline $\mathrm{D}$ & $\begin{array}{l}\text { Q: Could you please share with me about your experience of bullying? } \\
\text { A: I think that working with this organisation has a lot bias. } \\
\text { Q: What kind of bias? Could you please explain more? } \\
\text { A: Like for example, the technical officers are only male, not female. I am the only woman who is a project } \\
\text { technical officer, but I don't have a project of my own that I can oversee. This is a fake position. I worked } \\
\text { as an assistant to a technical staff. I coordinate with local authority, I draft a speech, I translate a document } \\
\text { form English to Lao, I prepare all the logistic kind of things such as booking the guesthouse, travel } \\
\text { arrangement, taking a minute of meeting, writing a back to the office report, and so many. I think this is too } \\
\text { much for me because there is not only one project. What I feel really upset is that I am asked by the } \\
\text { technical staff who is having the same position like me. He is working here almost } 6 \text { years already. That is } \\
\text { why he uses his seniority to ask me to do those work. There's also another junior technical staff who is } \\
\text { male but he's never been ask to do these kinds of work. } \\
\text { Q: Could you please tell a little bit why you said your position if fake? } \\
\text { A: Because in the job description it said like project technical officer has to oversee the project, but no. I } \\
\text { am working under one of the senior project technical officer. I would say I am his secretary or assistant. } \\
\text { Q: Do you have any idea why this person always asks you to do those work, instead of your male } \\
\text { colleague? } \\
\text { A: May be because of I am a female so he might think that those works are for women. I sometime think } \\
\text { that my position should be named as "assistant project officer or secretary to a project officer" instead of } \\
\text { project technical officer because I did not do any technical works at all. }\end{array}$ & 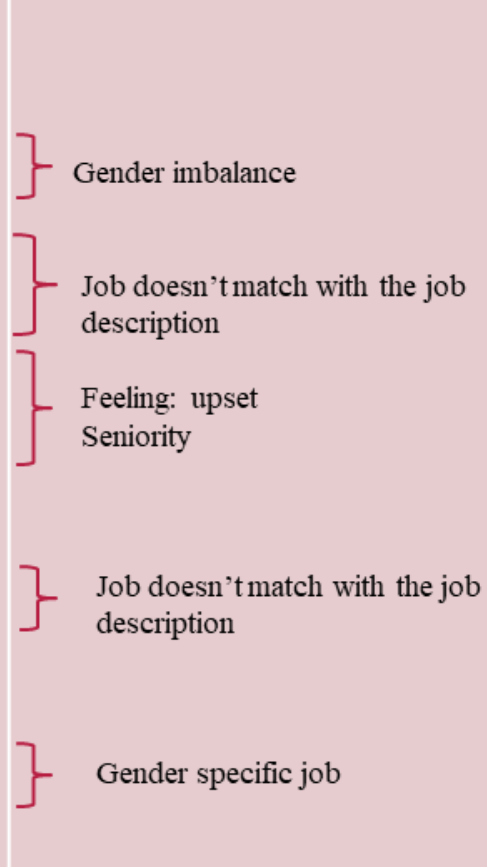 \\
\hline
\end{tabular}

Table 3. 4: Example of coding process 
After coding, I developed the larger categories. I was guided by my analytical framework and the adapted category development process by Constas (1992), who argues that "the provision of detailed descriptions of how categories are developed will help clarify issues (such as the credibility and transferability) related to the analysis of qualitative data" (p. 225). Constas suggests that while developing the categories, researchers should pay attention to the originality of the category that is derived, for example, "Where did the category come from (before data collection of after data collection)?" After re-thinking and combining, the final category emerged. This final category, in this study, is regarded as one of the central themes. Table 3.5 demonstrates the category development procedures adapted from Constas (1992).

\begin{tabular}{|c|c|c|c|c|}
\hline \multirow[t]{2}{*}{ Participant } & \multirow{2}{*}{$\begin{array}{l}\text { Development } \\
\text { question }\end{array}$} & \multicolumn{2}{|c|}{ Category (when developed) } & After re-thinking and \\
\hline & & $\begin{array}{l}\text { Before data } \\
\text { collection }\end{array}$ & $\begin{array}{l}\text { During data } \\
\text { collection }\end{array}$ & \\
\hline \multirow[t]{2}{*}{ A } & $\begin{array}{l}\text { Where did the } \\
\text { category come } \\
\text { from? }\end{array}$ & - & Gender role & Gender issue \\
\hline & $\begin{array}{l}\text { How do I justify } \\
\text { this category? }\end{array}$ & - & $\begin{array}{l}\text { Interpreted from the } \\
\text { interview and link it } \\
\text { to the concept of } \\
\text { gender }\end{array}$ & My comment \\
\hline \multirow[t]{2}{*}{ Participant } & \multirow{2}{*}{$\begin{array}{l}\text { Development } \\
\text { question }\end{array}$} & \multicolumn{2}{|c|}{ Category (when developed) } & After re-thinking and \\
\hline & & $\begin{array}{l}\text { Before data } \\
\text { collection }\end{array}$ & $\begin{array}{l}\text { During data } \\
\text { collection }\end{array}$ & \\
\hline \multirow[t]{2}{*}{ B } & $\begin{array}{l}\text { Where did the } \\
\text { category come } \\
\text { from? }\end{array}$ & $\begin{array}{l}\text { Gender } \\
\text { segregation of } \\
\text { work }\end{array}$ & Gender specific job & Gender issue \\
\hline & $\begin{array}{l}\text { How do I justify } \\
\text { this category? }\end{array}$ & Literature & My comment & Literature \\
\hline
\end{tabular}

Table 3. 5: Theme development procedure (example: theme: gender issues) 
Before, I interpreted all the categories into the themes for the findings; I compared and contrasted my first category level that I identified in my transcript. Then I chose the categories that are most strongly related to the overall objective of my research questions.

The final stage of my data analysis was the interpretation and I emphasised strongly what was shared and experienced by the participants, depending on what they had in common, and/or a range of issues that I found to be important. The interpretation was based on the analytical framework and epistemology that I used in this study.

It is possible that the way data is used, analysed and interpreted in this study is justified by my belief, views, assumptions and experiences (Constas, 1992). It should be kept in mind that rather than being straightforward as suggested in the models above, this analysis process was a back and forth process as I had to carefully compare the transcribed documents by re-listening to the voice recording in order to make sure that I had captured all the important ideas of workplace bullying that were perceived and experienced by the interviewees.

Guided by Constas (1992) throughout the category or theme development processes, and in relation to my research question and sub-questions, I have identified four key themes, each of which has sub-themes as shown in Table 3.6. These themes are regarded as my findings and will be presented in Chapter 4, the findings.

\begin{tabular}{|c|c|}
\hline Key themes & Sub-themes \\
\hline Workplace bullying & $\begin{array}{ll}\text { - } & \text { Personal bullying } \\
\text { - } & \text { Job-related bullying } \\
\text { - } & \text { Physically intimidating bullying }\end{array}$ \\
\hline Gender and workplace bullying & $\begin{array}{l}\text { - Gender roles/norms } \\
\text { - Gender discrimination } \\
\text { - Gender specific jobs }\end{array}$ \\
\hline Culture and workplace bullying & $\begin{array}{l}\text { - } \text { Marital status } \\
\text { - } \text { Power distance } \\
\text { - Bureaucracy/hierarchy in organisations } \\
\text { - } \\
\text { - } \text { thnocentrism } \\
\text { - } \\
\text { Westerner privilege } \\
\text { Religion }\end{array}$ \\
\hline Effect of bullying and coping & $\begin{array}{l}\text { - The overall effects } \\
\text { - Forms of bullying and coping techniques }\end{array}$ \\
\hline
\end{tabular}

Table 3. 6: Identified themes for data analysis 


\subsection{Conclusion}

This study is an exploratory research study on gender and workplace bullying in Laos which details the women's perceptions and experiences of workplace bullying. Therefore, qualitative research with an interpretivist approach was found to be the most appropriate one, as this approach focuses on interpreted experience of each Laotian woman. For data collection, the snowball technique was used to reach the participants, and semi-structured interviews were undertaken in different places in Vientiane capital with ten participants including myself. The data analysis was done based on the five processes suggested by O'Leary (2017) as well as based on my own analytical framework. My researcher position and ethical concerns were also discussed in this chapter. 


\section{Chapter 4. Findings}

\subsection{Introduction}

In this chapter, I attempt not only to provide answers to my research questions based on the literature, but also create new categories of workplace bullying based on my participants' data. The key ideas I have brought through from the literature includes the NAQ-R framework, the four out of five components of the concept of workplace bullying by Rayner et al., (2005), and the concept of power distance. Importantly, by looking at the context, I gained insights into the factors that may contribute to workplace bullying in the Lao context. I have termed these ideas risk factors, referring to the factors that make bullying more likely to happen, and these give more context to the NAQ-R framework because they are unique to the individuals that have experienced bullying in the Lao workplace. The main research question and its sub-questions are as follows:

How do Laotian women employees experience bullying in their workplace?

a). How do they perceive bullying?

b). How do they cope with it?

c). How is their perception of bullying affected by the Laotian context?

d). How is their perception of bullying affected by their position in their workplace?

These findings have been obtained using the methods described in the previous chapter. There are four main themes which I have identified in the data and based on my research questions. These are shown below. 


\begin{tabular}{|c|c|}
\hline Key themes & Sub-themes \\
\hline Workplace bullying & $\begin{array}{ll}\text { - } & \text { Personal bullying } \\
\text { - } & \text { Job-related bullying } \\
\text { - } & \text { Physically intimidating bullying }\end{array}$ \\
\hline Gender and workplace bullying & $\begin{array}{ll}\text { - } & \text { Gender roles/norms } \\
\text { - } & \text { Gender discrimination } \\
\text { - } & \text { Gender specific jobs }\end{array}$ \\
\hline Culture and workplace bullying & $\begin{array}{l}\text { - Marital status } \\
\text { - Power distance } \\
\text { - Bureaucracy/hierarchy in organisations } \\
\text { - } \\
\text { - } \text { Westhocentrism } \\
\text { - } \\
\text { Religion }\end{array}$ \\
\hline Effect of bullying and coping & $\begin{array}{l}\text { - The overall effects } \\
\text { - Forms of bullying and coping techniques }\end{array}$ \\
\hline
\end{tabular}

The findings show that workplace bullying exists in numerous ways, depending on the context of the situation. Importantly, I contextualise the NAQ-R by situating it in the Laotian context. In doing this, I have utilised the NAQ-R from an interpretative, rather than from its original objective point of view. The risk factors I have identified in this research give more explanation and context to how bullying is experienced. These are presented in Table 4.1 below:

\section{Risk factor for workplace bullying in the Lao context}

Physical appearance
Individual characteristics
Bias/personal dislike
New graduate or non-working experience
Gender issues
- Gender roles
- Gender discrimination
- Gender specific jobs
Cultural issues
- Marital status
- Power distance
- Bureaucracy/hierarchy in organisations
- $\quad$ Westhnocentrism
- Religion

Table 4. 1 Risk factors for workplace bullying in the Lao context 
The chapter proceeds as follows. In section 4.2, I examine workplace bullying based on the participants' perceptions through the interpretative lens of the NAQ-R, a scale of bullying developed by Western researchers. By applying the NAQ-R, I found that various forms of workplace bullying existed including personal and job-related bullying. Additionally, I identified the potential risk factors that can stimulate these forms of workplace bullying. Furthermore, other forms of workplace bullying beyond those identified in the NAQ-R framework were also identified by the participants. In section 4.3, I examine the relationship of gender and workplace bullying through the lens of gender and the gendered organisation concept. In section 4.4, I analyse how culture can be a risk factor for workplace bullying through the lens of social dominance theory. In section 4.5, I bring up the effects of workplace bullying as well as present how women have coped with the bullying. In sections 4.4 and 4.5, as well as describing what the form of workplace bullying based on culture takes, I also examine the reasons behind such perceptions, and how women make their coping technique choices. Finally, in section 4.6, this chapter is concluded.

\subsection{Workplace bullying}

As I discussed earlier, the concepts of workplace bullying that I use are not only based on the NAQ-R framework, but are also based on the idea of power distance, as well as four out of five components suggested by Rayner et al., (2005) (negative behaviour experienced by individuals, negative emotional effects on individuals, the target perceiving themselves as being bullied and, the target perceiving themselves with less power and having difficulty defending themselves). Importantly, I intend not only to identify workplace bullying based on the NAQ-R framework, but I also to identify new insights about workplace bullying based on my participants' experiences.

According to the NAQ-R, forms of workplace bullying have been classified as job-related bullying, personal bullying, and physically intimidating bullying. During the interviews, these three main classifications of workplace bullying were experienced by most of Laotian women interviewed. Importantly, the risk factors provide more contexts to the NAQ-R framework. 


\subsubsection{Personal bullying}

Personal bullying in this study refers to both direct and an indirect forms of aggression that participants have experienced in their workplace. The direct forms of aggression include facing a hostile reaction when approached, and indirect forms of aggression include spreading rumours/gossiping (Zapf et al., 2011). Based on the NAQ-R framework, twelve items were developed to measure personal bullying. In this study, Laotian women had experienced nine items. The three items that were not experienced are: being ignored or facing a hostile reaction when you approach, it being hinted or signaled that you should quit your job, and having allegations made against you. As I utilised the NAQ-R from its original objective view to a subjective view, I found that one of my participants was being teased based on her physical appearance. The NAQ-R does include teasing, but it does not contextualise it in this way. In other words, it is not explicitly based on appearance. Subsequently, I have identified physical appearance as a risk factor for personal bullying. Table 4.1 demonstrates the emergent findings beyond the NAQ-R framework. 


\begin{tabular}{|c|c|c|c|}
\hline NAQ-R & \multirow{2}{*}{$\begin{array}{c}\text { Personal } \\
\text { bullying } \\
\text { experienced by } \\
\text { participant }\end{array}$} & \multicolumn{2}{|c|}{ Emerged in the data } \\
\hline Personal bullying & & $\begin{array}{r}\text { Risk factors for } \\
\text { bullyin }\end{array}$ & $\begin{array}{l}\text { bullying and form of personal } \\
\text { sult of those factors }\end{array}$ \\
\hline $\begin{array}{l}\text { - Being humiliated or ridiculed in } \\
\text { connection with your work } \\
\text { - Having key areas of responsibility } \\
\text { removed or replaced with more } \\
\text { trivial or unpleasant tasks } \\
\text { - Gossiping or spreading and rumours } \\
\text { about you } \\
\text { - Being ignored or excluded } \\
\text { - Having insulting or offensive } \\
\text { remarks made for you, your attitude } \\
\text { or your private life } \\
\text { - Hints or signals from others that you } \\
\text { should quit your job } \\
\text { Repeated reminders of your errors } \\
\text { or mistakes } \\
\text { Being ignored or facing a hostile } \\
\text { reaction when you approach } \\
\text { Persistent criticism of your errors or } \\
\text { mistakes } \\
\text { Practical jokes carried out by people } \\
\text { you don't get along with } \\
\text { Having allegations made against } \\
\text { you } \\
\text { Being the subject of excessive } \\
\text { teasing and sarcasm }\end{array}$ & $\begin{array}{l}V \\
V \\
V \\
V \\
V \\
\text { V } \\
\text { V } \\
\text { x } \\
\sqrt{ } \\
\sqrt{ } \\
\text { x } \\
V\end{array}$ & $\begin{array}{l}\text { Risk factor } \\
\text { - } \begin{array}{l}\text { Physical } \\
\text { appearance }\end{array}\end{array}$ & $\begin{array}{l}\text { Being teased (NAQ-R } \\
\text { does include it, but it is } \\
\text { not contextualised from } \\
\text { the subjective point of } \\
\text { view) }\end{array}$ \\
\hline
\end{tabular}

Table 4. 2: Personal bullying (the NAQ-R vs. the emergent findings)

The table above illustrates that there was one risk factor, physical appearance that was identified by one participant for personal bullying which the NAQ-R does not include. For instance, curved legs and a flat nose, are physical features that result in personal bullying, a form of teasing and this leads to low self-confidence. According to Participant J:

I know that my legs are not nice and I have curved legs. It does not look nice when I wear the uniform. My colleagues told me not to wear a skirt, wear a sin (a long traditional Lao skirt which covers the legs) instead. They might not think anything but this made me feel unconfident to wear a skirt. I was also teased that my nose is flat. That's why when it is hot and my face gets sweaty then my glasses are always loose. When they talk about my nose they usually laugh. To me, it is not funny. I don't like it. (Participant J) 
It should be noted that even though teasing is an item that appears in the NAQ-R framework, it does not specify whether physical appearance is the focus of the teasing. I conclude that not having certain aspects of appearance, in other words a particular kind of norm related to physical appearance, can be considered as a risk factor for personal bullying. Many readers might argue that this does not make sense as not all people will get bullied because of this. However, as bullying is unique to each individual, I have a strong opinion that it makes sense to assert that physical appearance can be a risk factor for personal bullying as a particular individual in a particular context experienced this. In my opinion, physical appearance is a personal and highly sensitive issue and the impact of this kind of teasing can be extremely harmful.

It should also be noted that, in the context of Participant $\mathrm{J}$, the bullies were their colleagues. This is important as I consider that power distance can seriously cause workplace bullying. The experiences of Participant $\mathrm{J}$ indicate that despite the low power distance in this context, the concept of social dominance theory is relevant. She was dominated by the vast majority of people who held views about the perfect women's body being a particular way.

\subsubsection{Job-related bullying}

Job-related bullying refers to negative treatment that applies to each individual's job and tasks within the workplace. It is also defined as the way individuals can get bullied by being assigned very difficult jobs which could be too much/too long/too easy, not interesting; or are intentionally not given training (Zapf et al., 2011). Based on the NAQ-R framework, seven items have been developed to measure job-related bullying. The majority of participants in this study had experienced all of the items.

Beyond those identified in the NAQ-R framework, there are three new items of job-related bullying that Laotian women in this study experienced. These include the unfair refusal to support training, colleagues choosing not to cooperate, and being assigned a job that is too simple or undemanding. 
Importantly, these forms of job-related bullying are influenced by personal factors (bias/personal dislike, individual characteristics), and new graduate/non-working experience, which I identified as risk factors for job-related bullying. Table 4.3 shows forms of job-related bullying and the risk factors that emerged in the data.

\begin{tabular}{|c|c|c|c|}
\hline NAQ-R & \multirow{3}{*}{$\begin{array}{c}\text { Job-related bullying } \\
\text { experienced by } \\
\text { participant }\end{array}$} & \multicolumn{2}{|c|}{ Emerged in the data } \\
\hline Job-related bullying & & \multicolumn{2}{|c|}{$\begin{array}{l}\text { Risk factors for job-related bullying and forms of job- } \\
\text { related bullying as a result of those factors }\end{array}$} \\
\hline \multirow{4}{*}{$\begin{array}{l}\text { Someone withholding } \\
\text { information which affects } \\
\text { your performance } \\
\text { Being ordered to do work } \\
\text { below your level of } \\
\text { competence } \\
\text { Having your opinions ignored } \\
\text { Being given tasks with } \\
\text { unreasonable deadlines } \\
\text { Excessive monitoring of your } \\
\text { work } \\
\text { Pressure of not to claim } \\
\text { something to which by right } \\
\text { you are entitled (e.g. sick } \\
\text { leave, holiday entitlement, } \\
\text { travel expenses) } \\
\text { Being exposed to an } \\
\text { unmanageable workload }\end{array}$} & & Risk factor & $\begin{array}{l}\text { Form of job related } \\
\text { bullying }\end{array}$ \\
\hline & $\sqrt{ }$ & $\begin{array}{l}\text { - Bias/personal } \\
\text { dislike }\end{array}$ & $\begin{array}{l}\text { - The unfair refusal to } \\
\text { support training }\end{array}$ \\
\hline & $\begin{array}{l}\sqrt{ } \\
\sqrt{ } \\
\sqrt{ }\end{array}$ & $\begin{array}{l}\text { - Individual } \\
\text { characteristics }\end{array}$ & $\begin{array}{l}\text { Colleagues choosing } \\
\text { not to cooperate which } \\
\text { can affect the job } \\
\text { performance }\end{array}$ \\
\hline & $\sqrt{ }$ & $\begin{array}{l}\text { New graduate or } \\
\text { non-working } \\
\text { experience }\end{array}$ & $\begin{array}{l}\text { Being assigned a job } \\
\text { that is too simple or } \\
\text { undemanding }\end{array}$ \\
\hline
\end{tabular}

Table 4. 3: Job-related bullying (the NAQ-R vs. the emergent findings)

Personal factors contribute to job-related bullying. The first example can be seen in the case of Participant B, a senior administrator and procurement assistant. In her opinion, she perceives bias as a personal dislike that causes an unfair treatment related to requests for training. She described the following situation:

I proposed to my boss that I want to be trained, but I was rejected and was told that there is a handbook and I can learn from that. There were many staff that came after me, but they all were sent to abroad for E-cash training. I think my boss did not like me and obviously what happened to me was bias. (Participant B)

In my opinion, based on her context, bias cannot only be defined as a personal dislike, but also can be perceived as a risk factor for job-related bullying. In addition, it is important to note that the nature of bullying is related to the job, but it is initiated by personal factors such as bias/personal dislike. This is an example of the contextualisation of workplace bullying, which 
the NAQ-R does not provide. Therefore, I argue that bias/personal dislike can be not only the risk factor for job-related bullying, but also for personal bullying, depending on the context of the situation. Outside of the workplace, these factors could lead to personal bullying, but in the workplace context, job-related factors can be part of bullying behaviour making it job-related.

Another example can be seen in the case of Participant I, an administrative staff member who described how her individual characteristics count as a risk factor for job-related bullying. She argued that her colleagues chose not to cooperate with her because of her characteristics. For example, the tone of her voice is quite high and this is why they did not being cooperate with her. Building on her opinions, my first impression toward her was that her personality is quite confident. She looks like a leader and her tone of voice is quite confident. By seeing it in this sense, it seems that not only her confident demeanor is a risk factor, but also being a woman and a subordinate, that is driving job-related bullying because her colleagues intentionally chose not to cooperate with her, and this affected her job performance.

It is important to note that, in the Laotian context, people should be careful not to display too much confidence because it is typically negative and some Laotian people especially those who are in a position of power seem to dislike subordinates who are more knowledgeable than them.

Finally, a new graduate or non-working experience is also a main risk factor that drives jobrelated bullying. Based on the opinion shared by two participants, that factor can also open up the chance of "being ordered" or "being assigned work that is too easy for them". Participant I, an administrator, shared that she was a new graduate and had no experience at all, and this led to her not being assigned any work that related to her position. She said:

I was a new graduate and at that time. I was asked to do a job like recording the customer's names, do a photocopy, buying lunch for my colleagues. (Participant I)

Another example can be seen in the case of Participant J. When she was a new graduate at her first workplace and did not have working experience, she just did a basic job such as translated 2-3 pages of some official letter from Thai to Lao and vice versa, photocopied, and counted cash. This work was not challenging at all. It was very simple and, according to her, any of the staff could do it. Many people may think that this finding is not important, but I would argue that it is important because it is all about trust. Therefore, if new graduates or those 
without work experience are being trusted to perform complex jobs, then bullying can be said to occur because they perceive that a lack of trust and delegation of simple jobs is bullying. The shared perceptions of these two women can be a key message for both new graduates or those with no work to be aware of this kind of treatment and organisations can benefit from hearing this as they can prevent this from happening.

\subsubsection{Physically intimidating bullying}

In this study, physically intimidating bullying refers to verbal or non-verbal aggressive, intense, and explicit behaviour that individual have experienced in the workplace (Zapf et al., 2011). Based on the NAQ-R framework, three items have been developed to measure physically intimidating bullying, and of all the items, only one item that participants in this study had experienced was being a target of bad temper by boss/colleagues.

Beyond those identified in the NAQ-R framework, there are two new items of physically intimidating bullying that Laotian women in this study experienced: a hateful attitude or improper attitude, and being spoken/responded to rudely or loudly by colleagues.

Table 4.4 demonstrates forms of physically intimidating bullying in NAQ-R and that emerged in the data.

\begin{tabular}{|c|c|c|}
\hline NAQ-R & Experienced by & Emerged in the data \\
\hline Physically intimidating bullying & & Physical intimidating bullying \\
\hline $\begin{array}{l}\text { - Being shouted at or being the target of } \\
\text { spontaneous anger } \\
\text { - Intimidating behaviours such as finger- } \\
\text { pointing, invasion of personal space, shoving, } \\
\text { blocking your way } \\
\text { - Threats of violence or physical abuse or } \\
\text { actual abuse }\end{array}$ & $\begin{array}{l}\sqrt{ } \\
\mathrm{x}\end{array}$ & $\begin{array}{l}\text { - a hateful attitude/improper } \\
\text { attitude } \\
\text { being spoken to rudely and } \\
\text { loudly by colleague }\end{array}$ \\
\hline
\end{tabular}

Table 4. 4: Physically intimidating bullying (the NAQ-R vs. the emergent findings)

The two new items that I identified as physically intimidating bullying are quite significant because it affects the feeling of participants and it enhances the power relations, not only the hierarchical power distance, but also at the same level of a position. 
Participant G's experienced this:

During my time with this boss, I was so disappointed with his attitude toward me. Every time when he got mad because of his work, he always blamed me and the way he acted was very improper. The way he used his eyes was in a very hateful way which I hated. (Participant G)

It can be noted from the above shared experiences that physically intimidating bullying is associated with a formal position in which the bully is the boss. However, it is also important to note that physically intimidating bullying does not always reflect the hierarchical position in the organisation because there is evidence below that shows that it can also happen among colleagues and the bully does not need to be in a higher position. An example can be seen in a case of Participant $\mathrm{J}$, who shared the following:

As is the nature of my work, I always have to deal with a secretary to the head of the organisation. One day, I was asked by the deputy head of the organisation to get the letter signed urgently, and I brought that letter to the secretary. She looked at me with her angry face and said, "The boss is not in the office right now." After hearing this, I was about to leave her office, but she called me, "Come here. Look, the format is not correct." Honestly speaking, I don't really like the way she used her finger. It's very rude and she acted like she was my boss. She said to me loudly. I didn't like her attitude because when I came close to her desk, she pointed her finger on the letter and asked me, "Who drafted this letter, this is wrong format?" After that she used her pen and crossed the letter firmly in front of me. I had no idea what happened to her. She was bad tempered and acted inappropriately to me. I was in a mood too because of her attitude. (Participant J)

In my opinion, based on Participant J's context, the secretary may have thought that the nature of her work has to direct what is right or wrong in regards to the format of the letter. This may have made her feel like she had more knowledge and more power over her colleagues. However, she was not supposed to act like that to her colleague, even though she was angry based on her own reason. It can seen from these two examples that the context suggests how the idea of power works in a different situation, and that this is beyond the NAQ-R framework. 


\subsection{Gender issues and workplace bullying}

As discussed earlier, I will use the concept of gendered organisation by Acker (1990) to analyse how gender is perceived in Lao organisations. My findings show that gender takes a number of different forms including gender roles, gender discrimination, and gender-specific jobs. These forms are considered as the risk factors for workplace bullying. Table 4.4 demonstrates forms of gender as risk factors for workplace bullying.

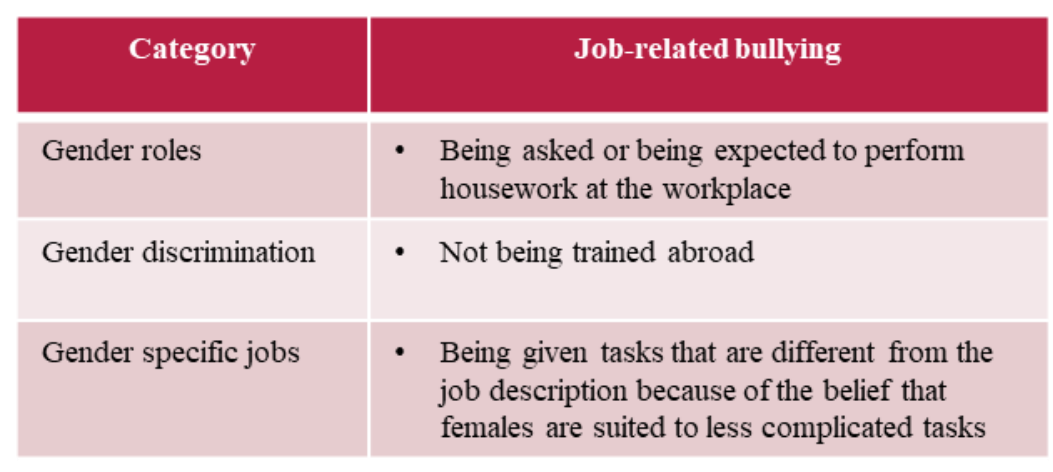

Table 4. 5: Gender issues and workplace bullying

Two participants were not satisfied with the gender norms related to how males and females should behave and this seemed to lead to harmful impacts on individuals who experienced this. As participant A, a senior gender advisor, described:

I was asked to cook, clean the house, wash the toilet and wash the clothes for all the male staff in that staff house. My salary was not increased because I did not do whatever I was asked regarding the house work. I think this was not fair. Why do I have to serve males? I decided to resign because I thought I was oppressed by the male colleagues in that house. (Participant A)

It can be seen from the above quotation that Participant A clearly expressed her opinion about how a set of ideas about the role of females had a negative impact on her performance, and this led to her salary not being increased. Based on my knowledge about Lao gender roles and the findings from this study, I argue that this kind of gender role assignment is the biggest and most common stereotype impacting Laotian women, and typically they are negative. In this 
context, the participant thought that it was not fair and most importantly she thought that she was oppressed by the male colleagues. As an insider researcher, this was not a surprising finding to me. The roles that are assigned to Laotian women, in fact, can be considered to be a huge factor that causes bullying, and for this participant, bullying that occurred through gender roles can be categorised as job-related bullying and personal bullying. As for job-related bullying, she was asked to do housework which was not in her job description, and because she did not perform her gender role, her salary was not increased. As for the personal bullying, the housework that she had to do is not in the workplace, but was in the staff-house. Therefore, this can be considered to be personal bullying. We can further see that gender roles in which Laotian women are expected to abide by are in fact not normal because it should be absolutely acceptable for Laotian men to serve food or do household chores. The same participant exclaimed:

If we are team, then every male staff member should have to do it too. My male colleagues always complained that they have nothing to eat because I did not cook for them and they were not satisfied with my behavior. (Participant A)

Therefore, it can be stated that the socially constructed nature of gender roles, in this context, can have a negative harmful impact on individuals in regards to performance in the workplace. Most importantly, oppression (the situation where female colleagues are less privileged because of their gender) is the term that has been used by Participant A to describe her experience and this is accurate because of the fact that she thought that she was being subjected to unfair gender roles that applied to her just because she was female. This kind of gendered bullying does not only contribute to the idea of inequality regimes, but also contributes to gender inequality with regard to pay.

Another example can be seen in Participant H, a project advisor, who shared the following:

Even though there are few women here at the village's office, they cannot make any decisions, they have to follow the decision made by head of the village and usually they are males. They are there just to serve, to cook and to clean the office and do the office's work like register letters in and out, and take note when there is a meeting. (Participant H) 
Her statement indicates how gender roles work in that particular context. In my opinion, women in Laos are expected to not only do the chores at home, but also at the workplace. Additionally, the above statement clearly shows how gender-specific jobs work in this organisation. Women were tasked with a job that was less complicated and chore-focused. Importantly, it should be noted that gender-specific jobs are related to power distance between men and women. The unequal power relation is particularly evident in this workplace where men hold supervisory positions more than women. This can be considered to be a form of workplace bullying because it drives women to follow gender roles when they do not want to.

Further example in regards to a belief in gender-specific jobs can be seen in the case of Participant D, a project technical advisor. She expressed the following:

In this organisation, mostly the technical officers are only male, not female. I am the only woman who is a project technical officer, but I don't have a project of my own that I can oversee. I am working under one of the senior project technical officer. I would say I am his secretary or assistant. I have to take minute of meetings and I am asked to help doing work of so many projects. (Participant D)

From the above quote it can be seen that even though a female is in the same position as a male, it does not mean the female will be tasked according to the job description, and this is a form of job-related bullying. Based on my opinion, a plausible interpretation of this form of bullying is that her male colleague thinks that females are suitable for less complicated tasks like a secretary or an assistant. Therefore, she was not allowed to perform tasks as mentioned in the job description. It can also be noted that, in this context, job-related bullying is also associated with gender imbalance in which males outnumber females. As a result, she was not assigned to do job as per the description. However, it is important to note that job-related bullying does not always reflect the gender imbalance in the organisation because there is evidence in the literature and in this study which shows that bullying can occur in femaledominated organisations as well.

While the expectation of traditional gender roles and gender specific jobs can contribute to workplace bullying for females, it is important to recognise that gender discrimination can also be a factor that influences workplace bullying. The same participant described this: 
Women in this organisation have never been for training. There are only males who are the bosses going for training abroad and my boss is included. When he came back he was supposed to share the knowledge from the training by organising a half-day workshop in the office to colleagues, but he never shared. (Participant D)

Even though the above interviewee does not state exactly how gender discrimination can lead to workplace bullying, it can be interpreted that there are two forms of discrimination including an unequal treatment in employment opportunity in terms of being selected for training based on gender, as well as knowledge sharing. She implies that women did not receive the same opportunity of being trained abroad compared to men. In addition, during the interview, I observed that when she talked about women in this organisation having never been for training, her face did not show happiness and her tone of voice implied that she was not satisfied with what has happened. Therefore, it can be interpreted that gender discrimination can lead to job-related bullying such as the lack of training.

\subsection{Cultural issues and workplace bullying}

This study is informed by social dominance theory which explains that all societies consist of power hierarchies, where one or more social groups dominate other groups (Salin \& Hoel, 2013). By situating this in the context of Laos, I found several cultural-related issues such as marital status, power distance (bureaucracy/hierarchy in organisations), Westerner privilege, religion, and ethnocentrism, meaning that inside Laos, one's ethnic group is centrally important and Lao-Tai are the dominant group. These can be considered crucial risk factors for bullying in the Laotian workplace. Table 4.4 illustrates cultural issues and workplace bullying that emerged in the data. 


\begin{tabular}{|c|c|c|c|c|}
\hline \multicolumn{2}{|c|}{ Cultural issues } & Under each cultural & Personal bullying & Job-related bullying \\
\hline \multicolumn{2}{|l|}{ Marital status } & Being older and single & $\begin{array}{l}\text { - Being teased by } \\
\text { colleagues }\end{array}$ & - \\
\hline Power distance & $\begin{array}{l}\text { Bureaucracy/hierarchy } \\
\text { in organisations }\end{array}$ & Being subordinate & - & $\begin{array}{l}\text { - } \quad \text { Work delayed } \\
\text { - } \quad \text { Beinnot claim holiday } \\
\text { commanded to do work or } \\
\text { things that individuals do } \\
\text { not feel like doing } \\
\text { - Being stealing jobs }\end{array}$ \\
\hline \multicolumn{2}{|l|}{ Ethnocentrism } & $\begin{array}{l}\text { Dressing in other ethnic } \\
\text { group's customary } \\
\text { clothing }\end{array}$ & $\begin{array}{l}\text { - Being controlled } \\
\text { through the way of } \\
\text { dressing }\end{array}$ & - \\
\hline \multicolumn{2}{|c|}{ Westerner privilege } & Being local & - & $\begin{array}{ll}\text { - } & \text { Ideas ignored } \\
\text { - } & \text { Workload } \\
\text { Unfairness salary-applied }\end{array}$ \\
\hline \multicolumn{2}{|l|}{ Religion } & Being Buddhist & - & - Unfairness training-applied \\
\hline
\end{tabular}

Table 4. 6: Cultural issues and workplace bullying that emerged in the data

Marital status is related to national culture in Laos, and there is the way of thinking about women and gender in Laos, as mentioned in section 2.4.3. My findings showed that someone was being bullied by her colleagues because she was older and not married. This was shared by Participant $\mathrm{C}$, an accountant:

My colleagues make a joke of my age and say that I am old. I am teased that I am not beautiful plus old so no one wants to be my boyfriend and that is why I am still single. This is very rude. This makes me feel uncomfortable and I feel like this is my inferiority because of that. (Participant C)

As an insider researcher, I did not expect cultural issues such as marital status to be risk factors for personal bullying. However, many Lao women have similar bullying experiences to Participant $\mathrm{C}$ that are related to age and marital status. In addition, this finding emerges in my data and it is crucial to note that this risk factor can be sensitive for some women in Laos. Particularly as in Participant C's context, this can lead to the stage of emotional abuse because she was not happy with that kind of joking. Not all women may be sensitive to this, but to others, particularly older and single women, they clearly are sensitive issues. This highlights the issues related to cultural beliefs which expect women to get married, and this also links to 
a socially constructed view of gender roles, in which Lao women are expected to be wives and mothers.

I argued earlier that power distance can be a risk factor for workplace bullying. My findings show that hierarchy is a cultural issue in Lao organisations. It prevents those who are subordinates from having rights as well as voice to express their thoughts toward their bosses. According to Participant F, a deputy director general, when she was a junior subordinate it made her worried about her progressing in her job because she had no rights to tell her boss to work actively. Compared to New Zealand, employees have rights to express their thoughts toward the performance of their bosses as long as it affects the employees' job.

While I was a junior employee, I was too worried about my work because my boss always held the work and I could not go any further if my boss did not approve. Even now, I don't have any rights to tell my boss to work actively and fast because I have to respect her position. (Participant F)

The above statement implies that as a subordinate, Participant F experienced job-related bullying because her work was delayed by her boss, and this absolutely could impact her performance. As an insider researcher and understanding Lao's hierarchical culture, I know that for employees to critically question their boss is something to be very careful about. From a human rights perspective, this can be a kind of abuse of basic rights that is the freedom of speech and thought. Laos has been ratified a member of several UN Human Rights Treaties such as the International Covenant on Economic, Social and Cultural Rights (CESCR), and the Convention on the Elimination of All Forms of Discrimination against Women (CEDAW) (UN Human Rights, 2018), and has accepted the ASEAN Human Rights Declaration in 2012. Thus Lao people can legally make a human rights complaint, but in practice there is very difficult because as an insider researcher, I know that any kind of human rights movement or campaign is politically sensitive. The Lao government treats this action as inappropriate and threatening to political stability (Saengouthay, 2015). If Lao people make a movement, this act may be against the government rules. Therefore any kind of harm or life safety may occur to those people.

Having no voice is considered to be another category under the idea of being a subordinate. The term voice was picked up by me during my interviews. It refers to the place where 
participants can report the bullying and their voice can be heard. In my findings, I considered having no voice to be a risk factor for workplace bullying and also it can cause bullying to continue to happen in the workplace. Three out of ten participants stated that there was no place for them to

report bullying issues. Participant $\mathrm{C}$, an accountant, shared that the organisation where she used to work did not apply the labour law particularly in regard to annual leave.

I would like the company to strictly apply labour law especially about the annual leave. Employees need time off from work. I would like the Ministry of Labour and Social Welfare to have a check on every company whether or not the law is applied. This is for the benefit of employees. In Laos we don't have, what we call, collective bargaining, so this is hard for Lao employees to negotiate with employers. (Participant C)

The above quotation clearly indicates how job-related bullying happened under the notion of having no voice, and the form of job-related bullying is a pressure of not being able to claim annual leave. This form of job-based bullying was considered to be a serious exploitation for Participant $\mathrm{C}$ because she stated, "The owner of the company just wants to get the benefit at the expense of the employees.” Therefore, I argue that having no voice is strongly associated with bullying in the workplace.

Another example under the idea of power distance can be seen in the case of Participants E and F. Participant E, a lecturer, described the following situation:

In the meeting, I gave comments on my boss's ideas. After the meeting he asked me to come to his office and I was blamed that I should not have commented on his opinion because as he is a boss I have to respect his ideas. I was very upset. He used his power as a boss to control my behaviour and my thoughts. (Participant E)

The above quotation indicates how Participant E was bullied by a person who was in a hierarchical position in the organisation, and this constitutes job-related bullying. In Participant E's context, as a subordinate, she was not only being forced, but also controlled not 
to question the boss. As an insider researcher, I know that Lao's hierarchical culture cautions employees to critically question their boss, and that this is something to be very careful about.

Another shared experience can be seen from the case of Participant F, a Deputy Director General. She stated:

I worked hard every day and my work was loaded (nowadays, my work is still loaded). My boss, she rarely comes to the office and works very little. The work that she's supposed to do, she gave it to me. Her work is priority. As she is my boss, I cannot say anything. What I really hate is that my boss never appreciates me. All the work that I did for her she did not say that the work was done by me. She always showed off that she was the only one who did the work. (Participant F)

Even though Participant F did not directly mention what form of job-related bullying this was apart from her having a heavy workload, in my opinion, her statement implies that her job was stolen as a result of being bullied by her boss, who is in a hierarchical position in her organisation. This is not included in the NAQ-R framework.

From the shared view of these two women, the important message that I take is related to power distance as hierarchy in organisations. This can contribute to job-related bullying which in turn can lead to potential forms of job-related bullying such as being forced to do jobs or things, and having work stolen. As a result, these two women felt unhappy as they saw it as an intentional abuse of power that made them feel upset.

While power distance is a risk factor for workplace bullying, I found that another cultural issue such as ethnocentrism, Westerner privilege and religious orientation can be another risk factor for workplace bullying. In terms of ethnocentrism, if people believe that one's ethnic group is centrally important, employees can get bullied easily. This was mentioned by Participant A, a senior gender advisor:

One day, I wore a Lao ethnic dress I got from fieldwork and went to the government agency office. I was not allowed to enter the building because I was not wearing a sin. I was so angry that day and I said to the person who did not allow me to enter the building that this dress belongs to a Lao ethnic group and this is Lao. You know how 
many ethnic group we have. Depending on this we have variety of dresses. So the $\sin$ is not the only dress that belongs to Lao identity (Participant A).

From my perspective, it can be argued that the ethnocentric attitude in the Laotian context can count as a particular risk factor that can be associated with personal bullying. Additionally, it is a tool that is being used to control the body of Laotian women through the way of dressing. This may also be identified as emotional abuse because the interviewee was extremely upset about this encounter and being controlled through her way of dressing.

As for the Westerner privilege with regard to salary differences between local and international employees, this can appear to be unfair treatment and workplace bullying particularly for participants who work with NGOs. One complained that, in the same professional position, international employees get paid more and work less, and this is unfair for locals. Participant A, a senior gender advisor, reported:

International staff always gets a higher salary than nationals although we are in the same position. I have oversight of many projects, but my international colleague has oversight of only one project. (Participant A)

In such a way, the above statement indicates not only job-related bullying, as per my interpretation, but also discrimination against local employees in terms of the unfair salary applied.

In addition to the unfair salary applied, it appears that the ideas of international employees seem to be valued more than local ideas. The same participant expressed this below:

One international staff wants to print the campaign about stopping violence against women on plastic bags and distribute it for free. Everybody in the meeting agrees with this idea except me because this damages and impacts the environment which conflicts with the organisation's policy. My ideas were rejected at the same meeting. I was told that if everybody agreed then you have to agree. That international staff member works only 3 months at that time and 3-4 internationals agree with him. They are having more voices but I have only one voice so they won. (Participant A)

The above quotation illustrates how the issues of Westerner privilege can lead to job-related bullying in the form of ideas being ignored. In my opinion, this form of bullying can link to 
the Aid dependency of Laos, and its status with regard to Western countries. This also implies that Westerners have more power than locals. Therefore, this can be seen to be associated with job-related bullying.

As for religion, the unfair treatment with regard to the training opportunities for Christians and Buddhists, can relate to workplace bullying. According to Participant $\mathrm{H}$, a project advisor, being Buddhist is seen to be treated differently from being Christian. She complained that her Christian colleagues got better opportunities to go abroad for training, and this is unfair treatment could be seen to be associated with job-related bullying, but also could be seen as religious discrimination.

It should also be noted that in this context the head of the organisation, who at that time she was working appeared to have a bias related to religious preference. As a result, she and her colleagues, who were Buddhist, did not receive opportunities to be trained abroad. However, it is important to note that job-related bullying does not always reflect the religious biases in the organisation. It seems from my research that it can be a potential risk factor which in turn can lead to workplace bullying. I am suggesting that this risk factor has to be explored more in future research.

In summary, beyond the NAQ-R framework, there are several risk factors that I have identified for workplace bullying in the Laotian context. Under each factor, various forms of workplace bullying are identified. Based on these risk factors, my new definition of workplace bullying is a negative and/or unwanted behaviour, regardless of frequency and duration, experienced by individuals, and all negative results are an outcome of the various risk factors as mentioned in Table 4.7. 


\begin{tabular}{|c|c|c|c|c|c|}
\hline \multicolumn{3}{|c|}{ Risk factors } & Personal bullying & Job-related bullying & Physically intimidating bullying \\
\hline \multicolumn{3}{|c|}{ Physical appearance } & $\begin{array}{l}\text { - Being teased (NAQ-R does } \\
\text { include, but it is not } \\
\text { contextualise the }\end{array}$ & - & - \\
\hline \multicolumn{3}{|c|}{ Bias/personal dislike } & - & - Unfair refusal for training application & - \\
\hline \multicolumn{3}{|c|}{ Individual characteristic } & - & $\begin{array}{l}\text { - Colleagues choose to not cooperate which can affect the job } \\
\text { performance }\end{array}$ & - \\
\hline \multicolumn{3}{|c|}{ New graduate or non-working experience } & - & - Being assigned job that less complicated & - \\
\hline \multirow{3}{*}{ Gender issues } & \multicolumn{2}{|l|}{ Gender roles } & - & $\begin{array}{l}\text { Being asked or being expected to perform housework at the } \\
\text { workplace }\end{array}$ & - \\
\hline & \multicolumn{2}{|l|}{ Gender discrimination } & - & - Not being trained abroad & - \\
\hline & \multicolumn{2}{|l|}{ Gender specific jobs } & - & $\begin{array}{l}\text { Being tasked differently from the job description because of } \\
\text { the belief that female is suitable for less complicated task }\end{array}$ & - \\
\hline \multirow{5}{*}{ Cultural issues } & \multicolumn{2}{|l|}{ Marital status } & $\begin{array}{l}\text { - Being teased because of being } \\
\text { older and single }\end{array}$ & - & - \\
\hline & Power distance & $\begin{array}{l}\text { Bureaucracy/hierarchy in } \\
\text { organisations }\end{array}$ & - & $\begin{array}{l}\text { - Work delayed } \\
\text { Cannot claim holiday } \\
\text { Being forced or being commanded to do work or things that } \\
\text { individuals do not feel like doing } \\
\text { Being stealing job }\end{array}$ & $\begin{array}{l}\text { - a hateful attitude/improper } \\
\text { attitude } \\
\text { being spoken to rudely and } \\
\text { loudly by boss/colleague }\end{array}$ \\
\hline & \multicolumn{2}{|l|}{ Ethnocentrism } & $\begin{array}{l}\text { - Being controlled the way of } \\
\text { dressing }\end{array}$ & - & - \\
\hline & \multicolumn{2}{|l|}{ Westerner privilege } & - & $\begin{array}{ll}\text { - } & \text { Ideas ignored } \\
\text { - } & \text { Work loaded } \\
\text { Discrimination (unfair salary applied }\end{array}$ & - \\
\hline & \multicolumn{2}{|l|}{ Religion } & - & - Discrimination (unfair training applied) & - \\
\hline
\end{tabular}

Table 4. 7: Risk factors and forms of workplace bullying 


\subsection{Effects of workplace bullying and coping techniques}

\subsubsection{Effects of workplace bullying}

I found that workplace bullying has been shown to have a negative impact on employee mental health and wellbeing. The shared experiences of the feelings show that most participants have encountered problems of anxiety, and poor emotional health. They described that bullying made them feel worried, more pressured, angry, upset, unhappy, dishonest, hurt, and unconfident. They had low self-esteem, were unable to sleep and thought too much. They experienced relationship problems, they felt unsafe about personal security, and were afraid of losing their job or being harmed and oppressed. These findings are not surprising to me because they confirm my preconceived knowledge in the literature.

\subsubsection{Workplace bullying and coping techniques}

Based on the literature, coping techniques refer to a process or style of coping that individuals employ in solving the issues of workplace bullying, depending on the context of the situation (Dehue et al., 2012). In this section, I am going to use the coping strategies including problemoriented/active and emotional-oriented/passive strategies, and apply these to my data and find out what types of strategies are reported by my participants. This section is constructed as follows. First, I present the types of techniques that participants used in coping with workplace bullying. I then describe how different types of workplace bullying were associated with different coping techniques. Finally, I profile how the effect of age and working experience are related to a choice of coping techniques.

\subsubsection{Techniques used in coping with workplace bullying}

I have identified various types of techniques used by participants in coping with workplace bullying and grouped them into problem-oriented/active and emotional-oriented/passive strategies. Problem-oriented strategies including resisting, fighting and arguing, whereas emotional-oriented strategies are sharing the problem with others such as one's husband and colleagues, trying not to think too much, not caring, ignoring, avoiding and accepting, finding 
new job and quitting a job. These techniques will be analysed in greater details in the following section.

\subsubsection{Types of bullying and coping techniques}

I argued earlier in the context of Laos, it is really hard to actually solve workplace bullying. My findings show that some participants did try to solve bullying by using the problemoriented/active strategies, and some tried to solve the problem by using the emotionoriented/passive strategies. According to these techniques, I have identified that different types of bullying were associated with different coping strategies. This is explained as follows.

\subsection{Personal bullying}

Under personal bullying, problem-oriented strategies are used by some participants. Arguing was the term mentioned by Participant D, a project technical officer. She used this technique when she was dealing with personal bullying. In her case she was blamed in front of other colleagues in connection with her work. The argument technique that she employed was responding back immediately with anger in front of other colleagues. She shared the following:

My boss blamed me out loud in front of my colleagues about why I did not ask him if I did not know the technical words in regards to my translation. I said to him that this is the first draft of the translation why you can't just go through it first and give me feedback so that I can make it correct and at the same time I can also learn the technical terms. I argued with him in front of colleagues. I felt really unhappy. I don't mind if he said this one-on-one. (Participant D)

As a result, the argument technique did not work well for her situation because after the argument, her boss always blamed her when she made mistakes and she was not given explanation of any work in before being tasked with it.

Another example of using the argument technique that did not turn out well can be seen in a case of Participant G, head of the finance and budget division. She had an argument with her 
boss in regards to her job, and because of this her boss shared her mistake with all of employees through e-mail.

He was very mad at me because he was blamed by the CEO regarding his work. He angrily said to me that I should double-check all the details of my work before giving it to him to sign and approve, I made a big mistake, he said. On that day, I was shocked because I didn't know what was going on. And then I asked him, "What is it the problem?" He said with anger and asked me to look at the number, "You know the CEO blamed me for this. This should not happen." And he told me to triple check my work before giving it to him to sign. I was so upset on that day and I said to him very angrily that I did my best and it is his job to double-check it before he signs. I and my boss had a very serious argument on that day and one day after he sent the email out to all of the employees and said very negative things about me. (Participant G)

The above statement is an example of the type of personal bullying as being humiliated in connection to her work by her boss in which her mistake was shared through e-mail. Importantly, this kind of personal bullying happened after the bullied person tried to defend herself by using a type of argument technique which to was immediately talk back with anger.

Even though the argument technique might cause bullying to continue happen, it does not mean that people should not be able to use this technique. In my opinion, they can use it as long as they feel that it sounds right to them.

\subsection{Job-related bullying}

Under job-related bullying, the problem-oriented strategy such as resisting/fighting technique was employed by participants. This term was stated by Participant A. The type of resisting technique that she used was to report bullying to the head of the organisation. She referred to this technique when she shared her opinion about how to cope with job-related bullying. She explained that she experienced such bullying as being monitored for a particular task, and being prohibited from sharing ideas without getting permission. She said that:

I think that people have to resist, fight. We as employees have to be brave enough to say things otherwise you will be oppressed all the time. Some people in this organisation resigned because of they could not work with this line manager. I think 
this is not a good way to solve the problem. I decided to report this to the head of the organisation because if I have to resign I think it is not good way to do things. (Participant A)

As indicated in the above statement, it should be noted she did not draw any conclusions whether that technique is suitable for all individuals. I would state that the above technique is suitable only for those who are confident and believe that reporting the bullying would make a situation better. In addition to Participant A, there were two participants ( $G$ and $J$ ) who used the above technique Participant $G$ was happy because her big boss understood, while Participant $\mathbf{J}$ was not as her case was not solved because her boss did not take any action.

It can also be noted that from my perspective, the resisting/fighting technique is not only a form of problem-oriented strategies, but also the way of dealing with power. This is because Participant A sought to solve the bullying by reporting it to the head of the organisation, rather than dealing directly with her line manager.

Another way of dealing with power can be seen in the case of Participant J:

My boss told me with his high voice that I have to leave at 6:30 pm because he will also leave at 6:30 pm. I was very angry at that day and I said to him, "Why don't you leave at $5 \mathrm{pm}$ today so that I can leave at $5 \mathrm{pm}$ too?" Then he said, "Five pm is not my time to go home." I talked to myself with a very angry motion saying, "Ah, I can't believe that this guy is extremely unreasonable." I took all my courage and told him gently but with internal anger, “I am sorry sir, I really can't stay until 6:30 pm. I will request your previous secretary to stay, thank you sir." After that I left the office with my heart and my body shaking because of anger. Deep inside, I was so afraid that he might fire me. (Participant J)

The above quotation indicates how Participant $\mathbf{J}$ was dealing with power. In her context, she did not report the situation to the head of the organisation. She just dealt with the bully, who was her boss directly. However the bullying still continued. It should be noted that this technique might not be advisable in every context because it might cause bullying to happen continuously and it can be worsened if the bullied were to be fired. 
To summarise, the above two quotations discussed above indicate different ways of dealing with power in order to solve the bullying.

\subsection{Age, working experience and coping techniques}

Age differences have been found to be associated with coping techniques. Younger individuals were more likely to use passive coping strategies such as finding a new job and quitting a job. Participant I comments:

As a new graduate and newly recruited staff member, my colleagues always asked me to do work apart from my own responsibilities. I was asked to buy lunch, and make a photocopy of so many thick documents. At that time, I talked to myself that I must go and I need a better job and I quit. I did not hesitate to quit my job at all because I am still young and have more opportunities to find a new and better job. (Participant I)

In addition to age, lack of working experience was also found to be an important reason for choosing a coping technique. The new graduate with no work related experience like Participant $\mathrm{J}$ used the passive coping strategies such as letting it be and gaining more experience. According to her, when she was a new graduate with no work-related experience, even though she had experienced job-related bullying in the form of being assigned less complicated jobs, she had to be patient. She thought that if she had to resign due to this reason, then she would never gain any job-related experience. Therefore, she decided not to quit and when the time passed by she gained more trust and she was assigned more important jobs. This message is important in my opinion, because if individuals who have similar experiences to Participant $\mathrm{J}$ want to get a better job they must have job-related experience. 


\subsection{Conclusion}

This study reported that workplace bullying occurs in various ways, depending on the context of situation of each participant. It found various risk factors for workplace bullying beyond the NAQ-R framework, and new forms of them emerged associated with those risk factors. The risk factors that I identified for workplace bullying (see Table 4.1) are typically crucial when understanding workplace bullying in the Lao context. Moreover, the effects of workplace bullying was shown to have a negative impact on Lao women's mental health and wellbeing. Also, I found that many types of coping strategies were employed in coping with different forms of workplace bullying, but many of these were not helpful and effective. Importantly, under the problem-oriented strategies, I perceived this as a way of dealing with power in a hierarchical organisation. Finally, I would argue that the risk factors particularly ethnocentrism, marital status, power distance, and Westerner privilege are important, when understanding workplace bullying especially in the Lao context. These risk factors are associated with gender and culture. Therefore, I strongly argue that gender and culture cannot be divorced from each other when understanding workplace bullying in the Lao context. These are among the issues that will be discussed in the next chapter. 


\section{Chapter 5. Discussion}

\subsection{Introduction}

As already expressed, I aimed to explore workplace bullying experienced by Laotian women, including myself, in their previous and current workplaces. In Laos, workplace bullying is not well recognised and understood by many Lao people and this study was the first bullying study to be conducted in Laos. Specifically, I intended to explore how gender as a social construct is associated with workplace bullying by paying attention to the perceptions and experiences of Laotian women who identified themselves as being bullied. Further, I sought to explore perceptions of workplace bulling and how they are affected by either the Lao context or their position in the workplace. I also explored the effects of workplace bullying on Laotian women as well as the coping techniques that they used. Finally, I had a strong desire to raise awareness about workplace bullying in Laos, and have argued that gender and culture are risk factors in influencing and responding to workplace bullying. Throughout the discussion, where relevant, studies or theories are used in order to provide insights about the topic being discussed. Importantly, I also discussed the ideas of risk factors that exist in Laos, which in turn can make bullying more likely to happen in the Lao context.

In this chapter, I provide discussion related to the key answers of my research question: How do Laotian women employees experience bullying in their workplace? and its sub-questions: a). How do they perceive bullying? b). How do they cope with it? c). How is their perception of bullying affected by the Laotian context? and d). How is their perception of bullying affected by their position in their workplace? The discussion points include workplace bullying in the Lao context and its relation to the risk factors such as gender and culture, as well as its effect on Laotian women with regard to their position in their workplace.

The chapter is organised as follows. In section 5.2, I discuss the ideas of risk factors for workplace bullying with a focus on gender and culture. In section 5.3, I discuss the effects of workplace bullying that participants experienced. In section 5.4, I discuss the coping techniques that employed by Laotian women in dealing with workplace bullying. In section 5.5, I discuss how workplace bullying affected by the position of Laotian women in their workplace. In section 5.6, I conclude this chapter with overall insights gained from this study. 
Throughout the discussion, where relevant, studies or theories are used in order to provide insights about the topic being discussed.

\subsection{Risk factors}

Risk factors are the ideas that I have identified as particular things that exist in Laotian context. Subsequently, I argue that these risk factors contribute to the occurrence of workplace bullying. These include gender and culture, which include marital status, power distance, and Westerner privilege. This is discussed in greater detail below.

\subsubsection{Gender and workplace bullying in Laotian context}

This study is informed by the theory of the gendered organisation by Acker (1990) which states that all types of organisations play a crucial role in reproducing mainstream management theories mostly dominated by men. By applying this in the context of Laos, my findings show that the Lao organisations in this study were gendered in that they reflected the socially constructed views of gender roles such as the gendered relationship between men and women in regards to household chores. The example can be seen in the case of Participant A, a senior gender advisor, reported in section 4.3 of my findings chapter. She experienced this particular aspect of the gendered organisation by being asked to perform housework at her workplace. This finding is specific and emerged in my data based on the idea of the gendered organisation, and because she did not perform her gender roles well, this impacted on her performance at work leading to her salary not increasing.

As I have argued that the concept of gender in this study refers to the social constructions surrounding males and females, roles and norms that are attached to Laotian men and women are created by Lao society or Lao culture. This is the main focus that I base my discussion and interpretation of workplace bullying on . Therefore, my findings inform my own argument in regards to the socially constructed nature of gender roles in the Lao context. Having a radical analysis, Lao women are not only expected to do the chores at home, but also at the workplace. In my opinion, this is extremely deep-rooted and it is hard to dismantle this expectation for the majority of Lao society. 
Gender specific jobs are seen to be another way that Lao organisations are gendered. I found that a female who is in the same position as a male is not tasked according to the job description because the male colleague thinks that females are suitable for less complicated tasks such as a secretary or an assistant. This finding informs the prevalence of workplace bullying based on the ideas about gender segregation of work. This relates to the fact that work or an occupation itself is dominated by a particular gender (Charles, 2003). However, it should be noted that in this context, gender segregation of work occurred in the organisations where there was a male-created and dominated structure of control and males outnumbered females. As a result, females in this study were not tasked to do a job as per its description, but were instead tasked with simple jobs that were well below their competency levels. This is the prominent form of job-related bullying that emerged in this study.

\subsubsection{Culture and workplace bullying in Laotian context}

Among the risk factors that fall under the idea of culture, I choose four cultural risk factors to be the points of discussion: marital status, power distance, Westerner privilege, and ethnocentrism. These four risk factors are specific to the Lao context.

\subsubsection{Marital status and workplace bullying}

Marital status is seen to be a risk factor for personal bullying. My findings show that Laotian women who are older and not married are facing personal bullying at work in the form of teasing. In my opinion, cultural differences are only obvious by comparing them with Western examples such as New Zealand. In New Zealand I believe women are less likely to be teased about their marital status, but in Laos, the value of women is culturally attached to the social construction of gender roles, that is they are expected to marry, be a wife and a mother. Therefore, if they cannot meet this expectation then they will be criticised by society (GRID, 2005).

Four women who are older and not married were teased by their colleagues and they felt uncomfortable with this cultural expectation. Thus, in this study, I would like to convey that even though this fact has only come from a few women, it is important to be aware of the fact that culture can lead to the tolerance and acceptance of bullying behaviour and can influence individuals' reactions toward the behaviour (Power et al., 2010). It can also be perceived as a 
factor that can cause workplace bullying because of the embedded stereotypes with Lao society regarding marriage. Thus, this evidence from my data does not only inform my own argument that gender and culture can be risk factors for workplace bullying, but also cannot be separated from each other when identifying and understanding workplace bullying.

\subsubsection{Power distance and workplace bullying}

According to Hofstede (1980), in countries where power distance is part of their organisational culture, employees tend to respect the attribution of authority. This can potentially lead to workplace bullying. My findings show that, in Laos, power distance is seen to be a risk factor for job-related bullying. Most women were more bullied by their bosses than by their colleagues. The evidence can be seen in the case of Participants A, E, H and F presented in Chapter 4 . These cases show that there was the misuse of power of certain individuals in the Lao organisational hierarchy, implying that they have legitimate power to conduct any kind of negative behaviour in a workplace. Therefore, based on my findings, I contend that in the Lao context, workplace bullying and hierarchical structure of power in organisations are inseparable, and to some extent, perpetrators can misuse their power to intimidate their subordinates (Hearn \& Parkin, 2001), and this abuse of power can escalate to bullying (Field, 1996).

I argue that in Laos because of its managerial prerogative culture (the boss having rights to control subordinates), employees are less likely to have enough courage to use their rights in order to express their thoughts about the behaviour of their boss. My findings show that one woman, Participant F, who was working with public organisation, had experienced job-related bullying because she does not feel brave enough or as though she has the rights to complain about her boss' behaviour. She was always worried about the progress of her job as she does not have enough courage to tell her boss to work effectively. Her boss not committing to signing work off caused delays in Participant F's work. As an insider researcher, this finding is not surprising to me because I know that public sector organisations in Laos show a high level of bureaucracy and high power distance which can represent a high level of managerial prerogative. As a result, this is likely to lead to the occurrence of job-related bullying. 
Therefore, based on my findings, it is reasonable to claim that in the Lao public sector, due to its managerial prerogative practices, workplace bullying and its undesirable consequences in terms of psychological wellbeing and safety may occur because employees respect the power and authority distribution and accept of unfair treatment (Nguyen et al., 2017). This argument is now open to be discussed and explored more in future research.

\subsubsection{Westerner privilege and workplace bullying}

Based on the ideas of social dominance theory which maintain that all societies consist of power hierarchies, where one or more social groups dominate other groups (Salin \& Hoel, 2013), I have identified Westerner privilege to be a risk factor for workplace bullying in the Lao context. Job-related bullying occurred in association with Westerner privilege. Some participants, particularly those who used to work or are working with NGOs, mentioned the powerful position of foreigners (mostly from Western countries), in their organisations. They commented on the unfair treatment that was applied differently to local and international employees. Evidence can be seen in the case of Participant A, whose experience was that she was not only being paid less, but also her work was loaded, and her ideas were ignored. These are the forms of job-related bullying that occurred in her context. Based on this finding, I argue that in the Lao context, because of its status as a developing country relying on foreign aid (Saengouthay, 2015), there is a likelihood that the foreigner privilege in many NGOs can cause women in this study to be disadvantaged and ignored by Western people. It should be noted that workplace bullying is unique to each person's context, therefore it is not always the case that workplace bullying will occur in the context of Westerner privilege.

\subsubsection{Ethnocentrism and workplace bullying}

Based on the ideas of social dominance theory, ethnocentrism is a risk factor for personal bullying in the Lao context that I have identified. This idea is really specific in Laos because, as an insider researcher, I know that all Lao women are forced to wear the sin, the traditional skirt of the dominant group (Lao-Tai/Lao-Loom). If women do not wear sin, they are not allowed to enter government buildings. In my opinion, this is unreasonable to force women to do this. The national identity of Lao does not have to be attached to the identity of Laotian women by forcing them to wear the sin. Laos has 49 ethnicities (GRIDE, 2005), and this

means Lao women have different styles for their ethnic costumes. Therefore, the Lao 
government should remove the idea of the national identity being attached to Laotian women wearing the $\sin$, but also allow for other ethnic costumes to be valued as the part of Lao national identity as well. From my perspective, this is extremely harmful because it can cause emotional abuse to some Laotian women who do not want to be controlled through their way of dressing. The example can be seen in the case of Participant A, who was really upset about this ethnocentric attitude and being controlled through her way of dressing.

\subsection{Effects of workplace bullying}

In this study, I found that the stress and worry created by workplace bullying have a strong psychological impact on individuals. This finding adds up to various existing studies that show workplace bullying impact psychologically on individuals such as anxiety and depression (Nielsen et al., 2012). Most of women report that they are stressed, sad, worried, and unable to sleep. Therefore, it should be kept in mind that even though this study involves only ten samples, these symptoms that were found are significant as they can potentially developed into serious health related problems in the long run if individuals are exposed to the bullying for a long period of time (Nielsen et al., 2012). For example, with regard to stress, individuals have different stress management techniques, such as preferring to have high density foods which may result in weight gain which is a typical risk factor for diabetes (Tuomilehto et al., 2001). In contrast, there is a possibility that individuals who can manage to cope fairly well with the bullying situation may not result in health problems (Nielsen et al., 2012). Unfortunately, this study is unable to find out the long term health effect as a result of workplace bullying. Thus, it is reasonable for me to argue that, in Laos, there must be many employees who expose to workplace bullying for a long period of time and there must be some who can cope fairly well with the behaviour, and these employees are not included in this study. Additionally, from my perspective, the effects might be worse than in the case of some Western countries because there are fewer coping options for the Lao employees. 


\subsection{Coping with workplace bullying}

As mentioned earlier, in Laos, there is lack of support systems available for employees to cope with workplace bullying. My findings reveal that the Laotian women often had to cope with bullying by themselves, and the only coping strategies that they employed included problemoriented/active strategies and emotion-oriented/passive strategies. I discuss these strategies in detail, based on my participants' context below.

According to Dehue et al., (2012), problem-oriented strategies such as seeking support from someone to help by reporting the bullying behaviour to the boss/supervisor, is used when the bullied person believes that the stressful situation can be changed. These can be used only if the bully is not the boss. My findings show that some Laotian women employed this technique, but it did not solve their problems because the bully was the head of the organisation. According to Participant $\mathrm{J}$, she reported the bullying behaviour to her line manager, but her case was not solved because her manager was a subordinate of the bully, and he was not powerful enough to stop the bullying behaviour conducted by his boss towards her. This finding suggests that the problem-oriented strategy which was used by Participant $\mathrm{J}$ might be effective only if the boss/supervisor is not a subordinate of the bully. However, one woman interviewed, Participant A, who was bullied by her boss and reported the bullying behaviour to the head of the organisation had the bullying recognised and somehow the bullying did not occur as often after this.

Other problem-oriented strategies, for example resisting and arguing, refer to the bullied person immediately resisting the bully at the time. As for the resisting technique, I found that Participant $\mathbf{J}$ applied this, but she was not successful in stopping the bullying, and had more anxieties in regards in her job, as a result. As for the arguing technique, Participant D used this, but she was also not successful in stopping the bullying behaviour as she continued to experience it. However, I would suggest that this technique is effective in that the bullies at least know that they are misusing their power and this can calm the bully down at the time, and also raise their awareness. 
In my opinion, based on my findings, problem-oriented strategies such as seeking support from someone and resisting, are seen not only to be the techniques that can be used to minimise the bullying situation, but also indicate a different way of dealing with power. In the case of Participant A, she coped with the bully, who is her boss, by reporting it to the big boss, while Participants $\mathrm{J}$ and D, coped with the bully, who was their boss, by arguing with him directly. However, these two techniques could not solve the problem as the bullying continued to happen.

As for the emotion-oriented strategies where the bullied shares problems with colleagues, friends and families, these are used when the bullied person believes that the stressful situation cannot be changed (Dehue et al., 2012). My findings show that some Laotian women used these techniques to reduce their emotional distress associated with their bullying situation. One woman interviewed mentioned that she always shared her problems with her husband, who is supportive and listens to all of her problems. This enabled her to stand and fight again, while another woman reported that she always shared problems with her colleague (who is also her close friend) and this made her feel better as she had someone to listen to her problems. Even though it is suggested that emotion-focused strategies are seen to be the least effective in coping with bullying (Dehue et al., 2012), I recommend that the bullied person could use this as a temporary technique to reduce emotional distress, depending on the situation. This is because participants can share problems with others, and this helps to relieve stress even if it does not last for long.

As for passive coping strategies, which involve avoidance techniques such as quitting the job is found to be ineffective to cope with workplace bullying. My findings show that quitting the job was a coping technique that most of Laotian women used in coping with workplace bullying. This finding supports the view that workplace bullying seems to be a major factor in high levels of intention to leave the organisation (Nielsen et al., 2012). All women in this study intended to leave their organisations once they got the chance, and seven of them left and got new jobs. However, it should be noted that leaving a job and finding one in a new organisation might not turn out to be a good strategy to escape from a bully as the seven women who got new jobs were also facing a new bullying situation in their new organisation. This implies that workplace bullying happens in many organisations. Therefore, it is reasonable to suggest that, in order to prevent bullying in Laos, it would be better to raise 
awareness and initiate anti-bullying policies as well as establish an accessible and supportive organisation where people can report the bullying behaviour. Also, age is a factor that affects the decision to quit a job. In my findings, younger individuals are more likely to use this technique, than older ones because they think that they have more opportunities to get new better jobs.

Regarding the coping strategies, some Laotian women, such as Participant C, expressed their thoughts that their voice could not be heard because there was no place for them to report the bullying. Participant $\mathrm{C}$ shared the information that the organisation where she used to work did not apply labour laws particularly in regards to annual leave. As a result, she was not able to claim her annual leave, and she considered this as the job-related bullying. Even though this finding is based on a few participants, it is an important message which suggests that in order to prevent workplace bullying in Laos, an anti-bullying policy should be developed so that employees can feel secure and are able to raise their voice about workplace bullying. WorkSafe New Zealand is good example of the guidelines for preventing and responding to workplace bullying that Laos can initially refer to. This guideline provides the definition of workplace bullying, outlines the responsibilities of stakeholders, and mentions the possible organisational prevention of workplace bullying and its management initiatives (WorkSafe NZ, 2014). Importantly, what I can get from this guideline is that employees have the right to be protected and secure and experience wellbeing wherever they work. In Laos, employees do not have these rights. Also, in New Zealand, under the Employment Relations Act, in all employment agreements, it is an obligation to provide a safe workplace for employees. If an employer cannot meet this obligation by failing to manage bullying and creating an unsafe workplace, employees may raise a personal grievance (Employment New Zealand, 2018). Laos, to the best of my knowledge, does not have an act like this. Therefore New Zealand is an effective exemplar for Laos in terms of how bullying could be initially addressed in workplaces. 


\subsection{Practical implications}

Therefore, as a practical implication, I first suggest that the bullied person, in the Laotian context, where there is no formal organisation to report the unwanted behaviour, should use coping strategies that I have discussed, depending on the context. In terms of the problemoriented strategy. For example, reporting the bullying behaviour to the manager or the head of the organisation. I would recommend to use this only if the bully is not a boss or the boss is not the subordinate of the bully. Another technique such as resisting technique, I am suggesting to apply this only if individuals are brave enough to do so because this might have risks in regards to job security and might lead to having stress and anxiety. As emotionoriented strategies cannot stop or even minimise bullying behaviour, I recommend that rather than applying it if it helps to reduce stress.

Importantly, the coping strategies that women in this study used to cope with workplace bullying indicate that different strategies are needed in Laos, compared to Western country such as New Zealand. In Laos, the bullied persons has to deal with the bullying on their own due to the lack of a legal and human resource framework, while in New Zealand, the bullied employees can raise a claim of bullying to their manager or directly to a Human Resources division or individual. Also the complaint can be notified to the WorkSafe New Zealand office. In addition, under the New Zealand legal framework, employers have an obligation to provide a safe working environment. If workplace bullying arises, they need to deal with it and ensure that it stops occurring (Employment New Zealand, 2018).

\subsection{Human rights perspective}

Finally, this study was guided by the concepts of workplace bullying in Western countries, gendered organisation and social dominance theory. While these concepts are important, I have become aware through my research experience and as an insider researcher that the abuse of human rights exists in developing countries like Laos. In my opinion, the inclusion of a human rights perspective in future bullying research could provide an interesting and more comprehensive critical discussion on the workplace bullying phenomenon. I believe that from the human rights perspective, workplace bullying in Laos is mostly in a form of abuse of 
rights due to women having no rights and no place to complain about being bullied, compared to Western countries such as New Zealand.

\subsection{Summary of discussion points}

The overall insight gained from this study is that workplace bullying, in the Lao context occurs in various ways and it is affected by a number of risk factors including gender and culture. The Lao organisations were gendered in many ways such as gender roles, gender specific jobs and gender discrimination, which led to job-related bullying. Additionally, cultural risk factors such as marital status, power imbalance, Westerner privilege and ethnocentrism were found specifically in the Lao context. They are important factors that need to be taken into consideration when understanding workplace bullying in Laos. Further, the effects of workplace bullying such as stress, sadness, worry and inability to sleep are the symptoms that impact Laotian women. These symptoms can be worse due to the lack of coping options available, and often participants have to cope with the bullying by themselves using problem-oriented/active strategies (including asking someone to help), and emotionoriented/passive strategies (including sharing problems with spouses and friends/colleagues, and leaving the organisation).

I anticipate that my findings can be used as a reference to inform regulations or guidelines related to workplace bullying in Laos. New Zealand is an effective exemplar for Laos in addressing and preventing the workplace bullying phenomenon. Most importantly, gender and culture are seen to be strongly interrelated and hard to separate from each other when understanding workplace bullying in Laos. 


\section{Chapter 6. Conclusion}

\subsection{Introduction}

In this chapter, I summarise the key findings both inductively and deductively in relation to my research questions. I then present the contributions of my study. Next, I talk about its relevance to other situations and make suggestions for future research. Finally, I give my closing statement.

\subsection{Key findings to the research questions}

The main objective of this study was to explore gender and workplace bullying in the nonWestern context of Laos, where many Lao people are not familiar with the concept of bullying, and research on workplace bullying has not been studied at all. I have attempted to provide a better understanding of workplace bullying by drawing on ten Laotian women's perceptions and experiences of bullying, including myself, in their previous and current workplace.

With the help of a social constructionist epistemology, an interpretivist approach, a qualitative methodology, and the guidance of the concepts of workplace bullying in the NAQ-R framework, gendered organisation theory and social dominance theory, I was able to provide a useful understanding of a complex and unique experiences of workplace bullying from through the voices of Laotian women. In addition, beyond the NAR-Q framework, I have been able to contribute new ideas about bullying with a strong focus on the context of situation. Subsequently, I introduce the ideas of risk factors for workplace bullying.

My findings highlight the fact that workplace bullying exists in a number of different ways, depending on the context of the situations. As I situated the NAQ-R in the Lao context, I have utilised it from the interpretivist rather than from its original objective point of view. This allowed me to identify and have a better understanding about how workplace bullying is perceived by Laotian women and this was unique to each of them. Subsequently, I have identified several risk factors which exist for workplace bullying particularly in the Lao context. These are discussed below. 


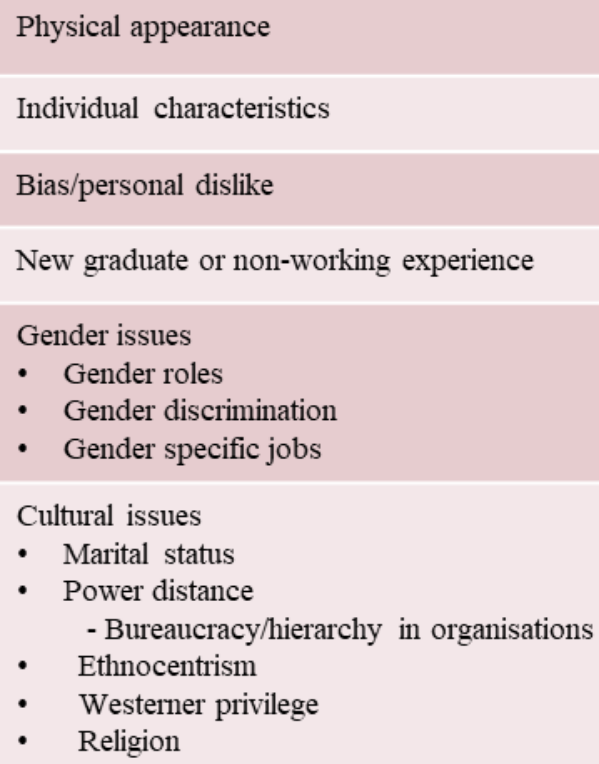

These risk factors are crucial when understanding workplace bullying in Laos particularly in regards to the cultural risk factors. Under these risk factors, I found not only culture such as marital status as a risk factors for personal bullying, but also other new ideas of culture have emerged in my data such as ethnocentrism, Westerner privilege, and religion. These are risk factors for personal bullying and job-related bullying respectively. Importantly, Westerner privilege and religion are risk factors that fall into the ideas of social dominance, not in a form of number, but in a form of power in hierarchical positions. Ethnocentrism is also based on the idea of social dominance in which Lao-Tai or Lao-Loom outnumber other ethnicities in Laos. These lead all Lao women to have to follow the way of Lao-Loom dressing by wearing the $\sin$. If they do not wear the sin, they will not be allowed to enter the workplace, especially Lao public organisations.

My findings also shed light on workplace bullying in regards to the gender and culture. Here I found that these two are not only the risk factors for workplace bullying, but are also strongly interrelated and cannot be separated from each other when understanding workplace bullying in Laos. In addition, my findings show that even though my participants are more urbanised, relatively privileged, and well-educated compared to other Lao women and some other Lao men, they still experience workplace bullying and its negative effects. 


\subsection{Research contribution}

The study was successful in analysing and interpreting workplace bullying in general, as well as from a gendered perspective in particular. General findings about bullying were similar to the findings in some Western countries, for example, in terms of the effects and coping of workplace bullying. Some other findings were different, such as culture.

As for gender and workplace bullying, findings from this study contributed to the ideas of inequality regime by Acker (2006) in which bullying becomes a kind of gendered oppression. This leads to gender inequality in terms of pay and recognition. Some findings were similar to Western findings in regards to the perpetrators, who can be both males and females, and whose role has a high degree of power in a hierarchical structure where bullying takes place. This research has also identified gender as a risk factor for bullying. This has been shown by the women in this study, through their experiences of being bullied in ways that appear to be influenced by the social construction of gender roles and norms.

In general, this is a new contribution of gender and workplace bullying in Asian countries, especially South East Asia countries. By having a strong focus on context, the findings enriched understandings of individual's perceptions and experiences in regards to gendered workplace bullying in Laos, and also in Asia.

Further, the inclusion of risk factors provides rich evidence that enhances our understanding of workplace bullying perceived by Laotian women. More importantly, gender is not only a risk factor for workplace bullying, but also culture. They cannot be separated from each other when understanding or interpreting workplace bullying in the Lao context. For example, compared to New Zealand, Lao women are more likely to be teased by their co-workers or society if they are not married. This is because the socially construction of gender roles expect a woman to be a wife and mother. These expectations are related to gender norms and cultural expectations. Therefore, this is a significant contribution to the existing studies on workplace bullying from a gendered and cultural perspective.

I also anticipate that these findings can contribute to raising awareness and understanding of the working lives and conditions of women in Laos. As well, the research can be used as a reference to inform policies or guidelines related to workplace bullying in Laos. 


\subsection{Relevance to other situations and future research exploration}

In this section, I, firstly, present my views about how my findings are useful in other situations. I then suggest areas for further exploration of workplace bullying in the Lao context.

\subsubsection{Relevance to other situations}

The findings of this study are useful and important in a number of ways. Firstly, they show that gender and culture cannot be separated from each other when understanding and interpreting workplace bullying. Importantly, cultural differences are only obvious by comparing experiences with other cultures. In this study, I compare Lao culture with New Zealand culture in areas such as marital status, laws and regulations. My findings shows that Lao women are more likely to be teased in their workplace if they are single and older. This is because they are expected to be a wife and a mother. If they cannot meet this expectation, they will be criticised by society. In general, this finding is important in that it informs people to be aware that they should take care in talking about women in relation to their marital status, though we should always keep in mind that workplace bullying is a unique experience for each person and so, the marital status might not be perceived as being bullied by other Lao women.

Secondly, the study reminds us that Laos is a developing country and depends on foreign aid. Because of this, many foreigners are employed in various NGOs for their expertise. As a result, foreigners are perceived as more powerful in terms of knowledge and experiences. This leads to a kind of negative behaviour in the workplace. Some participants perceived that foreigners' ideas are more likely to be heard within their organisations, and they receive better insurance policies, compared to their Lao colleagues. As this seen to be perceived as an unfair treatment, policy makers in any NGOs have to be aware of this issue ensure fairness to both groups of employees.

Finally, as Laos lacks of legal or human resource management framework, the finding of this study informs policy developers and human resource persons to pay more attention to the phenomenon of workplace bullying and establish relevant policies to address and prevent 
bullying from occurring. An initial anti-bullying legal framework can be drafted based on the example of New Zealand, as I already explained.

All and all, the findings that I have presented are the empirical evidence in the form of the unique experiences of ten Laotian women in the Lao context, based. Readers can use their own judgment whether or not these findings can be used as a reference in their own work. In my opinion, these findings are useful for Lao organisations, and will potentially be useful in other countries especially Asian countries, where there is a similar concept of gender, cultural beliefs, and governance.

\subsubsection{Future research exploration}

There are numerous areas for further exploration of workplace bullying in the Lao context. Firstly, the body of literature in the field of workplace bullying in Laos is limited, and this is because workplace bullying is not well known by many Lao people. While this study has contributed to the knowledge of Lao people generally, further study should be explored more in a different or a specific set of careers.

Secondly, this qualitative research explored workplace bullying subjectively from the perspectives of ten Laotian women including myself. While these perspectives are important, I acknowledge that the pervasiveness of workplace bullying is also a collective experience, and that future studies should explore it both qualitatively and quantitatively.

Thirdly, while gender is critically associated with workplace bullying, unfortunately this qualitative study was not focused on Laotian men. Future studies could explore the perceptions of men about workplace bullying. This will provide comparative insights into understanding this phenomenon. This is important because from a gender and culture perspective, the value of Lao men is also attached to a number of gender expectations and Lao cultural beliefs and practices.

Finally, as well as the critical evaluation of studies on workplace bullying from a gendered perspective, this study found that traditional beliefs can also be a risk factor for workplace bullying. The inclusion of cultural perspectives in future research is highly recommended. In my opinion, cultural differences are only obvious when compared with other cultures. In the context of Laos, there are many ethnic groups, and among these groups there are many 
cultural beliefs and practices. It is important to know these beliefs and practices as they can be risk factors for bullying so that in the future, policy makers in Lao as well as in any Lao organisations can develop anti-bullying laws and guidelines that give a good definition of workplace bullying in a given context.

\subsection{Closing statement}

The focus of this study is to explore workplace bullying from a gendered perspective. I have enjoyed my research journey, and acknowledged the lessons that I have gained. The findings of this study inspire me to work more on this area, perhaps in my future workplace. I would like to raise awareness of workplace bullying in Laos. I want to be part of preventing and reducing this phenomenon in organisations. I, together with my participants, would like to raise our voices so that people understand that workplace bullying is unique to each person. As well as this, although it was not my intention to explore national cultural differences, I discovered that understanding gender and workplace bullying must be done in a given context and that they are inseparable. 


\section{References}

ADWLE. (2017). Sexual harassment in workplace in Vientiane Capital. Vientiane: ADWLE.

Acker, J. (1990). Hierarchies, jobs, bodies: A theory of gendered organizations. Gender \& Society: Official Publication of Sociologists for Women in Society., 4(2), 139-158. doi: $10.1177 / 089124390004002002$

Acker, J. (2006). Inequality regimes: Gender, class, and race in organizations. Gender \& Society: Official Publication of Sociologists for Women in Society., 20(4), 441-464. doi: $10.1177 / 0891243206289499$

ADB. (2011). Civil society briefs: Lao People's Democratic Republic. Vientiane. Retrieved from http://www.adb.org/publications/civil-society-briefs-lao-peoplesdemocraticrepublic

Agervold, M. (2007). Bullying at work: A discussion of definitions and prevalence, based on an empirical study. Scandinavian Journal of Psychology, 48(2), 161-172. doi: 10.1111/j.1467-9450.2007.00585.x

Archer, D. (1999). Exploring "bullying" culture in the para-military organisation. International Journal of Manpower, 20(1/2), 94-105. doi:10.1108/01437729910268687

Aryee, S., Chen, Z., Sun, L., \& Debrah, Y. (2007). Antecedents and outcomes of abusive supervision: Test of a trickle-down model. Journal of Applied Psychology, 92(1), 191201. doi:10.1037/0021-9010.92.1.191

ASEAN Human Rights Declaration. (2012). The Phnom Penh statement on the adaption of the ASEAN human rights declaration. Retrieved from http://www.asean.org/storage/images/ASEAN_RTK_2014/6_AHRD_Booklet.pdf

Bazhan, N., \& Zelena, D. (2013). Food-intake regulation during stress by the hypothalamopituitary-adrenal axis. Brain Research Bulletin, 95(C), 46-53. doi:10.1016/j.brainresbull.2013.04.002

Bartlett, J. E., \& Bartlett, M. E. (2011). Workplace bullying: An integrative literature review. Advances in Developing Human Resources, 13(1), 69-84. doi:10.1177/1523422311410651 
Bentley, T. A., Catley, B., Cooper-Thomas, H., Gardner, D., O’Driscoll, M. P., Dale, A., \& Trenberth, L. (2012). Perceptions of workplace bullying in the New Zealand travel industry: Prevalence and management strategies. Tourism Management, 33(2), 351360. doi:10.1016/j.tourman.2011.04.004

Blackwood, K. M. (2015). Workplace bullying in the New Zealand nursing profession: The case for a tailored approach to intervention. (Doctoral dissertation, Massey University, Albany, New Zealand). Retrieved from https://mro.massey.ac.nz/bitstream/handle/10179/7212/02_whole.pdf?sequence=2\&is Allowed=y

Bobbitt-Zeher, D. (2011). Gender discrimination at work: Connecting gender stereotypes, institutional policies, and gender composition of workplace. Gender \& Society: Official Publication of Sociologists for Women in Society, 25(6), 764-786. doi: $10.1177 / 0891243211424741$

Bryman, A., \& Bell, E. (2015). Business research methods (4th ed). New York, Oxford University Press.

Burr, V. (2015). Social constructionism (3rd ed). New York: Routledge.

CARE Int'1. (2018). Gender power analysis. Vientiane: CARE Int'l.

Carter, M., Thompson, N., Crampton, P., Morrow, G., Burford, B., Gray, C., \& Illing, J. (2013). Workplace bullying in the UK NHS: A questionnaire and interview study on prevalence, impact and barriers to reporting. BMJ Open 2013, 3(6) doi:10.1136/bmjopen-2013- 002628

Catley, B., Bentley, T., Forsyth, D., Cooper-Thomas, H., Gardner, D., O'Driscoll, M., \& Trenberth, L. (2013). Managing workplace bullying in New Zealand: Perspectives from occupational health and safety practitioners. Journal of Management \& Organization, 19(5), 598-612. doi:10.1017/jmo.2014.2

Charles, M. (2003). Deciphering sex segregation: Vertical and horizontal inequalities in ten national labor markets. Acta sociologica, 46(4), 267-287. doi: $10.1177 / 0001699303464001$

Cheo, R. (2017). Migrant workers and workplace bullying in urban China. Social Indicators Research, 132(1), 87-115. doi: 10.1007/s11205-015-1214-0 
Chirila, T., \& Constantin, T. (2013). Understanding workplace bullying phenomenon through its concepts: A literature review. Procedia-Social and Behavioral Sciences, 84, 11751179.

doi: 10.1016/j.sbspro.2013.06.722

Constas, M.A. (1992). Qualitative analysis as a public event: The documentation of category development procedures. American Educational Research Journal, 29(2), 253-266. doi: 10.3102/00028312029002253

Creswell, J. W. (2014). Research design: Qualitative, quantitative, and mixed methods approaches (4th ed). Thousand Oaks, CA: SAGE Publications.

Crimp, H. (2017). Insights into effective interventions for the prevention and management of workplace bullying in the New Zealand public service. (Masters thesis at Victoria University of Wellington, Wellington, New Zealand). Retrieved from http://hdl.handle.net/10063/6470

Criterion Venture. (2012). Gender handbook: A guide to understanding gender terms, analysis, and applications to social investing. Retrieved from http://criterioninstitute.org/resources/files ～/2012/08/The-Gender-Handbook-forInvestors.pdf

Dehue, F., Bolman, C., Vollink, T., \& Pouwelse, M. (2012). Coping with bullying at work and health related problems. International Journal of Stress Management, 19(3), 175-197. doi: $10.1037 / \mathrm{a} 0028969$

Dolan, K. A. (2014). When does gender matter?: Women candidates and gender stereotypes in American elections. Place of publication?: Oxford University Press. doi: 10.1093/acprof:oso/9780199968275.001.0001

Einarsen, S., Hoel, H., \& Notelaers, G. (2009). Measuring exposure to bullying and harassment at work: Validity, factor structure and psychometric properties of the Negative Acts Questionnaire-Revised. Work \& Stress, 23(1), 24-44. doi: $10.1080 / 02678370902815673$

Einarsen, S., Notelaers, G., Nielsen, M. B. (2011). Measuring exposure to workplace bullying. In E Stale., H. Helge., Z. Dieter., \& C. Cary (2nd ed.), Bullying and harassment in the workplace: Developments in theory, research, and practice (pp. 149-174). New York: CRC Press. 
Employment New Zealand. (2018). Bullying: Bullying in the workplace can create a risk to health and safety. It is a form of misconduct and must be dealt with. Wellington, New Zealand: Ministry of Business, Innovation and Employment. Retrieved from https://www.employment.govt.nz/resolving-problems/types-of-problems/bullyingharassment-and-discrimination/bullying/

Fahie, D. (2014). Doing sensitive research sensitively: Ethical and methodological issues in researching workplace bullying. International Journal of Qualitative Methods, 13(1), 19-36. doi: 10.1177/160940691401300108

Field, T. (1996). Bully in sight: How to predict, resist, challenge and combat workplace bullying. Wantage, England: Wessex Press.

Giorgi, G., Leon-Perez, J., \& Arenas, A. (2015). Are bullying behaviors tolerated in some cultures? Evidence for a curvilinear relationship between workplace bullying and job satisfaction among Italian workers. Journal of Business Ethics, 131(1), 227-237. doi:10.1007/s10551-014-2266-9

Godwin, J., \& Kember, D. (2018). An exploration of epistemological beliefs, learning environment expectations and persistence intentions: Insights into the shaping of student persistence in the first semester of university study at three Australian universities. In K. David \& C. Michael (Eds), Structuring the thesis (pp. 39-46). Singapore: Springer. $\quad$ Retrieved from https://link.springer.com/content/pdf/10.1007/978-981-13-0511-5.pdf

GRID. (2005). Lao PDR gender profile. Retrieved from http://documents.worldbank.org/curated/en/653921468276561976/pdf /453750WP00BOX0334096B01PUBLIC1.pdf

Griffin, G. (Ed.).(2017). Gender roles. In A dictionary of gender studies.. doi: 10.1093/acref/9780191834837.001.0001

Hearn, J., \& Parkin, W. (2001). Gender, sexuality and violence in organizations: The unspoken forces of organization violations. London, England: Sage.

Hofer, B. (2001). Personal epistemology research: Implications for learning and teaching. Educational Psychology Review, 13(4), 353-383. doi:10.1023/A:1011965830686

Hofstede, G. (1994). The business of international business is culture. International Business Review, 3(1), 1-14. $\quad$ Retrieved from http://www.embaedu.com/member/medias/212/2012 /12/201212516503571280.pdf 
Hofstede, G. (1997). Cultures and organizations: Software of the mind (Rev. ed.). New York: McGraw-Hill.

Hofstede, G. (1980). Culture's consequences: International differences in work-related values. Beverly Hills, CA: Sage Publications.

Hutadjulu, R. R., Saerang, D. P., \& Tielung, M. V. (2017). Exploratory study of workplace bullying towards employee performance, job stress, and employee loyalty at PT. PLN (PERSERO) area manado. Jurnal EMBA: Jurnal Riset Ekonomi, Manajemen, Bisnis dan Akuntansi, 5(3). Retrieved from file://C:/Users/ACER/Downloads/17560-354051-SM\%20(1).pdf

Hutchinson, J., \& Eveline, J. (2010). Workplace bullying policy in the Australian public sector: Why has gender been ignored? Australian Journal of Public Administration, 69(1), 47-60. doi:10.1111/j.1467-8500.2010.00669.x

Johnstone, R. (2017). The Australian regulatory framework for preventing harassment and bullying at work. In L. Loic (Ed.), Psychosocial risks in labour and social security law (pp. 253-268). Gewerbestrasse, Switzerland: Springer.

doi 10.1007/978-3-319-63065-6

Keashly, L., Fox, S., \& Lituchy, T. (2012). Workplace bullying and gender: It's complicated. In F. Suzy \& L. Terri (Eds), Gender and the dysfunctional workplace (pp.78-95). Cheltenham, United Kingdom: Edward Elgar Publishing.

Kindon, S., Pain, R., \& Kesby, M. (2007). Participatory action research: Approaches and methods. London \& New York, Routledge. Retrieved from https://ebookcentral.proquest.com/lib/vuw/detail.action?docID=325513\#

Kivimaki, M., Virtanen, M., Vartia, M., Elovainio, M., Vahtera, J., \& Keltikangas-Jarvinen, L. (2003). Workplace bullying and the risk of cardiovascular disease and depression. Occupational and Environmental Medicine, 60(10), 779-783. doi:10.1136/oem.60.10.779

Kouvonen, A., Stafford, M., De Vogli, R., Shipley, M. J., Marmot, M. G., Cox, T., \& Kivimäki, M. (2011). Negative aspects of close relationships as a predictor of increased body mass index and waist circumference: The Whitehall II study. American Journal of Public Health, 101(8), 1474-1480. doi:10.2105/AJPH.2010.300115 
Lao Statistics Bureau. (2017). Results of population and housing census 2015. Vientiane: Lao Statistics Bureau, Ministry of Planning and Investment. Retrieved from https://www.lsb.gov.la/en/\#.W3Ss1egzbIU

Lewis, S. E., \& Orford, J. (2005). Women's experiences of workplace bullying: Changes in social relationships. Journal of Community \& Applied Social Psychology, 15(1), 29-47. doi:10.1002/casp.807

Loh, J., Restubog, S. L. D., \& Zagenczyk, T. J. (2010). Consequences of workplace bullying on employee identification and satisfaction among Australians and Singaporeans. Journal of Cross-Cultural Psychology, 41(2), 236-252. doi:10.1177/0022022109354641

Matthiesen, S. B., \& Einarsen, S. (2007). Perpetrators and targets of bullying at work: role stress and individual differences.(Report). Violence and Victims, 22(6), 735-753. doi:10.1891/088667007782793174

McCarty, W. P., Solomon-Zhao, J., \& Garland, B. E. (2007). Occupational stress and burnout between male and female police officers. Policing: An International Journal of Police Strategies \& Management, 30(4), 672-691. doi:10.1108/13639510710833938

McCormack, D., Casimir, G., Djurkovic, N., \& Yang, L. (2006). The concurrent effects of workplace bullying, satisfaction with supervisor, and satisfaction with co-workers on affective commitment among schoolteachers in China. International Journal of Conflict Management, 17(4), 316-331. doi: 10.1108/10444060610749473

McGinley, A. C. (2008). Creating masculine identities: Bullying and harassment because of sex. University of Colorado Law Review, 79(4), 1151-1241. Retrieved from https://heinonline.org/HOL/Page?collection=journals\&handle=hein.journals/ucollr79\& $\mathrm{id}=1159$

Naito, S. (2013). Workplace bullying in Japan. In the Japan institute for labour policy and training, Workplace bullying and harassment (p. 113-133). Retrieved from http://eforum.jil.go.jp/english/reports/documents/jilpt-reports/no.12.pdf\#page=119

Nguyen, D. T. N., Teo, S. T. T., Grover, S. L., \& Nguyen, N. P. (2017). Psychological safety climate and workplace bullying in Vietnam's public sector. Public Management Review, 19(10), 1415-1436. doi:10.1080/14719037.2016.1272712

Nielsen, M. B., \& Einarsen, S. (2012). Outcomes of exposure to workplace bullying: A metaanalytic review. Work \& Stress, 26(4), 309-332. doi:10.1080/02678373.2012.734709 
Nielsen, M. B., Nielsen, G. H., Notelaers, G., \& Einarsen, S. (2015). Workplace bullying and suicidal ideation: A 3-wave longitudinal Norwegian study. American Journal of Public Health, 105(11), e23. doi:10.2105/AJPH.2015.302855

Notelaers, G., Vermunt, J., Baillien, E., Einarsen, S., \& De Witte, H. (2011). Exploring risk groups workplace bullying with categorical data. Industrial Health, 49(1), 73-88. doi:10.2486/indhealth.MS1155

Nouwen, A., Winkley, K., Twisk, J., Lloyd, C., Peyrot, M., Ismail, K., \& Pouwer, F. (2010). Type 2 diabetes mellitus as a risk factor for the onset of depression: a systematic review and meta-analysis. Clinical and Experimental Diabetes and Metabolism, 53(12), 2480-2486. doi:10.1007/s00125-010-1874-х

O'Leary, Z. (2017). The essential guide to doing your research project (3rd ed). London, England: Sage.

Park, S. (2013). Workplace bullying and harassment in South Korea. In The Japan Institute for Labour Policy and Training, Workplace Bullying and Harassment (p. 91-111). Retrieved from http://eforum.jil.go.jp/english/reports/documents/jilptreports/no.12.pdf\#page $=119$

Parzefall, M.-R., \& Salin, D. M. (2010). Perceptions of and reactions to workplace bullying: A social exchange perspective. Human Relations, 63(6), 761-780. doi:10.1177/0018726709345043

Plimmer, G., Proctor-Thomson, S., Donnelly, N., \& Sim, D. (2017). The mistreatment of public service workers: identifying key risk and protective factors. Public Money \& Management, 37(5), 333-340. doi:10.1080/09540962.2017.1328186

Power, J. L., Brotheridge, C. M., Blenkinsopp, J., Bowes-Sperry, L., Bozionelos, N., Buzády, Z., . . Nnedumm, A. U. O. (2010). Acceptability of workplace bullying: A comparative study on six continents. Journal of Business Research, 66(3). doi:10.1016/j.jbusres.2011.08.018

Rayner, C., \& Keashly, L. (2005). Bullying at work: A perspective from Britain and North America. In F. Suzy \& S. Paul (Eds), Counter productive work behavior: Investigations of actors and targets (pp. 271-296). Washington, DC, US: American Psychological Association. doi: 10.1037/10893-011 
Saengouthay, O. (2015). The influence of non-governmental organisations (NGOs) on primary education policy in Laos. (Masters thesis, Victoria University of Wellington Wellington, New Zealand) .Retrieved from http://hdl.handle.net/10063/5230

Safe work Australia. (2016). Guiding for preventing and responding to workplace bullying. Retrieved from https:/www.safeworkaustralia.gov.au/system/files /documents/ 1702/guide-preventing-responding-workplace-bullying.pdf

Salin, D. (2001). Prevalence and forms of bullying among business professionals: A comparison of two different strategies for measuring bullying. European Journal of Work and Organizational Psychology, 10(4), 425-441. doi: $10.1080 / 13594320143000771$

Salin, D., \& Hoel, H. (2013). Workplace bullying as a gendered phenomenon. Journal of Managerial Psychology, 28(3), 235-251. doi:10.1108/02683941311321187

Samnani, A. (2013). The Early Stages of Workplace Bullying and How It Becomes Prolonged: The Role of Culture in Predicting Target Responses. Journal of Business Ethics, 113(1), 119-132. doi: 10.1007/s10551-012-1286-6

Saunders, P., Huynh, A., \& Goodman-Delahunty, J. (2007). Defining workplace bullying behaviour professional lay definitions of workplace bullying. International Journal of Law and Psychiatry, 30(4-5), 340-354. doi: 10.1016/j.ijlp.2007.06.007

Shaghaghi, A., Bhopal, R. S., \& Sheikh, A. (2011). Approaches to recruiting 'hard-toreach'populations into research: a review of the literature. Health Promotion Perspectives, 1(2), 86-94. doi: 10.5681/hpp.2011.009

Sidanius, J., \& Pratto, F. (1999). Social dominance an intergroup theory of social hierarchy and oppression. Cambridge, United Kingdom: Cambridge University Press. Retrieved from https://doi.org/10.1017/CBO9781139175043

Simpson, R., \& Cohen, C. (2004). Dangerous work: The gendered nature of bullying in the context of higher education. Gender, Work \& Organization, 11(2), 163-186. doi:10.1111/j.1468-0432.2004.00227.x

Sjoholm, M. (2017). Gender-sensitive norm interpretation by regional human rights law systems. Boston: BRILL.

Soukkaseum, P. (2017). The relevance of vocational education to the livelihoods of rural youth, Luang Prabang Province, Laos. (Masters thesis, Victoria University of 
Wellington, Wellington, New Zealand). Retrieved from http://hdl.handle.net/10063/6917

Spector, P. E. (2012). Gender differences in aggression and counterproductive work behavior. In F Suzy \& L Terri (Eds), Gender and the dysfunctional workplace (pp.29-42). Cheltenham, United Kingdon: Edward Elgar Publishing.

Stebbins, R. (2001). Exploratory research in the social sciences. Thousand Oaks: SAGE Publications. doi: http://dx.doi.org/10.4135/9781412984249

Stone-Romero, E. F., Stone, D. L., \& Salas, E. (2003). The influence of culture on role conceptions and role behavior in organisations. Applied Psychology, 52(3), 328-362. doi:10.1111/1464-0597.00139

Sultana, F. (2007). Reflexivity, positionality and participatory ethics: Negotiating fieldwork dilemmas in international research. ACME: An International E-journal for Critical Geographies, 6(3), 374-385. Retrieved from http://siticeland.com/wp-content/uploads/ 2016/11/Sultana-2007.pdf

Takala, T., \& Piattoeva, N. (2012). Changing conceptions of development assistance to education in the international discourse on post-Soviet countries. International Journal of Educational Development, 32(1), 3-10. doi: 10.1016/j.ijedudev.2010.10.003

Teagarden, M. B. (2005). Culture, leadership, and organizations: The GLOBE study of 62 societies. Academy of Management Executive, 19(2), 162-163. doi:10.5465/AME.2005.16965495

Tuomilehto, J., Lindstrom, J., Eriksson, J. G., Valle, T. T., Hamalainen, H., Ilanne-Parikka, P., . . Uusitupa, M. (2001). Prevention of type 2 diabetes mellitus by changes in lifestyle among subjects with impaired glucose tolerance. The New England Journal of Medicine, 344(18), 1343-1350. doi:10.1056/NEJM200105033441801

UNDP. (2018). Gender inequality index. Retrieved from http://hdr.undp.org/en/composite/GII

UN Human Rights. (2018). Lao People Democratic Republic. Retrieved from https://www.ohchr.org/en/countries/asiaregion/pages/laindex.aspx

Xu, T., Magnusson Hanson, L., Lange, T., Starkopf, L., Westerlund, H., Madsen, I., . . . Rod, N. (2018). Workplace bullying and violence as risk factors for type 2 diabetes: A multicohort study and meta-analysis. Clinical, Translational and Experimental Diabetes and Metabolism, 61(1), 75-83. doi:10.1007/s00125-017-4480-3 
Zapf, D., Escartin, J., Einarsen, S., Hoel, H., \& Vartia, M. (2011). Empirical findings on prevalence and risk groups of bullying in the workplace. In E. Stale., H. Helge., Z. Dieter., \& C. Cary (2nd ed.), Bullying and harassment in the workplace: Developments in theory, research, and practice (pp. 75-105). New York: CRC Press.

WHO. (2018). Gender, equality and human rights. Retrieved from http://www.who.int/gender-equity-rights/understanding/gender-definition/en/

WorkSafe NZ. (2014). Preventing and responding to workplace bullying: Best practice guidelines. Retrieved from https://www.nzrda.org.nz/wp-content/uploads/workplacebullying-guidelines-DOL1.pdf 


\section{Appendices}

\section{Appendix A: Participant information sheet (English version)}

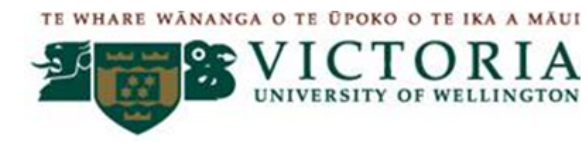

INFORMATION SHEET AND INVITATION TO PARTICIPATE

Gender and workplace bullying in Lao organisations

Researcher: Vanhsana Sayaseng, School of Management, Victoria University of Wellington

I am a Masters student in Management at Victoria University of Wellington. I am currently undertaking a research project which explores the issues of gender in workplace bullying in Lao organisations. My intention is to raise awareness about workplace bullying in Laos. This research has been approved by the Victoria University of Wellington Ethics Committee

Invitation

I would like to invite those who consider themselves to have been targets of workplace bullying to participate in this research. I plan to ask you about your experiences and your thoughts about them. Participation will involve an interview of about one hour, at a place and time convenient to you. Your participation is completely voluntary and you many decline to answer any questions or to terminate the interview at any time. If you agree, you will sign a consent form.

Confidentiality

This research is confidential. I will not use participant names or identifying details of any organisation in final reports, publications or presentations if it could lead to the identification of individual participants. Direct quotes may be used in the final report however they will not be attributed to any individual participant.

With your permission interviews will be audio recorded and transcribed. Only my supervisors and I will read the notes or transcript of the interview. The interview transcripts, summaries and any recording will be kept securely and destroyed after the research ends which will be at the end of July 2019. You will have the opportunity to see a summary of your interview and to comment on it.

What will the project produce?

The information from my research will be used in the preparation of my Masters thesis. Two copies of the final thesis will placed on closed reserve at the Victoria University library. Results of the research may also be published in both academic and professional journals, and may be presented at academic conferences or other events.

Research Summary

If you are interested in the final results of this study, I can email you a summary of research findings following completion of the examination process.

Who to contact if you have any questions about the research

If you have any questions, either now or in the future, please feel free to contact either Researcher contact information

Vanhsana Sayaseng

Mcom student

School of Management

Phone: 8562022230212

Email: sayasevanh@myvuw.ac.nz

Supervisor contact information

AProf Deborah Jones

Programme Director

School of Management

Phone: 6444635731

Email: deborah.jone@vuw.ac.nz

Human Ethics Committee information

If you have any concerns about the ethical conduct of the research you may contact the Victoria University HEC Convener. Aprof Susan Corbett. Email: susan.corbett@vuw.ac.nz or telephone: +6444635480 


\title{
Appendix B: Participant information sheet (Lao version)
}

\author{
TE WHARE WÃNANGA O TE OPOKO O TE IKA A MAUT

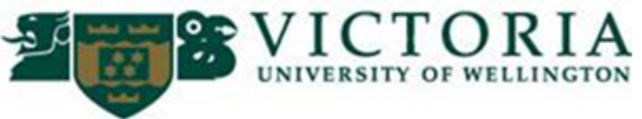

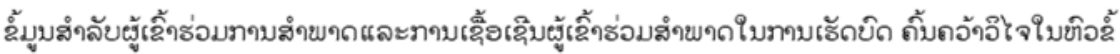

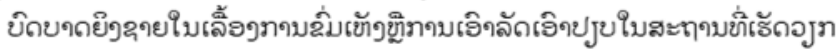

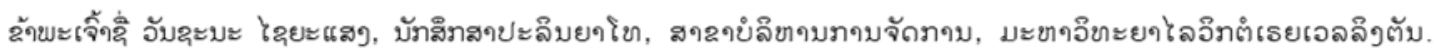

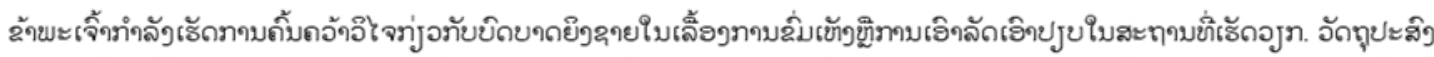

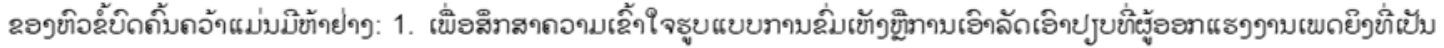

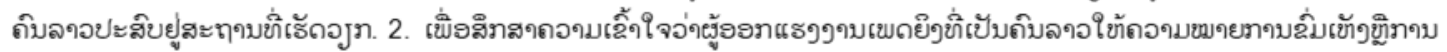

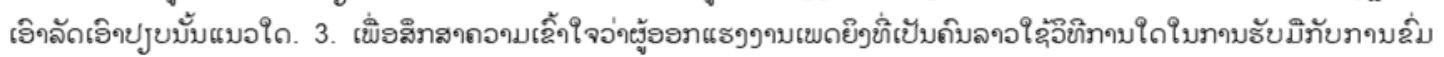

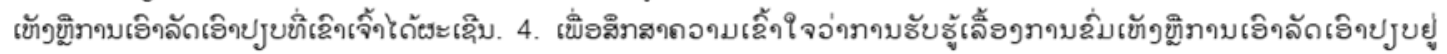

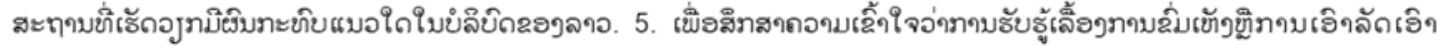

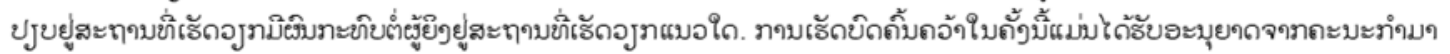

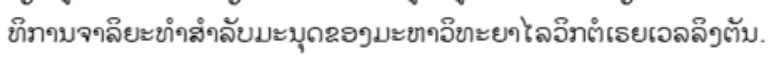

ภามเฉื้จเฉิบผผู้เลิ้าร่อมสำขขก

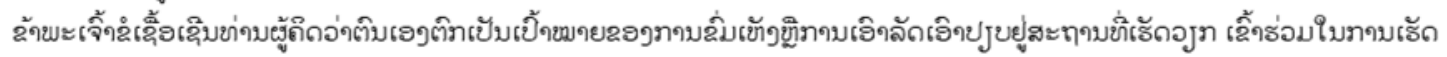

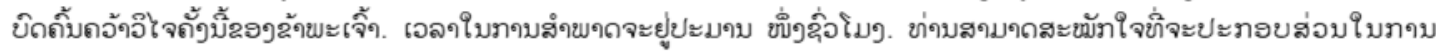

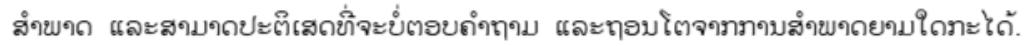

ทาบเทับธัภสาถอจมลับ

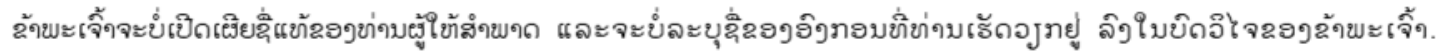

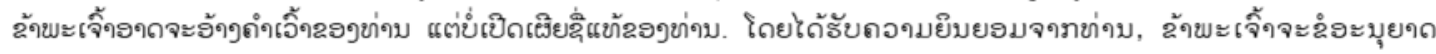

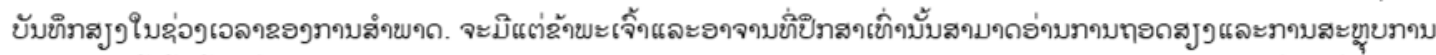

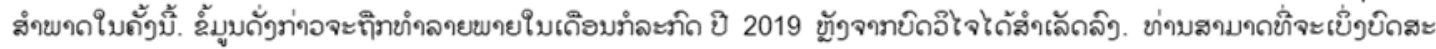

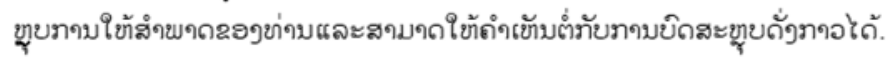

บิถอีไจบิ้จะทิภมำใด้แแบอใด?

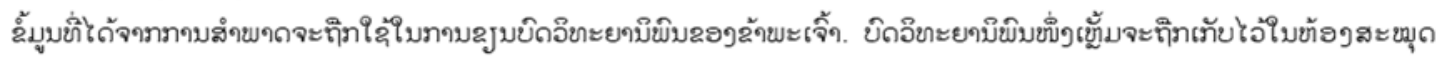

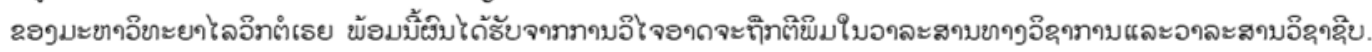

ภามสะขุขเบื้อใบทามสำขจด

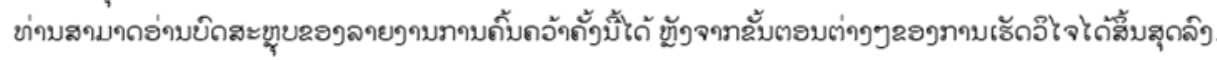

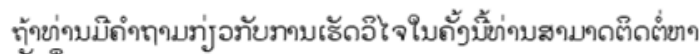

บัมสึรสา

วัมฉะมะ ไุยะแสๆ

โขละสับ 8562022230212

ธิเมอ: sayasevanh@myvuw.ac.nz

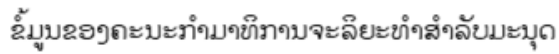

จจจาบขั่ปิรสๆ

ผู้ว่อยสาถสะถจจามกบโบธา โจบ

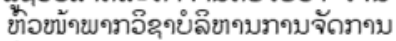

ใขละสับ: 6444635731

อิเมอ: deborah.jones@vuw.ac.nz

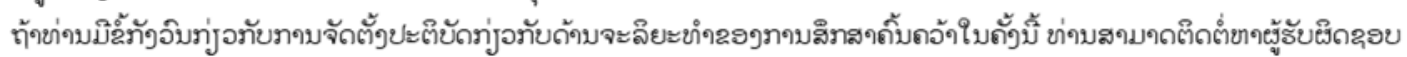

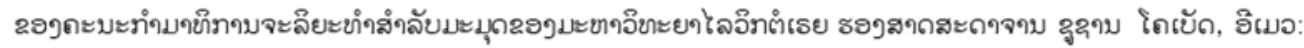

susan.corbett@vuw.ac.nz เยิโขละสัย 6444635480 


\section{Appendix C: Research consent form (English version)}

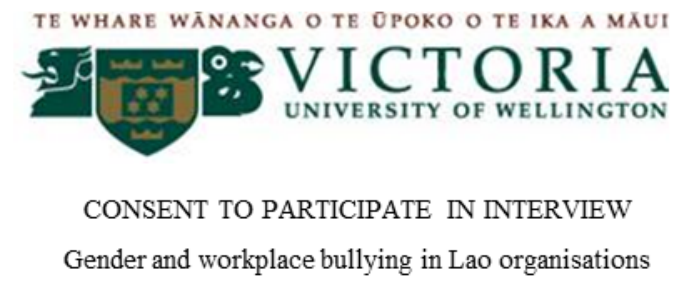

I have read through the attached information sheet and have been provided with adequate information relating to the nature and objectives of this research project. I have understood that information and have been given the opportunity to seek further clarification or explanations.

I understand that any information I provide will kept confidential to the researchers. The published results will not use my name, and no opinions will be attributed to me in any way that will identify me. I understand that all raw data recording my views will be securely stored and access restricted to the researcher and their supervisor. Results of the research may be published in both academic and professional journals. I understand that I can withdraw from this research project at any time before data collection is completed, 31 January 2018.

I agree to take part in this interview

I agree to this interview being audio recorded

I wish to receive a summary of my interview and I understand that I have the opportunity to comment on this.

I wish to receive a summary of the results of this research

Name of participant: Signature of participant: Date:

Researcher contact information

Vanhsana Sayaseng

Mcom students

School of Management

Phone: 856-20-22230212

Email: sayasevanh@myvuw.ac.nz
Supervisor contact information

AProf Deborah Jones

Programme Director

School of Management

Phone: 6444635731

Email: deborah.jones@vuw.ac.nz 


\title{
Appendix D: Research consent form (Lao version)
}

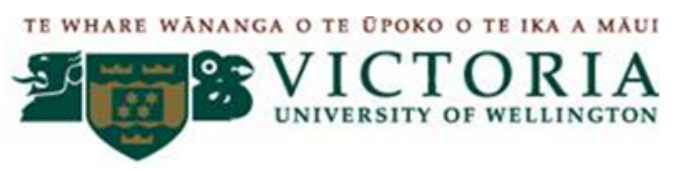

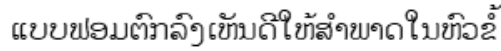

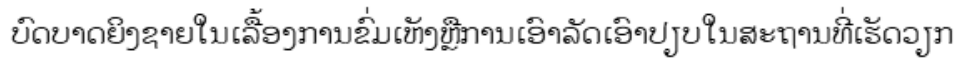

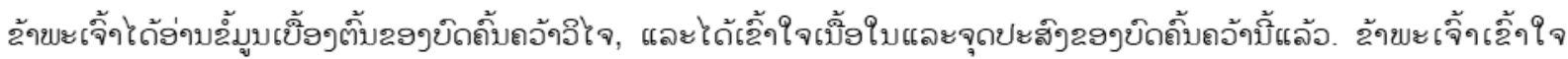

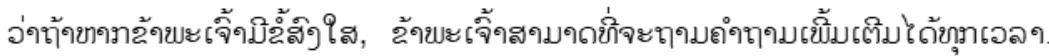

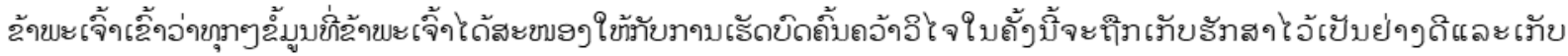

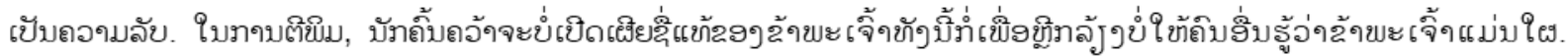

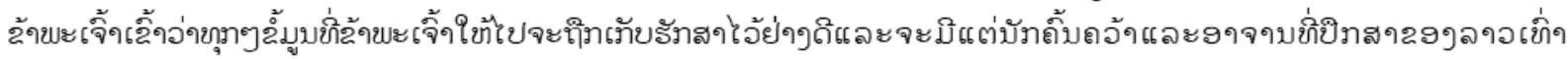

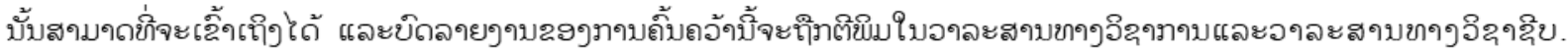

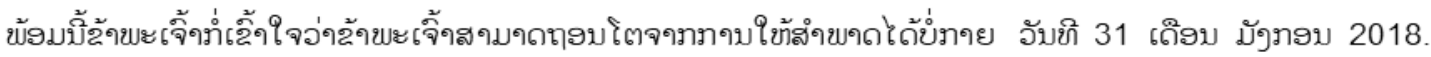

ฉ้จขะเจิ้าเขับถลิกิ่จะใข้สำขๆด

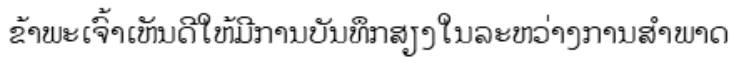

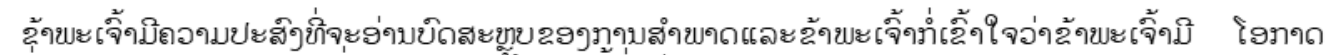

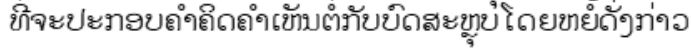

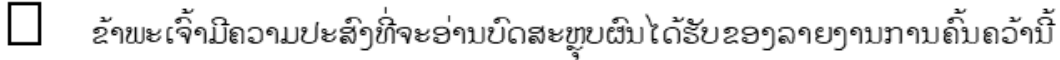

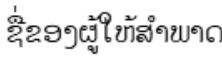
ลขยเฉับผผู้ใข้สำขจด อับยิ:

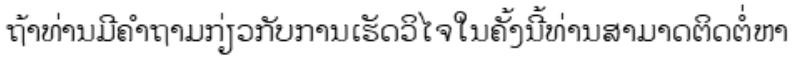

บัมสึาสๆ

อับฉะบะ ไุยะแสๆ

โขละสัข: 8562022230212

ฮิเมอ: sayasevanh@myvuw.ac.nz
9ๆจาบขั่ปิาสๆ

ผู้ว่อยสาถสะดจจา ถิบโบธๆ โจบ

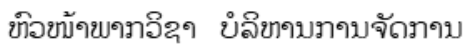

โขละสัข: 6444635731

ฮิเมอ: deborah.jones@vuw.ac.nz 